\title{
An anomalous atmospheric dust deposition event over Central Europe, 24 March 2007, and fingerprinting of the SE Ukrainian source
}

\author{
JINDŘICH HLADIL, LADISLAV STRNAD, MILAN ŠÁLEK, VLASTA JANKOVSKÁ, PAVEL ŠIMANDL, \\ JAROSLAV SCHWARZ, JIŘí SMOLÍK, LENKA LISÁ, LEONA KOPTÍKOVÁ, JAN ROHOVEC, VLASTA \\ BÖHMOVÁ, ANNA LANGROVÁ, MILENA KOCIÁNOVÁ, ROSTISLAV MELICHAR \& JIŘí AdAMOVIČ
}

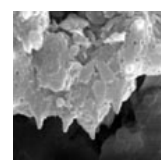

An anomalous event of Ukrainian quartz-dominated dust deposited in the Czech Republic and adjacent countries on 24 March 2007 was studied with special emphasis on sedimentology, mineralogy and geochemistry. The dust deposition combined a typical eolian depositional mode with one mediated by dirty rain or drizzle. The main stage of sediment deposition was short (several tens of minutes) and synchronous with rapidly increased concentration of particles smaller than $10 \mu \mathrm{m}$ in the atmosphere above ground. The polydisperse and multimodal sediment consisted predominantly of angular to subrounded quartz particles, of which $80-90 \mathrm{wt}$. $\%$ were silt sized $(4-63 \mu \mathrm{m})$. A small amount of sand grains up to $0.5 \mathrm{~mm}$ in size was regularly observed $(\leq 10 \mathrm{wt} . \%)$ and was higher than that of particles smaller than $4 \mu \mathrm{m}$. This relatively coarse material was transported by atmospheric flows over distances of 1400 to $2000 \mathrm{~km}$. The deposited silt film was fenestrally arranged and showed various reticulate and patchy patterns of several sizes. The intensity of deposition in the main deposition areas corresponded to $2.3 \mathrm{~g} / \mathrm{m}^{2}$ of particulate solids on average. The interpreted depositional processes are based on direct observation and dust microphysics. Besides the preferentially entrained and delivered quartz, the sediment contains also perthitic feldspar, chlorite and chloritoids, and notably low amounts of mica, clay minerals and carbonate. The element content does not contradict the supposed source based on meteorological observations, i.e., from surface argillaceous and sandy soils east of Kherson, Ukraine. Particularly minor and trace element distributions are almost identical and show a nearly perfect match, closely similar to those of standards for the upper crust (not sediments). Total Fe concentrations in the sediment are about 2-3 wt.\%, i.e., slightly less than those for the upper continental crust on average, yet with a large proportion of iron still bound in mineral inclusions in quartz and silicates. Smooth REE patterns correspond to the most common multi-cycle eolian material and are typical for the assumed source area. Lead isotope signatures combine a natural lithic imprint and anthropogenic contamination by petrol combustion, thereby giving a somewhat different trend compared to African sources. Palynological analysis enabled tracking of the trajectory of the dust-flow but also identified typical markers, such as ragweed pollen, from the source area. $\bullet$ Key words: dust, atmospheric deposition event, sedimentology, rheology, grain-size modality, pattern formation, geochemistry, lead isotopes, pollen and spores, eolian flux, climate change, Czech Republic, Ukraine, Europe, Recent/Holocene.

HLAdil, J., StRnAd, L., ŠÁleK, M., JANKOVSKÁ, V., ŠIMANdL, P., SCHWARZ, J., SMOLÍK, J., LiSÁ, L., KoptíKOVÁ, L., Rohovec, J., BÖHmovÁ, V., LANGRovÁ, A., KociánOVÁ, M., MElichar, R. \& AdAMovič, J. 2008. An anomalous atmospheric dust deposition event over Central Europe, 24 March 2007, and fingerprinting of the SE Ukrainian source. Bulletin of Geosciences 83(2), 175-206 (18 figures, 5 tables). Czech Geological Survey, Prague. ISSN 1214-1119. Manuscript received November 25, 2007; accepted in revised form February 25, 2008; issued June 30, 2008.

Jindřich Hladil, Lenka Lisá, Leona Koptíková, Jiří Adamovič, Jan Rohovec, Vlasta Böhmová \& Anna Langrová, Institute of Geology AS CR, v.v.i., Rozvojová 269, 16500 Prague 6 - Suchdol, Czech Republic; hladil@gli.cas.cz・Milan Šálek, Czech Hydrometeorological Institute, Brno Regional Office, Kroftova 43, 61667 Brno - Žabovresky, Czech Republic; salek@chmi.cz•Pavel Šimandl, Czech Hydrometeorological Institute, Central Forecasting Office, Na Šabatce 17, 14306 Prague 4 - Komořany; simandl@chmi.cz• Jaroslav Schwarz \& Jiřı Smolík, Institute of Chemical Process Fundamentals of the AS CR, v.v.i., Rozvojová 2, 16500 Prague 6-Suchdol, Czech Republic; schwarz@icpf.cas.cz - Ladislav Strnad, Laboratories of Geological Institutes, Faculty of Science, Charles University, Albertov 6, 12843 Prague 2, Czech Republic; lada@ natur.cuni.cz・Vlasta Jankovská, Department of Ecology, Institute of Botany AS CR, v.v.i., Pořiči 3b, 60300 Brno, Czech Republic; jankovska@brno.cas.cz・Milena Kociánová, Krkonoše Museum in Vrchlabí, Krkonoše National Park Administration, Husova 213, 54301 Vrchlabí, Czech Republic; mkocianova@krnap.cz・Rostislav Melichar, Department of Geological Sciences, Faculty of Science, Masaryk University in Brno, Kotlářská 2, 61137 Brno, Czech Republic; melda@sci.muni.cz. 
The wide-ranging effects of atmospheric dust deposition have influenced almost all sedimentary systems on the Earth since the Archaean. So far as it concerns lithic mineral dust, the most significant components were (and are) fine quartz, alumosilicate particles and specks of iron-rich minerals (Yamaguchi et al. 2005). Dust structure and the importance of relevant evidence is, however, greater with decreasing age and metamorphism of sediments, either in the Phanerozoic (Soreghan \& Soreghan 2002, Cecil 2004), or in the Neogene to Recent (Kukla 1970, 1977; Prospero et al. 2002). Eolian dust/aerosol components deposited in the geological past are effective tools for interregional stratigraphic correlation, especially if preserved in limestone or ice sheets (Hladil et al. 2006, Andersen et al. 2007). They also help to explain many aquatic and dry-land processes in the past and present, before and after the deposition of these materials (e.g., Jickells 1995, 1999; Grousset et al. 2003; Gao et al. 2007; Bout-Roumazeilles et al. 2007). The number of recently addressed issues and specific partial tasks on the rheology and geochemistry of this flux (and the number of papers) increases rapidly. This is mainly because research on present airborne-dust deposition events contributes to understanding the previous background sedimentation record and is also associated with key aspects of the present global climate change. Existing papers tend to focus on the atmospheric physics of dust transport and on the character of the respective aerosols but rarely describe the composition and structure of this specific eolian sediment during and immediately after its deposition. This article aims, therefore, to make such a cross-disciplinary sedimentological study that emphasizes complex information from a single deposited layer.

\section{The basic parameters and evolution of the event}

During 24 March 2007, an extremely severe (and suddenly developed) dust deposition event was observed over the area of the Czech Republic, especially over the eastern part, and this sediment covered also significant parts of neighbouring countries. These were deposits over a several hundred kilometres-wide belt, which corresponded to high and complex-structured dust plumes and particle/grain-bearing jets that moved rapidly westward, heading across Europe.

The general situation, shown in the synoptic chart (Fig. 1), suggests that between the slowly weakening pressure low located over the Balkan Peninsula and the high-pressure area over the European part of Russia, a relatively strong pressure gradient produced high winds bringing the air from eastern to Central Europe. According to reports from meteorological stations, the average velocity of the easterly wind over the southern Ukraine on 23-24 March was
$10-17 \mathrm{~m} / \mathrm{s}$. However, the gusts of wind responsible for the vigorous and massive dust-and-sand uplift of the Ukrainian black storm magnitude reached $30 \mathrm{~m} / \mathrm{s}$ or more (Pashkevich 1970, Birmili et al. 2008). The wind over the territory of Slovakia and the Czech Republic was a little weaker, reaching values of 4-7, occasionally $10 \mathrm{~m} / \mathrm{s}$, and on $24^{\text {th }}$ of March was mostly northeasterly (i.e., heading southwest). Wind speed in this southern part of the belt (beneath the clouds) was mostly lower compared to the northern part (e.g., S Poland). The temperature over Ukraine and Central Europe was mostly in the interval $5-14{ }^{\circ} \mathrm{C}$. In the deposition area (the whole southern part of the main deposition belt), thick clouds prevailed with common showers. However, under locally developed exceptional conditions, rainfall was either minimum/absent or very intensive for a few minutes. Light rain/drizzle dominated the mountain areas. Two days before, the situation was different: The highest temperatures were $3-7{ }^{\circ} \mathrm{C}$, mostly to partly cloudy, with very slow south-westerly wind $2-5 \mathrm{~m} / \mathrm{s}$, intermittent showers but snow at altitudes above $500 \mathrm{~m}$ a.s.l. (This accidentally created unusually favourable conditions for trapping of the dust - almost absolutely clean snow substrates.)

The dust, lifted by strong winds to heights of hundreds of meters to a few kilometres above the ground, was unusually rich in relatively coarse lithic particles in its main concentration phase. These rather than the ultra-fine particles were involved also in the main depositional phase later observed over large areas of Central Europe (Birmili et al. op. cit.) including the Czech Republic. The dust storm was detected over Ukraine by the Meteosat 8 (MSG-1) meteorological satellite, and the pollutant transport was confirmed by a computation of trajectory with the help of numerical weather prediction. Even the absorption and dispersion features in the solar spectrum, together with a preliminary study of the trapped or deposited material, were indicative of the fact that the composition of this dust was specific, much different from North African dust, which quite commonly has reached the territory of the Czech Republic, Central Europe and beyond in previous decades (Papayannis et al. 2005, Koltay et al. 2006, Littmann \& Steinrücke 1989).

General situation as seen in RGB composites: According to the Meteosat 8 information (see detailed methods in Appendix), several locations with emitted dust occurred shortly before the event. Two separate dust storms were observed at the Libyan coast and in eastern Ukraine, formed on 23 March 2007. Coeval dust uplift also occurred in a zone stretching between Libya/Egypt and Turkey but was most likely confined to separate atmospheric circulation domains quite separate from the Ukrainian dust (Fig. 2). Dust storms over the Sahara are considered a relatively frequent phenomenon (Goudie \& Middleton 2001, Sodemann et al. 2006, Koltay et al. op. cit.), whereas dust 


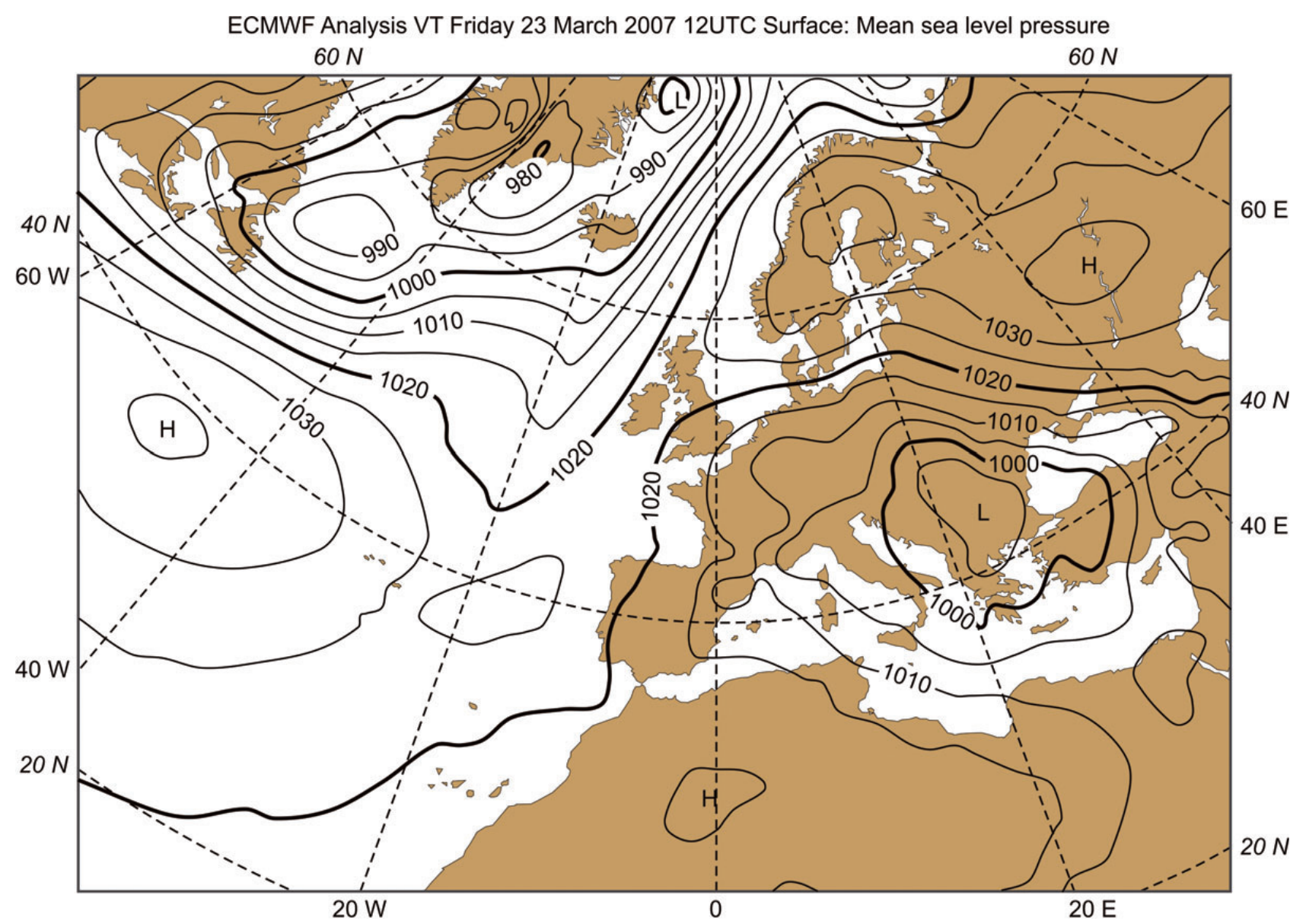

Figure 1. Mean sea level pressure over Europe on 23 March 2007, 12:00 UTC. A high-pressure gradient resulting in strong winds and a dust storm over the Ukraine is visible between the pressure low over the Balkan Peninsula and the pressure high over Russia and Scandinavia. [M. Šalek, @ (copyright permission for this purpose) 2007 ECMWF]

in the air over Ukraine has not been so frequently observed. Most likely, dust storms over Ukraine might not have been recognized before the introduction of the 24-h microphysics simulation of dust images (MD) available via Meteosats 8/9. Direct sedimentological and meteorological observations from SE Ukraine, however, suggest that soil deflation and eolian redeposition of silt- to sand-sized particles are quite common (Sazhin \& Vasiliev 1999).

SEVIRI-MSG indications of Ukrainian source: Following a careful visual inspection of the MD images, it was clear that the African dust storm reached only the eastern Mediterranean and to some extent only Syria and Turkey. The dust from eastern Ukraine, although partly obscured by clouds, moved obviously to the west, consequently hitting western Ukraine, Slovakia, Poland, the Czech Republic and eastern Germany (Fig. 3). The increased concentration of dust was detectable even over the North Sea and the Britain Isles, where the dust-polluted air arrived on $24 \mathrm{March}$ at about 19:00 UTC. There was also speculation that some of the dust from the Mediterranean was transported over the Black Sea and mixed partly with the Ukrainian dust (Birmili et al. op. cit., Bruckmann et al. 2008). The increased concentration of dust was also detected by the air quality monitoring system elsewhere along the plume transport path, but mainly in Central Europe. The concentration of $\mathrm{PM}_{10}$ and $\mathrm{PM}_{2.5}$ particles (i.e., particles up to $10 \mu \mathrm{m}$ and $2.5 \mu \mathrm{m}$ ) reached values several times higher than normally observed levels (Fig. 4). These observations are generally in agreement with critical conditions and concentrations responsible for partial deposition of dust over Central Europe, at 327 $\mathrm{PM}_{10}$ observation sites where the dust plume effects were recorded. Fifteen data sets from sites between Poland and Germany (Nowy Sacz and Meiningen, respectively) were published in detail - Birmili et al. op. cit.). The depositional event in the eastern Czech Republic corresponded to maximum PM concentrations after 11:00 UTC. The main episodes of deposition were relatively short at these sites, not exceeding a 1 -h period.

The computation of the trajectory using the Trajek numerical model ( $c f$. detailed methods in Appendix) also supports the Ukrainian origin of the dust (Fig. 5). The 


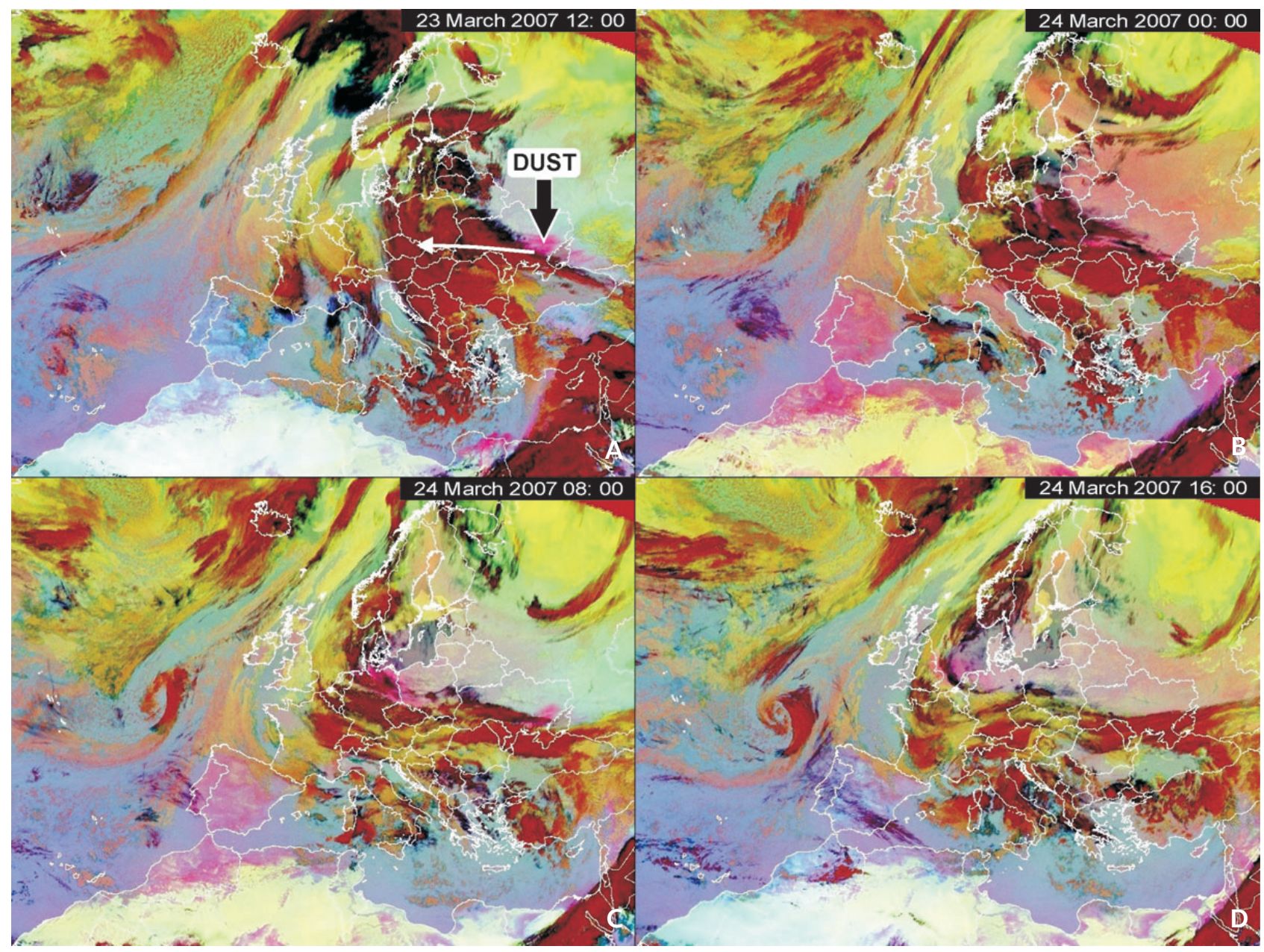

Figure 2. RGB product of the SEVIRI radiometer carried by Meteosat 8 (MSG-1), named "24-h microphysics", a weakly modified original product called "Dust", of 23 March 2007, 12:00 UTC (top left, A), 24 March 2007, 00:00 UTC (top right, B), 08:00 UTC (bottom left, C) and 16:00 UTC (bottom right, D). The presence of atmospheric dust, indicated by magenta colour, is apparent especially over eastern Ukraine on 23 March, $12: 00$ UTC, but also over the Libyan coast. Dust advection from Ukraine to central Europe is indicated by the white arrow on the first image. It is likely that air-borne dust is largely obscured by clouds; over Ukraine clouds were high and dense, indicated by red colour, with the exception of highly transparent 'icy' clouds, shown in dark blue. Lower-altitude clouds are more greenish. Although cloud covers much of Europe, the dust apparently also reached the British Isles at much less concentrations. [M. Š́lek, (C) 2007 EUMETSAT]

geographic map view in this diagram shows three paths for the computed trajectory originating at the same site $\left(48^{\circ} \mathrm{N}, 33^{\circ} \mathrm{E}\right)$ but at different heights above the ground $(100,300$ and $1000 \mathrm{~m})$. The starting time chosen is 10 UTC on 23 March 2007. At this time the dust storm was already in the mature stage (with the extent of the dust cloud above Ukraine estimated from satellite images at about $60,000 \mathrm{~km}^{2}$ ). A vertical profile for each trajectory is given at the bottom of Fig. 5. According to this approximation, the dust particles lifted by strong wind to the height of about $100 \mathrm{~m}$ at noon on 23 March 2007 were transported from southern Ukraine to the eastern Czech Republic late in the morning and to the western Czech Republic by noon of 24 March 2007. Dust particles lifted to a height of $300 \mathrm{~m}$ were transported even faster. They were moving close to the NE Czech border shortly after midnight of 24 March
2007 and over northern Bohemia in the morning. The dust at heights above $1 \mathrm{~km}$ was transported over Poland and Denmark. In the afternoon and evening of 24 March 2007, it reached the southern part of the North Sea. Later in the evening and throughout the night, this dust reached also England and other countries in NW Europe, which was also confirmed by satellite images. However, using the network of PM samplers Bruckmann et al. (2008) gathered important data about higher concentrations of these 'exotic and coarse' $\mathrm{PM}_{10}$ particles also over the north-western Germany, Belgium and Netherlands. The atmospheric situation, origin and transport of the dust deposited in Central Europe was described by Birmili et al. (op. cit.) who gave many valuable details to which we refer. By the method of back-trajectory, they also confirmed that the dust had originated in the territory of Ukraine, although they could not 


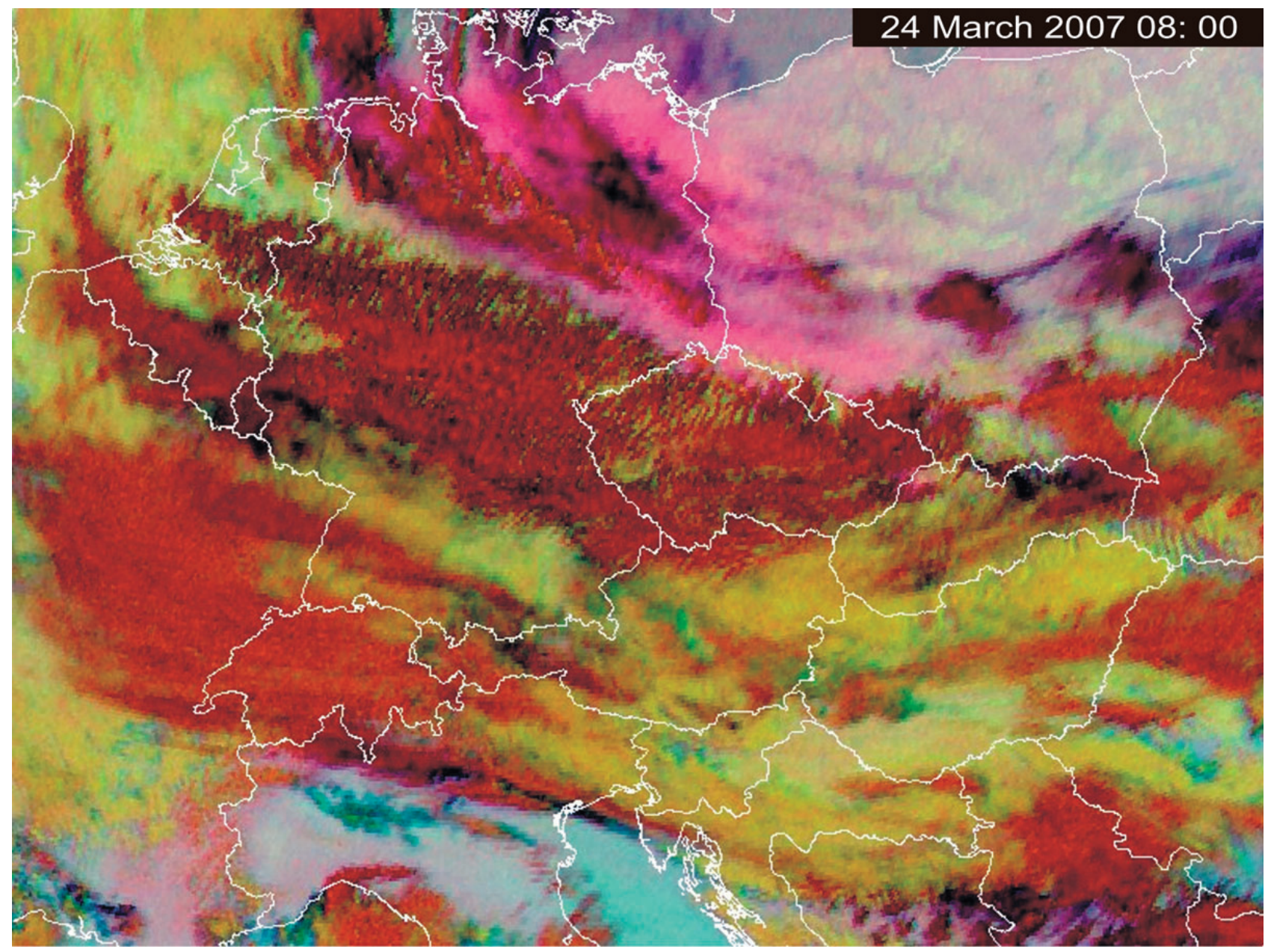

Figure 3. The same RGB product as in Fig. 3, but focused on the heart of central Europe. Dust is apparent in cloud-free areas over south-western Poland and eastern Germany but can also be spotted in the cloud "hole" on the Czech-Slovak border. [M. Šálek, ( 2007 EUMETSAT]

rule out the possibility that some minor fraction of the pollution was transferred from the eastern Mediterranean or the Sahara. Any significant contribution of Saharan dust to the observed dust pollution over Central Europe is, however, viewed as very unlikely.

Certainly one of the most interesting aspects of the dust event deposition was its relatively rapid increase and massive covering of the area by the sediment. The transport of the material at various heights above ground (including high levels above $1.5 \mathrm{~km}$ that were possibly responsible for the transport of the largest, up to $0.5 \mathrm{~mm}$ grains) did not precisely correspond to the timing of this sedimentation. As indicated by RGB images, the prevailing mass of the most concentrated dust was squeezed below, or partly held in, the clouds (Fig. 4). Because of the above-mentioned development of weather conditions, wet deposition of silt must be considered a significant (although not absolutely universal) factor of this sedimentation. The evolution of this relatively abrupt shedding by dirty rain (scavenging of dust particles by raindrops) can be held responsible for the locally apparent speed difference between the movement of the plume, layers or jets, and the main deposition phase of the sediment; the latter was at least partly controlled by precipitation.

In this context, an example from the Prague-Suchdol site may contribute to the understanding of the evolution of atmospheric aerosol and particulate matter concentrations during this sedimentation event (Fig. 6). At this monitoring station, a severe airborne dust pollution event was recorded on 24 March 2007 using the automatic beta radiation attenuation monitor equipped with a $\mathrm{PM}_{10}$ sampling head. After 2 a.m. (local time), the onset of a sharp increase in $\mathrm{PM}_{10}$ values was measured from the level of about $10 \mu \mathrm{g} / \mathrm{m}^{3}$. A narrow maximum with approximately 1-h $\mathrm{PM}_{10}$ maximum mass concentration averages of about $390 \mu \mathrm{g} / \mathrm{m}^{3}$ was recorded between 11 a.m.-12 p.m. This was followed by a sharp decrease lasting until 5 p.m. The second maximum at a level $110 \mu \mathrm{g} / \mathrm{m}^{3}$ was observed at $6 \mathrm{p} . \mathrm{m}$. Then, a slower decrease continued until the minimum of about $5 \mu \mathrm{g} / \mathrm{m}^{3}$ was reached at 3 p.m. on 25 March. The history of nitrogen 
TIME

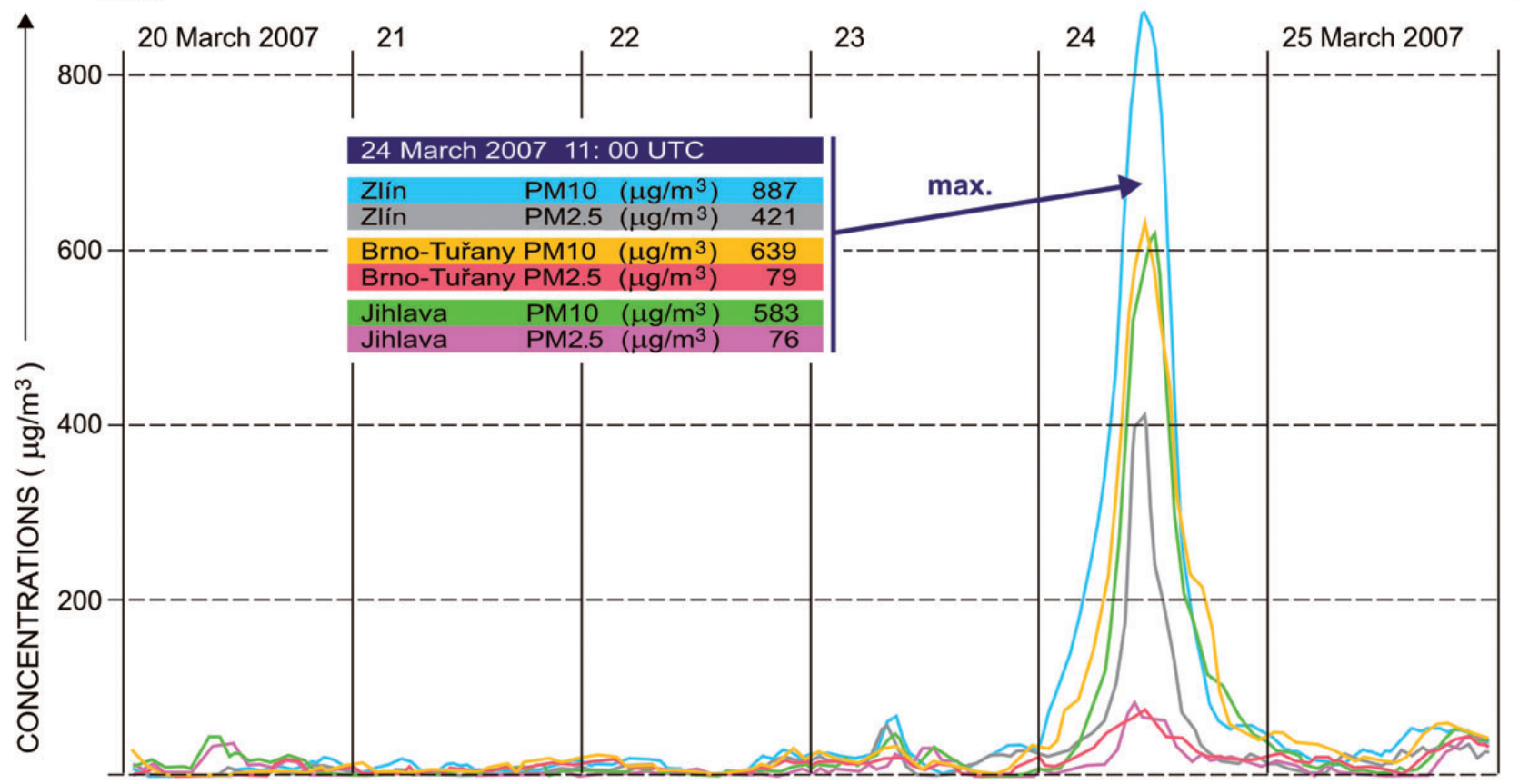

Figure 4. Concentrations of $\mathrm{PM}_{10}$ and $\mathrm{PM}_{2.5}$ particles (i.e., size up to $10 \mu \mathrm{m}$ and $2.5 \mu \mathrm{m}$, respectively) for the period of 20-25 March 2007 , measured at Brno, Jihlava and Zlín air quality monitoring stations located in the eastern Czech Republic. [M. Śálek, (C) CHMI]

oxides $\left(\mathrm{NO}_{\mathrm{X}}\right)$ concentration levels, which are tracers of traffic sources, reached a minimum on 24 March compared to other days. For details about wind, humidity, etc., we refer to the diagram (Fig. 6). Based on this fact, we can expect a very low local ( \pm Prague) contribution to the total $\mathrm{PM}_{10}$ mass level during this particular day. It can be estimated that about $90 \%$ of $\mathrm{PM}_{10}$ mass originated from long-range transported dust.

The composed diagram from the Suchdol data gives solid evidence of a rapid and short-term elevation of $\mathrm{PM}_{10}$ before noon of 24 March 2007, which was closely connected with the main episode of deposition of the relatively coarse silt and fine-grained sand. Birmili et al. (op. cit.) also found a considerable correspondence between the maximum concentrations of dust particles and the timing of the depositional episodes. These data provide, therefore, further constraints to the time of deposition, which was basically synchronous with the maximum dust concentrations in the atmosphere. Summarizing the measurements and observations, it can be stated that about $50 \%$ of the sediment was deposited during $15 \mathrm{~min}$ and $80 \%$ during $1 \mathrm{~h}$. Only a low and mostly decreasing concentration of $\mathrm{PM}_{10}$ persisted until the afternoon, with the lowest concentrations reached early afternoon the next day. The phase of periodic eolian re-emitting and resedimentation of this material started immediately after these minimum concentration values occurred. This rapid change was most likely caused by the degree of drying of the silt deposited on the ground and vegetation. However, the dust-related halos with only weakly developed supernumeraries (Bishop's effect, mostly, $c f$. Mims 2003, Vollmer 2005) were observable a day later (Kondziolka \& Maňák 2007). These were indicative of other finest particulate material in the atmosphere, i.e., not all these secondary sedimentation episodes must necessarily be explained by resedimentation.

\section{Sediment}

The sediment rapidly (as described above) covered 80-95\% of all available subhorizontal substrates and often adhered also to significantly inclined or subvertical surfaces (Fig. 7). The thickest layers of dried sediment were dark greyish-yellowish brown 10YR3/2 (Munsell Color 2000, Asahi Net 2007). Wet sediment was darker, about 10YR2/2. RGB variations in reflected light were low. In terms of industrial colour systems, the dry sediment was near $8676 \mathrm{~N}-8666 \mathrm{~N}-8816 \mathrm{~N}$ of the CSI (Color Charts 2007). Comparison of the collected reports confirmed that the quality and amount of this sediment were surprisingly invariable over the territories of several Central European countries in the $\mathrm{E}-\mathrm{W}$ direction (area equal to or exceeding $\mathrm{n} \times 10^{5} \mathrm{~km}^{2}$ ).

The average thickness of the sediment layer was $1.5 \mu \mathrm{m}$, but this is only an imaginary value because most deposited silt particles were of larger size (see below). At least for the main deposition areas of 24 March 2004, the sediment must be categorized as 'silt' (with a small amount 
of coarser admixture) rather than 'mud'. At micro-scale, the layer blanketing the substrate was not continuous, and the reticulate to patchy arrangement of the sediment allowed the colour of the substrate to be seen. For example, snow covered by dust particles showed light shades of 10YR7/1 (Fig. 7). A uniform sediment cover was found on large flat surfaces whereas complex relief with turbulent eddies in the atmospheric boundary layer led to a differentiation. Thicker layers of silt were accumulated on the frontal side of obstacles at high wind speed or, alternatively, on the lee side when wind speed decreased. The maximum observed primary thickening (i.e., with some reworking, but not redeposition) was $0.3-0.5 \mathrm{~mm}$. Thin coatings of various smooth and eggshell substrates seemed to have slightly increased 'adhesiveness', although neither 'sticky' or 'smearing' clay components nor the cementation were causing this appearance. A slightly increased resistance to re-suspension was also observed. Both these aspects can develop due to the presence of 'shard'-grained silts in combination with highly polydisperse and multimodal particle-size distributions (high internal friction).

Quantity of delivered sediment: The thickest local accumulations of this eolian/dirty-rain sediment were found, for example, in the Krkonoše Mts where the amount of delivered sediment locally reached $10 \mathrm{~mL} / \mathrm{m}^{2}$. On the other hand, many barren or slightly covered places were detected, so that the estimate of the mean amount of the sediment deposited in this area is much lower - only about $1.8 \mathrm{~mL} / \mathrm{m}^{2}$. The local excess of winnowed (adhered) material was also found in the Nízké Tatry Mts $-7.5 \mathrm{~mL} / \mathrm{m}^{2}$ (but estimates of the mean values are low $-0.8 \mathrm{~mL} / \mathrm{m}^{2}$ ). The medium values of $1.1-1.5(1.3) \mathrm{mL} / \mathrm{m}^{2}$, typical of this event, were found at Prague-Suchdol. For Czech and Slovak territories, a comparison of data from the sampling sites with the numerous images and reports allowed assessment of the mean amount of delivered material as roughly equivalent to $1.3 \mathrm{~mL} / \mathrm{m}^{2}\left(=2.3 \mathrm{~g} / \mathrm{m}^{2}=2300 \mathrm{~kg} / \mathrm{km}^{2}\right.$; at mean bulk density of dry deposited material $1.77 \mathrm{~g} / \mathrm{cm}^{3}$ and mean grain density of $2.65 \mathrm{~g} / \mathrm{cm}^{3}$ ). These are quite low estimates, which can be increased using the corrections for all possible infiltration or washing/redeposition effects. However, this difference is less than $15 \%$, as would be inferred from large subhorizontal snow plains in mountains or flat, low-permeable substrates in lowlands. For localities see Fig. 8 and Table 1.

This figure can be compared with average atmosphericdust deposition rates. For example, Yoshinaga (1998) estimated loess accumulation rates between $10-100 \mathrm{~g} / \mathrm{m}^{2} / \mathrm{yr}$. The intensity of this very recent event, given the possibility of its recurrence, therefore, approximates roughly the lower boundary conditions for 'loess sedimentation', of course in the broadest meaning of this term. In comparison with contemporary measured and reviewed budgets and accumulation rates of eolian dust (e.g., Reheis et al. 1995,

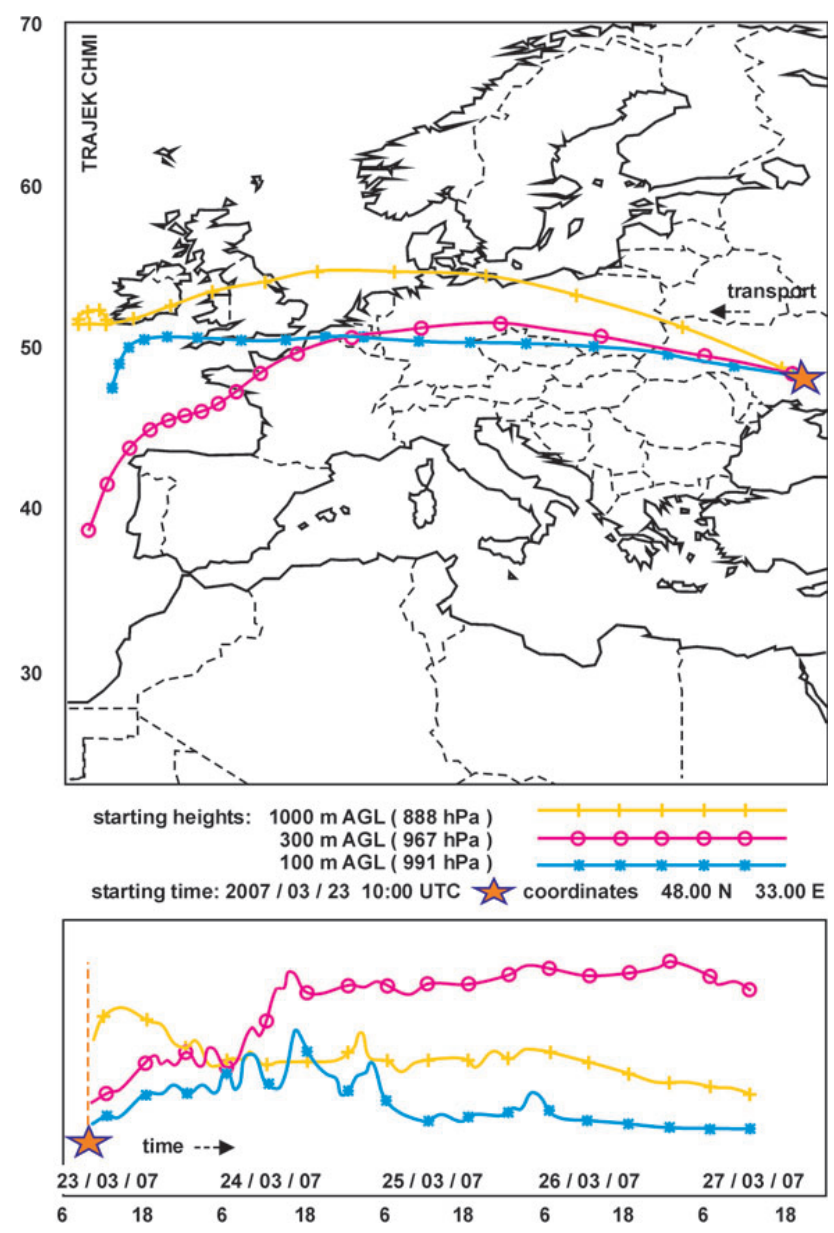

Figure 5. Top: geographic map with three particle trajectories originating at the same site $\left(48^{\circ} \mathrm{N}, 33^{\circ} \mathrm{E}\right)$ from different heights above ground, computed by the Trajek model using the weather prediction model of the ECMWF. Starting time is 10:00 UTC on 23 March 2007. A vertical profile of the particle trajectories is shown at the bottom. Trajectories: blue: starting height $100 \mathrm{~m}$; red: $300 \mathrm{~m}$, yellow: $1000 \mathrm{~m}$ above ground. Transport velocities are indicated by symbols $(*, o,+)$ for each 6 hours. Top: the vertical axis represents latitude (deg.); the horizontal axis represents longitude (deg.). Bottom: the vertical axis represents atmospheric pressure (hPa); horizontal axis represents date and time (UTC). [P. Šimandl, (C) CHMI]

Zender et al. 2004, Chin et al. 2007 and references cited therein), the values between $1-10 \mathrm{~g} / \mathrm{m}^{2} / \mathrm{yr}$ are typical for areas frequently fed by dust plumes, and an increase within, or above, this range suggests desert (or desertified) land sources. The quantification of this event-generated sediment also allows us to speculate about particulate load in this particular dust plume. The area with this sediment was at least $1000 \mathrm{~km}$ long by $400 \mathrm{~km}$ wide. If calculated further, such an area was covered by roughly $1 \times 10^{9} \mathrm{~kg}$ ( $=1 \mathrm{Tg}$, or $\mathrm{Mt}$ ) of the sediment. Under empirically derived conditions where such main sediment might represent only $0.3-0.4$ of the total particulate load (dilution and escape to long-term large-distance suspensions), we can estimate about $3 \mathrm{Tg}$ of particulate load in this plume. This speculative 


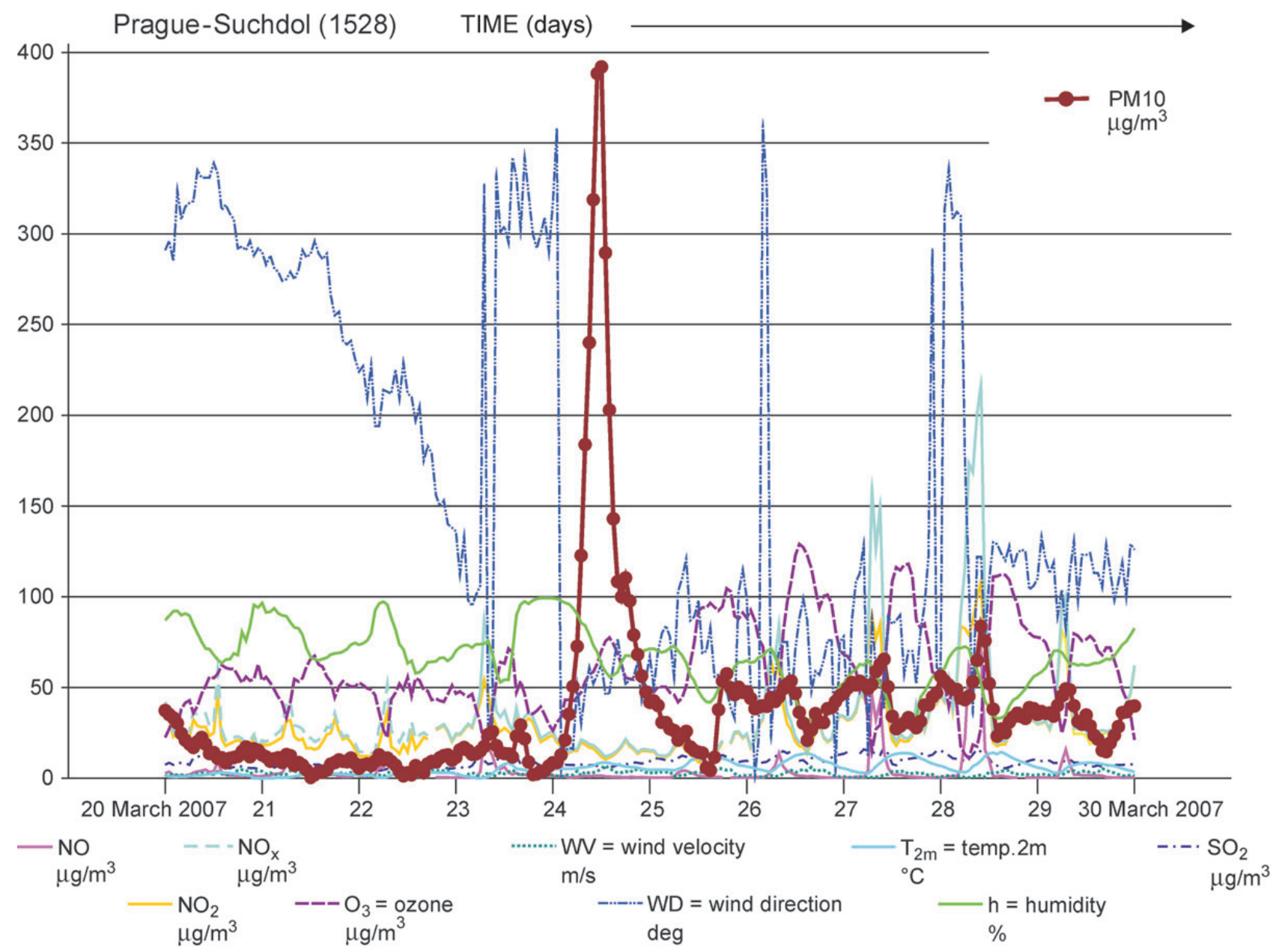

Figure 6. The evolution of $\mathrm{PM}_{10}$ concentrations at Prague-Suchdol site and the atmospheric parameters in the atmospheric boundary layer (close to ground), including the data about aerosol chemistry, speed and direction of wind, humidity, etc. Horizontal axis represents dates given in local time. [J. Schwarz, @ CHMI, ICPF ASCR]

amount is interesting, especially if compared with the present data on total atmospheric load of 8-36 Tg (Zender et al. op. cit.). Furthermore, this estimate of total dust amount based on really deposited sediment $(3 \mathrm{Tg})$ is significantly higher $(\times 50)$ than the $\mathrm{PM}_{10}$-related total dust mass estimates (60 Gg - Birmili et al. op. cit.) - see the discussion for possible solutions.

As mentioned above, the basic sedimentation modes often combined the mechanisms of eolian and wet (dirty rain) deposition. Prevailing dry, typically eolian conditions of deposition were rare on 24 March 2007 before noon (e.g., near Poděbrady, E of Prague). A few millimetres of rain fell over more than $3 / 4$ of the area of deposition whereas amounts of $20 \mathrm{~mm}$ or more were exceptional during this event. Drizzle and fog were present in mountainous areas above $1000 \mathrm{~m}$ a.s.l. As evidenced by satellite radar composites, the largest volume of dust in the atmosphere was transported just beneath the clouds. This suggests that water-locked dust particles were increasing in number on the oblique downward trajectory of raindrops. Such pro- gressive collection (scavenging) would also significantly increase particle-size dispersal during raindrop fall. The massive deposition of dust, therefore, had followed the rapidly increased concentrations of particulate matter in the atmosphere above the ground and also the short period of relatively increased rainfall. This fits the observations made by the authors, other consulted specialists and numerous volunteers, that $60-70 \%$ of the primary sedimentation occurred during the first several tens of minutes (20-40, usually $30 \mathrm{~min}$ ) whereas $95 \%$ of sedimentation lasted several hours (3-9, mostly $6 \mathrm{~h})$.

In a detailed view, the dirty-drop cratering spread the silt-sized material in a system of concentric rings and radial crests (Hladil \& Beroušek 1993 and literature cited therein). The intracrater network on the order of $0.01-1 \mathrm{~mm}$ locally changed to speckled patterns or fused smears depending on the roughness and resistance of the substrate, soaking/runoff and other parameters. Observations of halfmoon or loop-shaped aprons of condensed washed silt covering the outer ejecta fields were common. The overlapping of these 

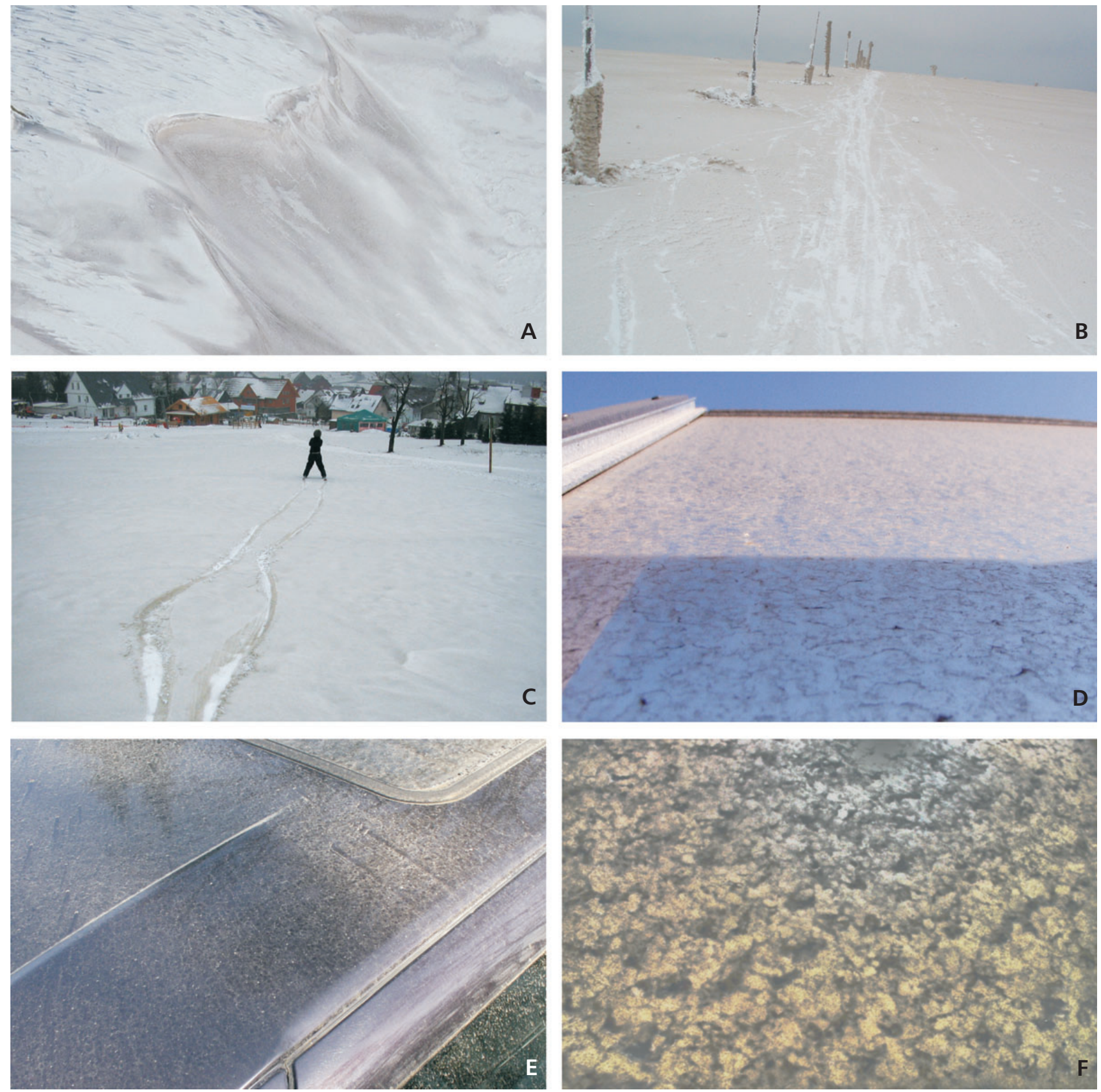

Figure 7. Macroscopic appearance of the sediment. $-\mathrm{A}-\mathrm{C}$ - dust blanketing the freshly snow-covered plains of mountains at altitudes of $1000 \mathrm{~m}$ and more. The whiteness of this snow substrate contrasts with brownish colour of newly deposited dust (e.g., places blown/washed of dust and ski tracks). A - Nízké Tatry Mts (N Slovak Republic), slopes of Dumbier Mt.; frontal lower edge in the picture (LE) = 120 m. B - Krkonoše Mts (N Czech Republic), Labská Bouda Lodge; LE 6 m. C - Krušné hory Mts (E Czech Republic), small mountain town of Boží Dar; LE 4 m. • D-F - Examples of dust deposited in snow-free lowlands. The selected surfaces were accidentally cleaned before the wet (dry and rain and 'dirty-rain') dust deposition event. D - Town of Púchov (NW Slovak Republic), roof window; LE 0.5 m. E - Town of Brno (E Czech Republic), roof of a car; LE 0.8 m. F - Town of Blansko (E Czech Republic), enamelled tiles on balcony; LE 0.2 m. [@ IAN, IGL ASCR and contributors acknowledged]

aprons shifted the scaling of the reticulate and patchy patterns to centimetres (Fig. 7). With higher precipitation and increased runoff these structures changed to fractal-dam pattern formations of thin transported and deposited layers. All these sedimentary processes resulted in the formation of material-rich nodes, which were resistant from the pre- ferred mode-selective texture that developed in the nodes. In this context, particularly the spacing ratios between particle-size modes of about 2-3 are very effective for increased yield stress and internal friction in such polydisperse and multimodal materials ( $c f$. Hladil et al. 2007). It is certainly worth noting that the typical eolian 


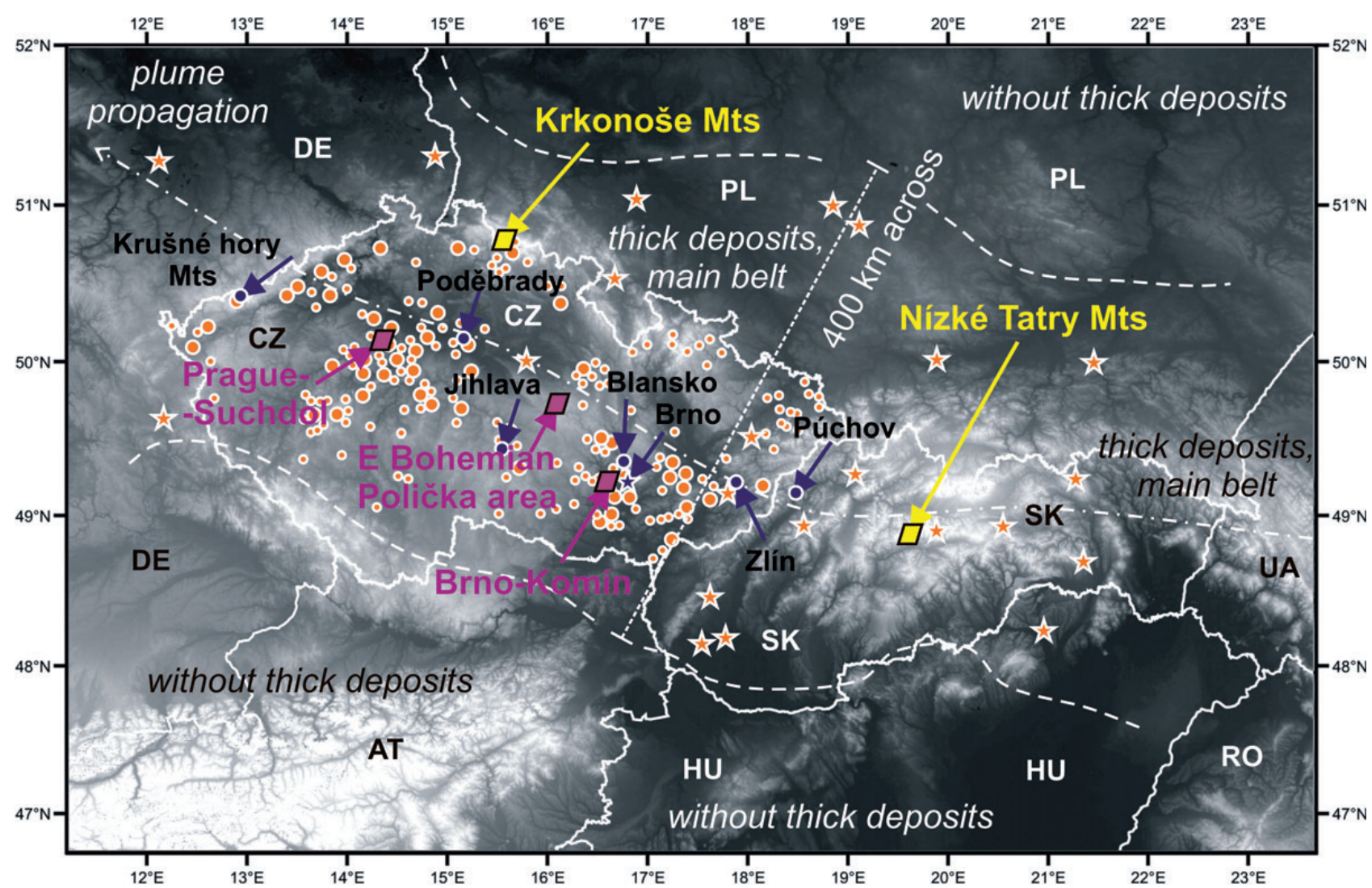

Figure 8. Location points and extension of the main-belt event-sediment cover. The area with the thickest deposits (dashed white lines) roughly corresponds to increased $\mathrm{PM}_{10}$ concentrations in air above the ground ( $c$. Birmili et al. 2008), but the sediment did not completely obey these concentration gradients, being more uniformly distributed over the Czech and Slovak territories. Explanation: Single and multiple reports managed by IAN (orange filled circles, small and large, respectively); other reports (orange filled asterisks); localities mentioned in the text (dark blue filled marks of both types, with arrows); the principal sampling sites (rhombs and arrows; yellow - the mountain areas with fresh snow substrates, violet - the lower altitude areas where freshly cleaned surfaces were available). Abbreviated country names (boundaries by white solid line): AT - Austria, CZ - Czech Republic, DE - Germany, PL - Poland, RO - Romania, SK - Slovakia, UA - Ukraine. [J. Hladil, C IGL ASCR, IAN, J. Kondziolka and contributors acknowledged]

deposits of this event also showed multiscale rippled to speckled patterns, and developed into variable network structures of tenths to tens of millimetres in size. And again, this was largely conditioned by the specific quality of the material. To summarize, some principal features occurred repeatedly, as follows: 1 - the areal structure of the sediment was reticulated/speckled, which usually occurs in several orders of magnitude (from $0.01 \mathrm{~mm}$ to $10 \mathrm{~cm}$ ); 2 - ultra-thin and loosely arranged lenses alternated in a vertical section. The middle parts of these intermittent blankets showed a tendency to firm structuring and were composed of tridisperse silts with spacing ratios between modes of about 2-3;3 - the ambient washed or blown blankets contained moderately sorted silt of unimodal or bimodal particle-size distributions; and 4 - distal sediment escaping to porous substrate, resedimented with runoff or blown away showed moderate to good sorting. The thickest secondary accumulations were finely laminated and consisted of very fine silts and muds alternating with occasional 'sandwiched laminae' of medium to coarse silt.
There was also a specific technical aspect in that these multimodal, angular silt-dominated sediments exhibit a remarkable resistance to cleaning procedures. Any unimodal silt fouling can be cleaned more easily.

As shown from the above, the particle-size distribution is one of characteristics distinguishing this sedimentary material from other dust sedimentation. Basically, the event sediment was a highly polydisperse and multimodal silt-sized material (Fig. 9 and Tab. 2). Sediment from tens of localities was rapidly studied for comparison, and that from three sites (Krkonoše, Nízké Tatry, and PragueSuchdol) was selected for further detailed microscopic analyses. Dried and homogeneously composed sediment was studied by means of scanning electron microscopy (for detailed methods see Appendix). Equivalent diameters of particles and grains were calculated, with subsequent cumulation of calculated volumes to $5 \mu \mathrm{m}$-graded particle-size categories/fractions (from nanometres to $45 \mu \mathrm{m}$ level) and numerical estimation of the relevant mass per fraction. The direct result of these procedures was the 
Table 1. Location of samples. Sampling sites are arranged from ESE to WNW, along with the main plume propagation axis (compare Fig. 8). Two Ukrainian sampling points are described below. [J. Hladil, R. Melichar]

\begin{tabular}{|c|c|c|c|c|c|}
\hline LOCALITY - NAME & FURTHER DESCRIPTION & \multicolumn{2}{|c|}{$\begin{array}{l}\text { GEOGRAPHIC } \\
\text { COORDINATES }\end{array}$} & CIRCUMSTANCES & {$[\mathrm{m}]$} \\
\hline \multicolumn{6}{|c|}{ MAIN SAMPLING SITES - NATURAL DUST-EVENT SEDIMENT, CZECH AND SLOVAK TERRITORIES } \\
\hline Nízké Tatry Mts, SK & $\begin{array}{l}1 \text { km SE of Dumbier Mt., near Štefánikova } \\
\text { chata Lodge }\end{array}$ & $48^{\circ} 55^{\prime} 56^{\prime \prime} \mathrm{N}$ & $19^{\circ} 38^{\prime} 60^{\prime \prime} \mathrm{E}$ & lee side of a crest $*$ & $0.25 \times 0.25$ \\
\hline Brno-Komín, CZ & $\begin{array}{l}\text { W periphery of Brno, Lísky Street, green } \\
\text { residential area }\end{array}$ & $49^{\circ} 13^{\prime} 24^{\prime \prime} \mathrm{N}$ & $16^{\circ} 32^{\prime} 60^{\prime \prime} \mathrm{E}$ & balcony $* *$ & $1.0 \times 1.0$ \\
\hline $\begin{array}{l}\text { E Bohemian Polička } \\
\text { area, CZ }\end{array}$ & $\begin{array}{l}\text { Borová u Poličky, green residential area, near } \\
\text { nursery school }\end{array}$ & $49^{\circ} 44^{\prime} 12^{\prime \prime} \mathrm{N}$ & $16^{\circ} 09^{\prime} 52^{\prime \prime} \mathrm{E}$ & car surface $* *$ & $1.4 \times 2.85$ \\
\hline Krkonoše Mts, CZ & $\begin{array}{l}1 \mathrm{~km} \text { SE of the Vosecká bouda Lodge, } \\
0.25 \mathrm{~km} \text { WSW of Sokolník Mt. }\end{array}$ & $50^{\circ} 46^{\prime} 33^{\prime \prime} \mathrm{N}$ & $15^{\circ} 31^{\prime} 14^{\prime \prime} \mathrm{E}$ & shallow depressions $*$ & $0.25 \times 0.25$ \\
\hline Prague-Suchdol, CZ & $\begin{array}{l}\text { Inst. Geol. ASCR, S margins of Lysolaje, } \\
\text { green residential area }\end{array}$ & $50^{\circ} 07^{\prime} 37^{\prime \prime} \mathrm{N}$ & $14^{\circ} 22^{\prime} 55^{\prime \prime} \mathrm{E}$ & table-tennis outdoor table $* *$ & $1.5 \times 2.65$ \\
\hline \multicolumn{6}{|c|}{ COMPARATIVE SAMPLING OF “SOIL” SURFACE - THE SOURCE AREA, SE UKRAINE, KHERSON REGION } \\
\hline Ukraine B2 & $\begin{array}{l}\text { E of Kherson, } 20 \mathrm{~km} \text { E of Tsyurupinsk, } \\
\text { Velyki Kopani }\end{array}$ & $46^{\circ} 28^{\prime} 17^{\prime \prime} \mathrm{N}$ & $32^{\circ} 59^{\prime} 51^{\prime \prime} \mathrm{E}$ & yellowish-brown silty soil *** & $0.25 \times 0.25$ \\
\hline Ukraine B3 & $\begin{array}{l}\text { the same site, } 5 \mathrm{~km} \mathrm{~S} \text { of the large circular } \\
\text { field with eolian sand dunes }\end{array}$ & $46^{\circ} 28^{\prime} 16^{\prime \prime} \mathrm{N}$ & $32^{\circ} 59^{\prime} 52^{\prime \prime} \mathrm{E}$ & $\begin{array}{l}\text { yellowish-brown sand } \\
(<0.4 \mathrm{~mm}) * * *\end{array}$ & $0.25 \times 0.25$ \\
\hline
\end{tabular}

Legend: $(*)$ fresh snow substrate, $(* *)$ thorougly cleaned few hours before, $(* * *)$ natural surface. See the Appendix for detailed techniques.

determination of the above-mentioned, obvious silt multimodality to very exact detail (Fig. 9). Although this multimodality possibly reflects several superimposed processes (see next paragraph below), the arrangement of modes is not completely random and resembles a quasi-regular nonlinear frequency modulation. The most significant finding was that $80-90 \mathrm{wt} \%$ of solid particles were in the silt size category $(4-63 \mu \mathrm{m})$. Regular occurrences of small but not negligible amounts of sand grains ( $\leq 10$ wt. \%) were confirmed. The upper limits of their equivalent diameter were approximately $\leq 0.5 \mathrm{~mm}$. The highest concentrations of large grains were found in the Krkonoše Mts and E Bohemian Polička regions, on snowed plains and clean surfaces, respectively. The grains of $0.1-0.5 \mathrm{~mm}$ sizes must have come from the about 1.5-km high boundary-layer jet, as suggested by Birmili et al. (op. cit.), or even a higher jet that could also have transported them. Interestingly, nanometre-sized particles and secondary aggregated aerosol nuclei were mainly absent from this sediment. The moderately-expressed to well-separated particle-size modes from 2-4 were particularly visible in the southern part of the deposition belt, e.g., the material from Prague-Suchdol shows a typical, quasi-regular modality development beginning from three modes at 10-15, 20-25 and 30-35 $\mu \mathrm{m}$ categories. The next three modes developed on less frequent sub-millimetre-sized grains are approximately located at 80, 220 and $350 \mu \mathrm{m}$. On the other hand, a slightly obliterated multimodality was found in the Nízké Tatry Mts. This does not contradict the hypothesis that the multimodal sediment is related to increased precipitation scavenging of dust particles. However, the strong multimodality found in the Krkonoše sediment (high altitude, small raindrops only) seems to thwart any attempts for the simplest or universal explanations.

Such a degree of multimodality is, of course, only infrequently described from dust sediments. The most common, current concepts concentrate mainly on bimodal compositions of eolian silt, with the particle-size modes mainly at the lower limit of medium and very fine silt classes (i.e., short suspension-time silt -vs- long suspension-time fine component, Sun et al. 2002, 2004, or coarse -vs- fine quartz fluxes, CQF and FQF, Lim \& Matsumoto 2006). In the field of sedimentology, eolian sediments with three or more modes are often assigned to polygenetic aggraded, mixed or amalgamated structures. In the field of fly dust, monthly sampling in vertical sections appears to corroborate the predominance of unimodal and bimodal silt in dust plumes and sediments (Prins et al. 2007). In spite of this, the evidence of multimodal particle-size distribution in a single dust plume has become more important in present-day research because of the interest in loess storms (e.g., Qin et al. 2005) and also tentatively Martian dust (Yizhaq 2005). This concerns mostly the medium to coarse silt-size categories, where a visible gap is often placed between the most remarkable loess mode, 20-60 $\mu \mathrm{m}$ and long-travel dust mode, 2-6 $\mu \mathrm{m}$ (Smalley et al. 2005) but several other gaps still occur in these two categories ( $c f$. Tanner 1958, Smalley et al. op. cit.). Contrastingly, the scatter of particle-size modes in our samples is more complex, dominated by fine silt category and consisting of a broad quasi-regular series of modes. Such particle-size distributions may resemble rather modulated frequency bands rather than Tanner's zig-zag distributions. 
Table 2. Numerical data complementary to the graphical information about multimodal particle-size distribution in the dust-event sediment (compare Fig. 9). PRG - Prague-Suchdol, TAT - Nízké Tatry Mts, KRK - Krkonoše Mts. [J. Hladil]

\begin{tabular}{lrrrrrr}
\hline $\begin{array}{l}\text { Grain size } \\
\text { category }\end{array}$ & PRG & \multicolumn{3}{c}{ TAT } & KRK & \\
\hline$\mu \mathrm{m}$ & wt.\% & \multicolumn{1}{c}{$\mathrm{N}$} & wt.\% & $\mathrm{N}$ & wt.\% & $\mathrm{N}$ \\
\hline $0-5$ & 2.7 & 974 & 5.8 & 1110 & 0.9 & 663 \\
$5-10$ & 9.4 & 247 & 9.4 & 174 & 8.1 & 412 \\
$10-15$ & 17.2 & 86 & 9.1 & 32 & 8.3 & 171 \\
$15-20$ & 9.5 & 17 & 10.2 & 14 & 12.4 & 36 \\
$20-25$ & 16.4 & 14 & 19.5 & 12 & 12.9 & 29 \\
$25-30$ & 10.3 & 5 & 11.9 & 4 & 13.0 & 16 \\
$30-35$ & 15.4 & 4 & 10.0 & 2 & 13.3 & 10 \\
$35-40$ & 10.7 & 2 & 8.8 & 1 & 15.5 & 8 \\
$40-45$ & 8.5 & 1 & 15.3 & 1 & 15.6 & 5 \\
\hline total & 100 & 1350 & 100 & 1350 & 100 & 1350 \\
\hline
\end{tabular}

In general, seven principal mechanisms can bring silt-sized particles to multimodality under these conditions: 1 - control of multimodality by different petrological/geological origin of particles, as demonstrated for quartz by Smalley et al. (op. cit.); 2 - inheritance of palimpsest-type multimodality of source material; 3 - fluctuations in the turbulent flows from which particles come (multiscale, from troposphere to boundary layer); 4 - selfstratification principles applied to the thin running layer; 5 - ripple and fractal dam pattern formations in thin transported and deposited layers; 6 - a combination of dry and wet sedimentation modes (particles from air and raindrops); and 7 - palimpsest-like reworking simultaneous with deposition of silt layers (alternating deflation and sedimentation: fluctuating magnitudes of raindrop impacts, splash, runoff, sedimentation, infiltration and trapping). The first two points relate to hypothetical distal factors, the middle three points refer to the poorly known rheology of these suspensions and consolidating sediments, and the last two points are modifications of the principle of a multi-source/multi-process origin of multimodal sediments. The latter points have never been studied in applicable conditions and in sufficient detail. Although the interpretation remains ambiguous and inconclusive, the beginning of the modality rhythms in the fine silt class is indicative of proximal sedimentary processes rather than of distal ones.

The variability of silt particle geometries (e.g., Figs 10, 11) was assessed according to sphericity and roundness. The presence of angular to subangular particles prevails almost absolutely. For a more exact assessment, the sphericity $(\mathrm{S})$ /roundness (R)-regularity $(\mathrm{G})$ system was used (Krumbein 1941, Cho et al. 2006). Especially finer classes of silt between 5 and $35 \mu$ yielded almost invariable shape proportions with increasing particle size, with a low variation between sampling sites. Particle geometries were determined with a certain degree of simplification: first, the shapes according to this system were simplified to 2D outlines; and secondly, only each fiftieth $\mathrm{S}-\mathrm{R}$ was calculated while the other $\mathrm{S}-\mathrm{R}$ (N 5000) was only graphically compared to them. The cumulative shape analyses of the deposited dust particles 5-35 $\mu \mathrm{m}$ in size suggest mainly that the frequencies reached a clear peak at class S0.7-R0.3 with $23 \%$ of all grains (Fig. 12). The maximum shape frequencies at S0.7-R0.3 (and also S0.9-R0.3) were almost exclusively related to quartz, whereas the secondary elevations at S0.7-R0.1 were increased by feldspars of fresh appearance (cleavage). With the exception of the branch toward field S0.3-R0.1, which involved also micas, organic minerals and other accessory minerals, all other slight elevations, combined with a high regularity of particles $(\mathrm{G}=0.5$ to 0.9$)$, corresponded mostly to quartz. Concerning the regularity alone, the most frequent values of about 5.3 characterize the whole material.

The shape and surface microtexture of sand grains was studied for fractions $250-500 \mu \mathrm{m}$, and the richest samples from E Bohemian Polička region and the Krkonoše Mts were used (cleaned and fresh-snow substrates). This size category included only quartz grains, fragments of soil crusts or peloids and larger biomorphs (Fig. 13). The dominance of quartz was characteristic, similarly as in finer size categories. Quartz grains were boiled in hydrochloric acid, and 25 proportionally selected grains were studied in detail by means of scanning electron microscopy. About $40 \%$ of these large grains showed obvious fluvial rounding and microtexture characteristics (see Mahaney 2002 for criteria), and about $20 \%$ were only little affected by subsequent alterations. Other large grains showed signs of eolian and mainly eolian and then colluvial processes (Fig. 13, among F-E-D examples). Among other components, purely pedogenic quartz shapes slightly prevailed over typical colluvial-shaped quartz grains, although a transitional category between them can be also defined. The large grains of pedogenic quartz have numerous, smooth conchoidal fractures of fresh appearance. Less abundant but ubiquitous soil crust fragments and porous nodules/peloids consisted of clay minerals, iron oxides, organic and carbonate precipitates with a large proportion of very fine silt-sized parti-

Figure 9. Particle-size distributions across a significant part of the silt size category in the sediment. Mass of grains per a class and number of grains are compared. Multimodal distribution characteristics vary for different sites and were controlled by different, proximal depositional processes (see the text). Arrangement of modes may resemble a quasi-regular nonlinear frequency modulation. [J. Hladil] 

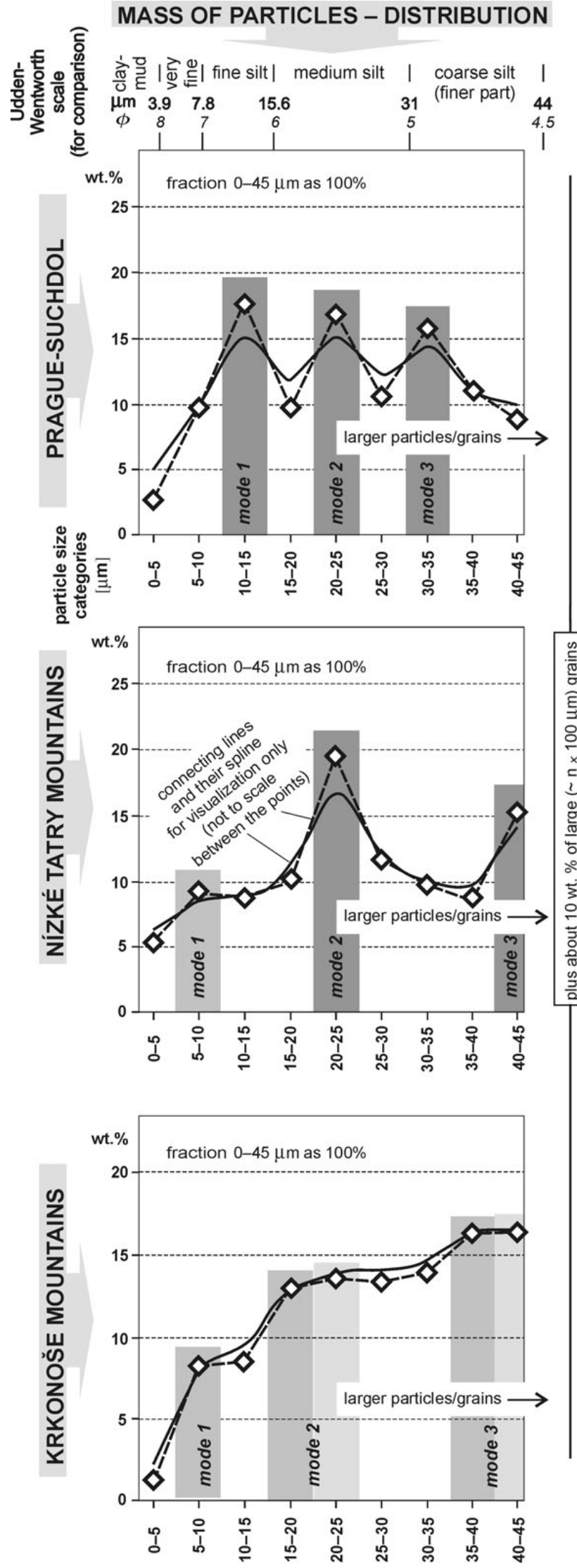

\section{NUMBER OF PARTICLES - DISTRIBUTION}
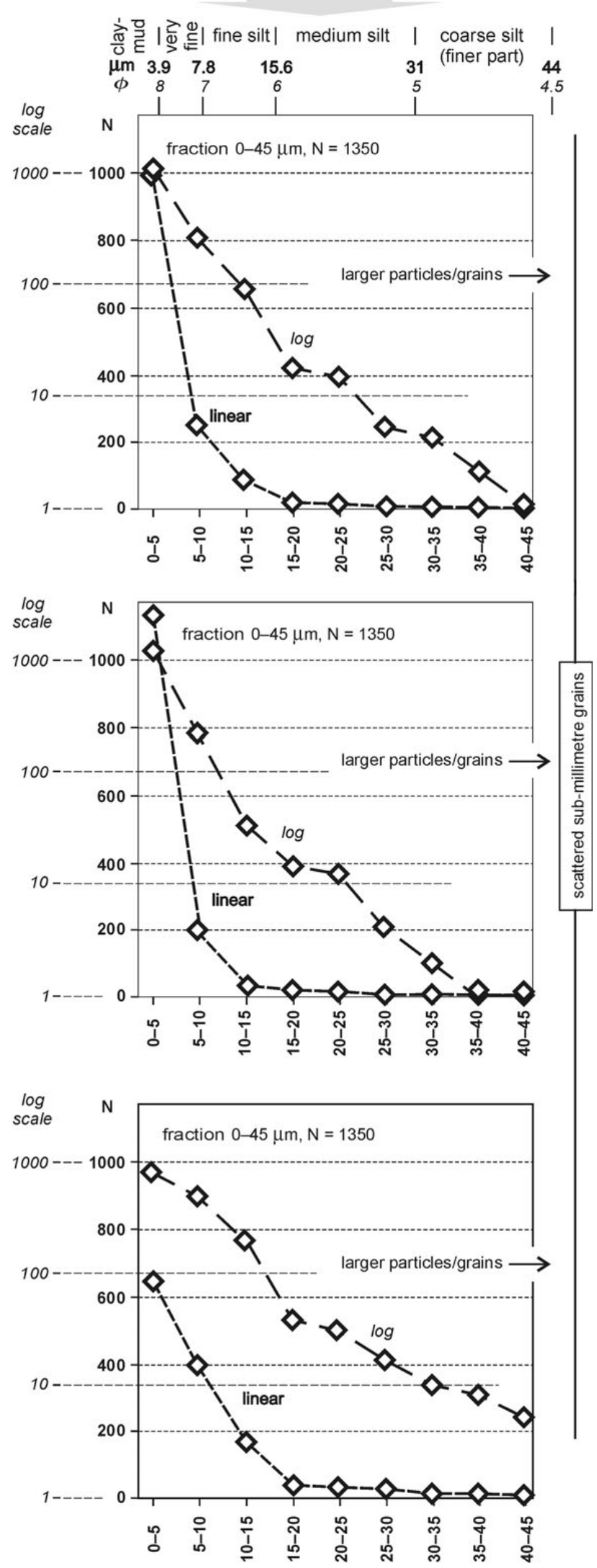

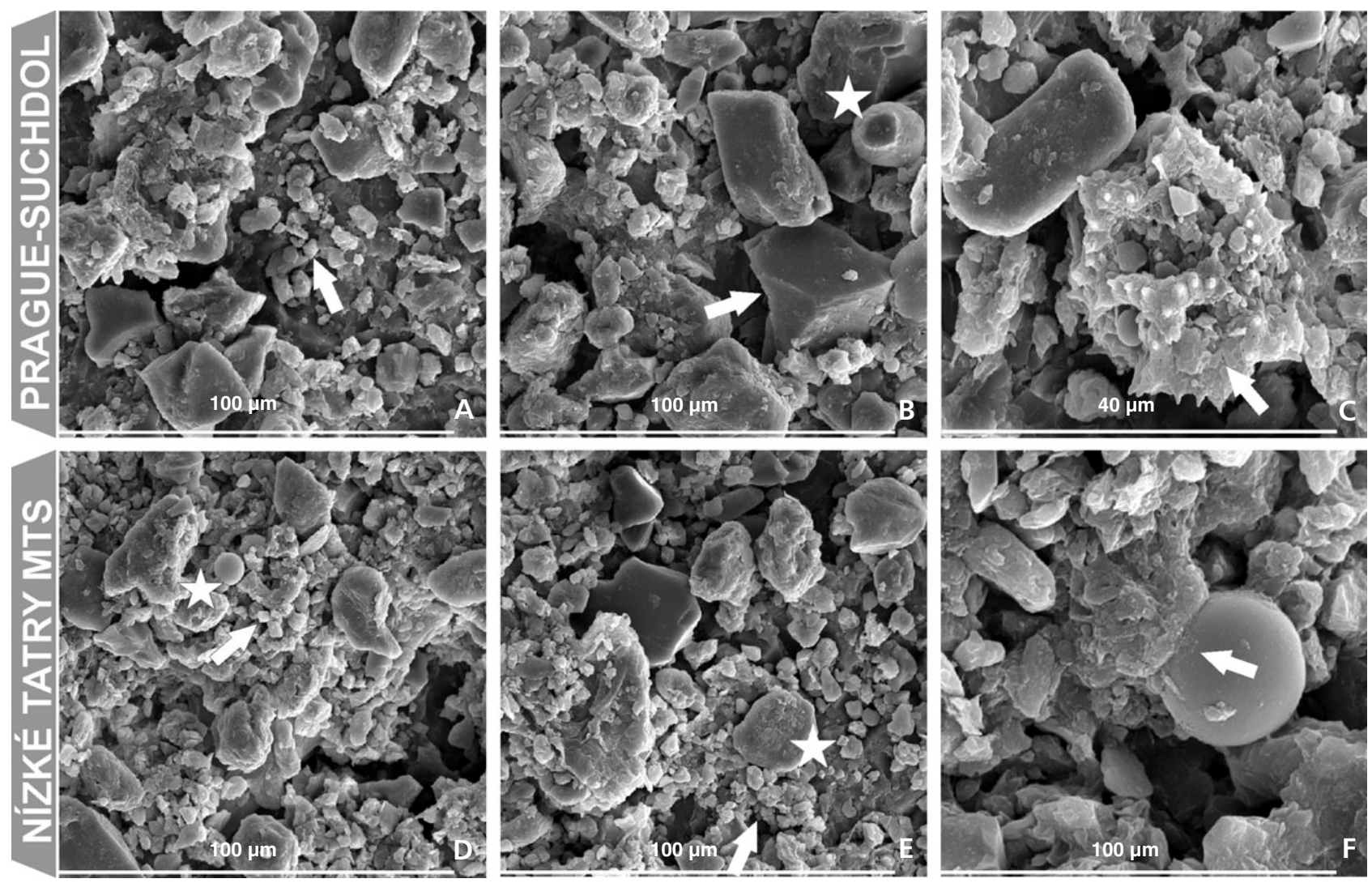

Figure 10. SEM images from two principal sampling sites illustrating the ranges of local variations in thicker layers of dried sediment. • A - apparent abundance of particles with equivalent diameters (ED) of about $20 \mu \mathrm{m}$ and $2 \mu \mathrm{m}$. Even the small particles are often angular and consist of quartz (arrow). - B - the particles with ED of about $25 \mu \mathrm{m}$ are accompanied by a more continuous dispersal between ED $10 \mu \mathrm{m}$ and $1 \mu \mathrm{m}$. Large quartz particles have planar and conchoidal fractures (arrow; compare also A). Rounded object is biomorph (asterisk). $\bullet \mathrm{C}$ - rounded quartz in contrast to porous organic structure (arrow) which acts as a sediment baffle for fine silt and mud particles. $\bullet \mathrm{D}-$ an almost continuously developing polydispersion below 'mode 1 '. Small-sized, smooth grass pollen are present in quartz dominated material (asterisk); extremely rare are tiny rhombohedra of calcite (arrow). $\bullet$ E - small particles of smectite, chlorites and organic flakes (arrow); fine/medium silt-sized, hydrated/altered chloritoid grain with pitted surface (asterisk). - F - nanometre-scale particles adhering to relatively smooth surface of a grass pollen (arrow). [L. Koptíková, A. Langrová]

cles. Their microfabrics most likely correspond to former hardsetting microtextural layers or patches in the source soil. Very similar results were obtained also for large-grain assemblages from other places. In transmitted light, some pores in fragmented soil crusts showed also lepidocrocite laths between goethite needles. This may be indicative of dissected soil cover in the source area or even presence of crust soil formation on places where the groundwater level was close to the soil surface ( $c f$. Smeck et al. 2002). Altered rock-forming minerals and porous, secondary mineral mixtures were only sporadically detected. Almost none of the large quartz grains were substantially coated. The absence of desert coatings or relicts of cemented or aggregated grains is typical for areas with an average yearly rainfall above 400 mm/yr (SE Ukraine mostly 500-600 mm/yr). Etched pits are also rare, limited only to a few grains of altered feldspar and garnet.

Studies on the mineral composition of the dust event sediment, particles and grains, were based on energy dispersive X-ray microanalysis in combination with opti- cal microscopy (transmitted light). Again, several tens of samples were subjected to cursory examination, while samples of Prague-Suchdol, Nízké Tatry and Krkonoše Mts sediments were studied in detail. Clasts of pure quartz consistently prevail (compare Figs 10 and 11). Qualitative proportions of grain-by-grain determinations match almost perfectly the whole-sediment chemical compositions (see below). The overall error of measurements was low, of the order of only a few percent, approximately equal to the natural variability of this material. The calculated average mineral composition is $59 \mathrm{wt} . \%$ quartz, 16 wt.\% K-feldspar (perthitic/antiperthitic compositions were not uncommon), 11 wt.\% plagioclase (albite and oligoclase, rare andesine and labradorite), 5 wt. $\%$ mica and clay minerals, 4 wt. $\%$ possible chlorites, and 3 wt. $\%$ Fe-oxides and complex mixtures. The remaining 2 wt.\% can be assigned to organic material, fresh and altered organic matter, undifferentiated inorganic solutes, and also water and other volatiles in minerals. The optical inspection of quartz sediment particles in transmitted 

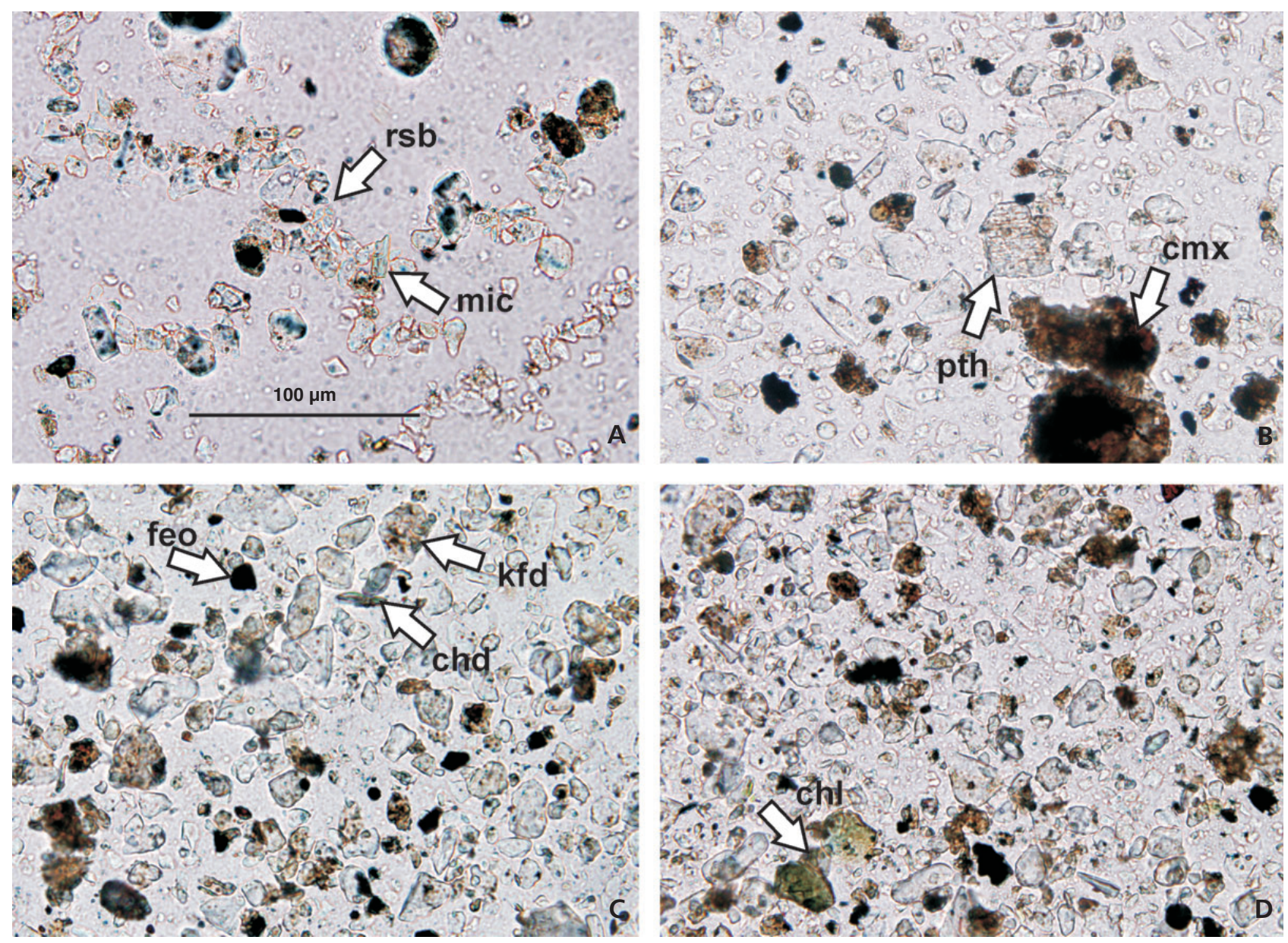

Figure 11. Variability in fine and medium silt particle populations, Krkonoše Mts (polarisation microscope, transmitted light, parallel nicols, oil immersion). $\bullet$ A - thin layers with dominant population of very fine quartz silt. Reticulate structured pattern formations with densely packed barriers (rsb). Flakes and prolate 'prismatic' fragments of micas (mic). $\bullet$ B - transparent quartz particles prevail. Feldspar grains have often perthitic texture (pth). Porous, very complex mineral mixtures with various iron oxides are present $(\mathrm{cmx}) \cdot \bullet \mathrm{C}-$ opaque grains of iron oxides, mostly haematite are rare (feo). K-feldspars (kfd) and tiny fragments of bluish-greenish chloritoids (chd) occur only in accessory amounts. • D - rare grains of bright brownish grass-green chlorites were found (chl). [J. Hladil]

light provided best evidence for their 'shard'-like shapes and dominance of planar and even concave surfaces. Using transmitted light, the perthitic feldspars previously indicated by EDX (energy dispersive $\mathrm{x}$-ray) analysis were also unequivocally confirmed. Rare $20 \mu \mathrm{m}$ flakes of chlorite are mostly greenish-yellowish in colour. Crystals of chloritoids (13-25 $\mu \mathrm{m}$ ) form two different populations, which are, respectively bluish-greenish and dark reddish-purple. The former often occur together with micas whereas the latter are twice the size and have equidimensional shapes. Feldspar grains range from short fragments with perfect cleavage (and fresh appearance) to irregular altered grains. Large flakes of mica and clay minerals are absent; these minerals form only $\mathrm{nm}-\mu \mathrm{m}$-sized crystallites/crystals involved in altered feldspar, and/or fragments of soil crusts and pellets. Iron oxides, organic matter and crystalline organic minerals are regular accessories whereas other minerals (dolomite, zircon, rutile, ilmenite, apatite, epidote, garnet?, titanite? particles smaller than $1 \mu \mathrm{m}$ ) are extremely rare. The material was depleted in typical heavy minerals in the medium silt-size category. The fact that adhesion of dominant quartz (quartz to quartz or quartz to glass) was at the upper limits of possible values (Biryukov 1995) was observed but cannot be fully interpreted at the present resolution of rheological measurements.

\section{Chemical composition of sediment}

Major element compositions of thicker compacted layers of silt-sized particles $0-45 \mu \mathrm{m}$ were studied by EDX. Considering the results of ICP-MS and ICP-OES, i.e., inductively coupled plasma mass and inductively coupled plasma optical emission spectrometric analyses, the oxide mass values were corrected to a subtotal of about $98 \mathrm{wt} . \%$, which 


\section{PRINCIPLES}

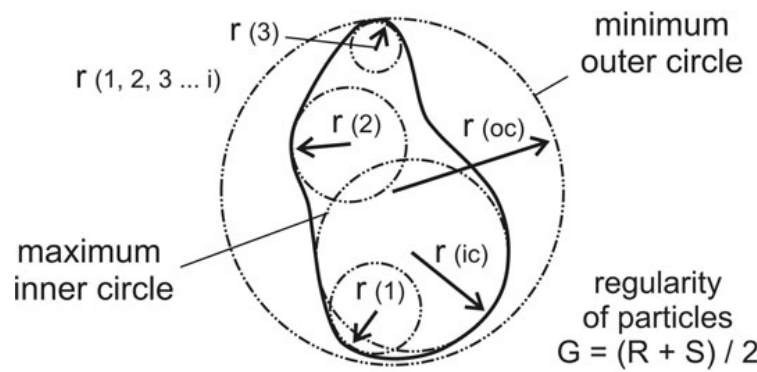

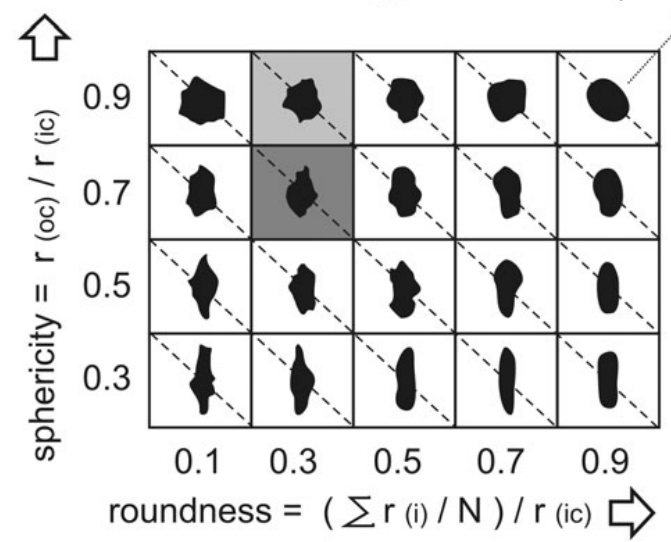

7

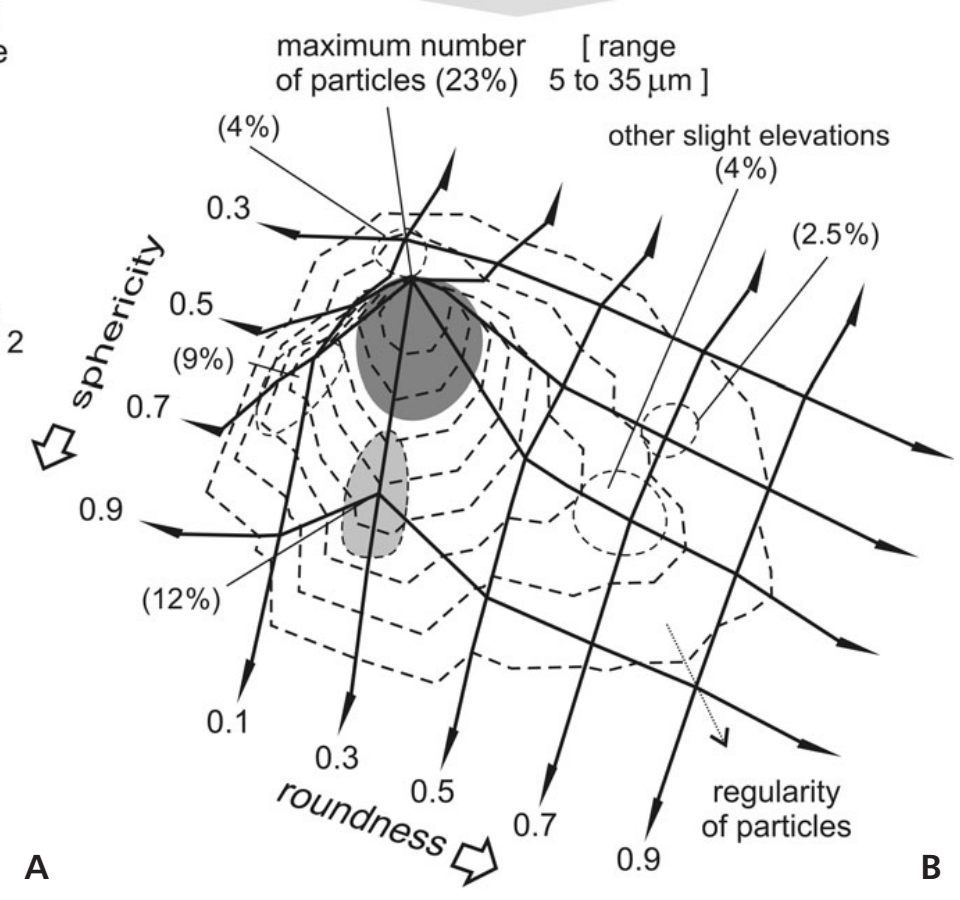

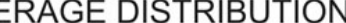 IN THE DUST SEDIMENT}

Figure 12. Abundance of different grain shapes. • A - explanation of 'sphericity/roundness' description system based on principles by Krumbein (1941) (see the text; modified). $\bullet$ B - the most representative shape distribution obtained by merging of various parts of the sediment from various sampling sites (5000 measurements and assignments were accumulated; distribution expressed in percent per class). [J. Hladil]

was the most likely level to provide enough space for minor elements, their oxides and volatiles. Silica contents exceed $70 \mathrm{wt} . \%$ and alumina contents are about $10 \mathrm{wt} . \%$. The fine fraction of the silt-sized sediment contains only a few percent of $\mathrm{Na}_{2} \mathrm{O}, \mathrm{K}_{2} \mathrm{O}, \mathrm{CaO}, \mathrm{MgO}$ and $\mathrm{Fe}_{2} \mathrm{O}_{3}$ (see Fig. and Tables for details). The calculated $\mathrm{Na}_{2} \mathrm{O} / \mathrm{K}_{2} \mathrm{O}, \mathrm{CaO} / \mathrm{MgO}$ and $\mathrm{MgO} / \mathrm{Fe}_{2} \mathrm{O}_{3}$ ratios were $1.3,1.9$ and 0.5 , respectively $(=\mathrm{Na} / \mathrm{K}, \mathrm{Ca} / \mathrm{Mg}$ and $\mathrm{Mg} / \mathrm{Fe}$ of $1.2,2.2$ and 0.4$)$. These values are almost identical to the average upper continental crust compositions (McLennan \& Taylor 1999, McLennan
2001). The ICP-MS determined concentrations of Mn are roughly comparable to 0.06 wt.\% level for the UCC (McLennan 2001) or 0.05 wt.\% level for different dust deposits (e.g., medium "loess", McLennan \& Murray 1999, or "African" dust, Reid et al. 2003). However, the EDX data suggest a redistribution of $\mathrm{Mn}$, with increased concentrations on the surface of grains $(0.2 \mathrm{wt} \%)$. Surprisingly, the average chemical compositions are almost independent of particle size. Many natural dusts show otherwise. A somewhat different chemical composition was found only for

Figure 13. Morphology and surface microtextures of rare large grains (medium sand size class). White dashed line separates the dominant quartz grains from other objects of comparable sizes. Explanation of letters: F - features related to fluvial processes. F-E and F-E-D - morphological and micromorphological superposition of fluvial-eolian and fluvial-eolian-deluvial processes, respectively. D and D-P - examples of colluvial and colluvial-pedogenic signatures. P - pedogenic quartz grains of fresh appearance, conchoidal fracture. OG - organic-walled objects. PPC - fragments of soil crusts and nodules. AG - strongly altered grains of silicate minerals. Numbers: 1 - crystal shapes are partly preserved. Conchoidal fractures and V-shaped marks were partly abraded and locally erased by dotted abraded-edge surfaces. 2 - fluvial surface microtextures more complexly abraded during eolian processes. 3, 4 and 5-grains with superposition of fluvial, eolian and colluvial features. The latter are inferred from planar and box (3), subconchoidal and (4) crushed fractures. 6 to 10 - examples of grains with typical fluvial signatures; 6 to 8 - tetrahedral shapes on zoned quartz crystals and their foliated aggregates, 9 and 10 - subrounded shapes with rough surface textures in detail. 11 to 13 - moderately zoned quartz grains with prevailing planar, box, subconchoidal and crushed fractures. 14 to 15 - previous signatures were partly superimposed by scallop-shaped pits and microfractures. 16 to 19 - four different examples of pedogenic silicites. Conchoidal and microstriated fractures can be attributed to mechanics of suspect chestnut soils or extreme changes in moisture and temperature. 20 - an undetermined organic object (?'giant grass pollen grain') with degraded organic matter hardened by silica and other hydrous silicate and hydroxide substances. 21 - porous fragment of a soil crust. 22 and 23 - possible fragments of soil nodule and peloid, respectively. 24 to 25 - moderately altered platelet-shaped fragments of feldspars; 24 - morphology typical for densely etch-pitted K-feldspar, 25 - morphology usually characterizing weakly pitted fragments of oligoclase. 26 - a chip of undetermined aphanitic rock; moderate etch-pitting and low degree of alteration. [L. Lisá, J. Hladil, V. Böhmová] 

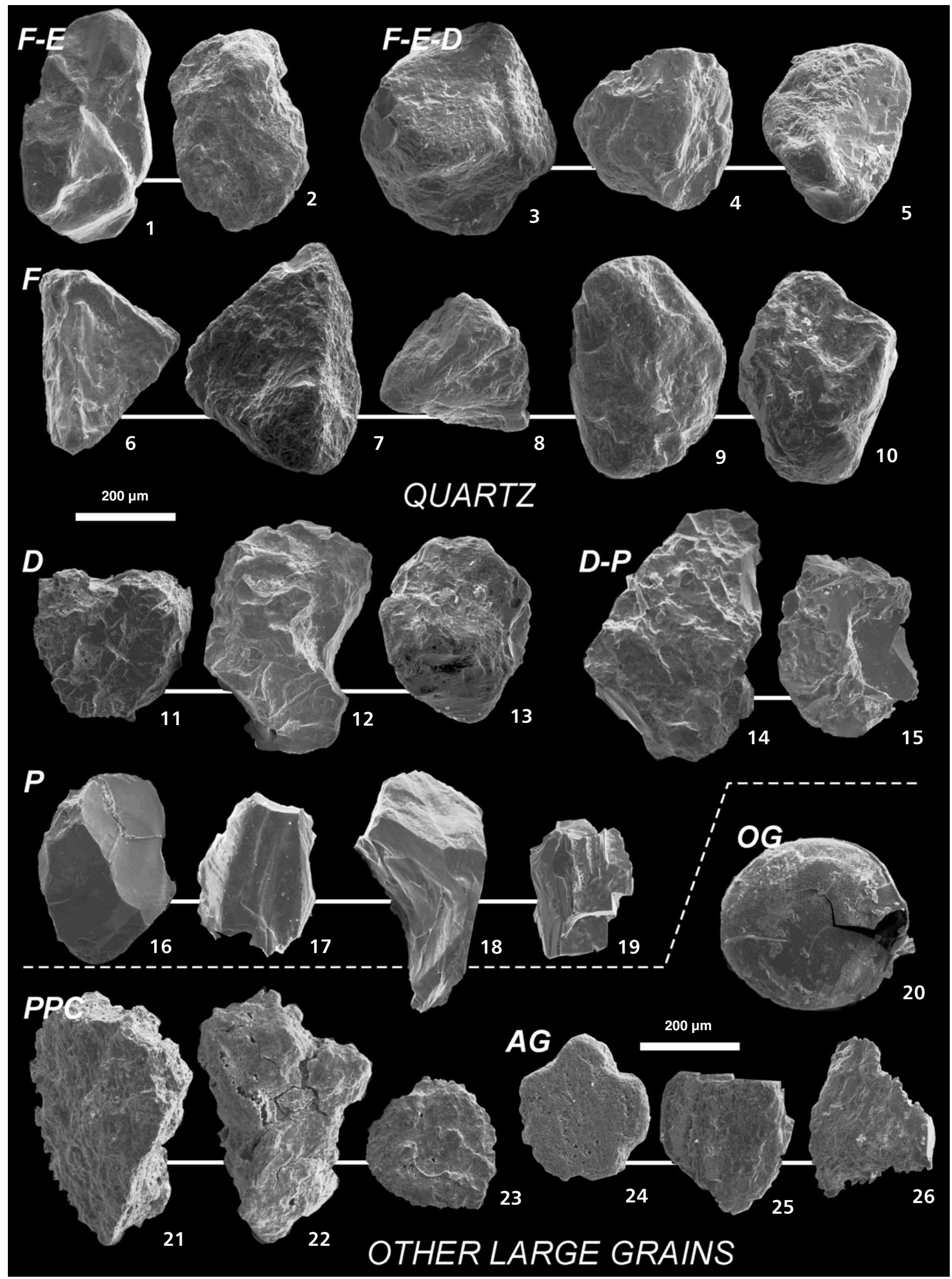

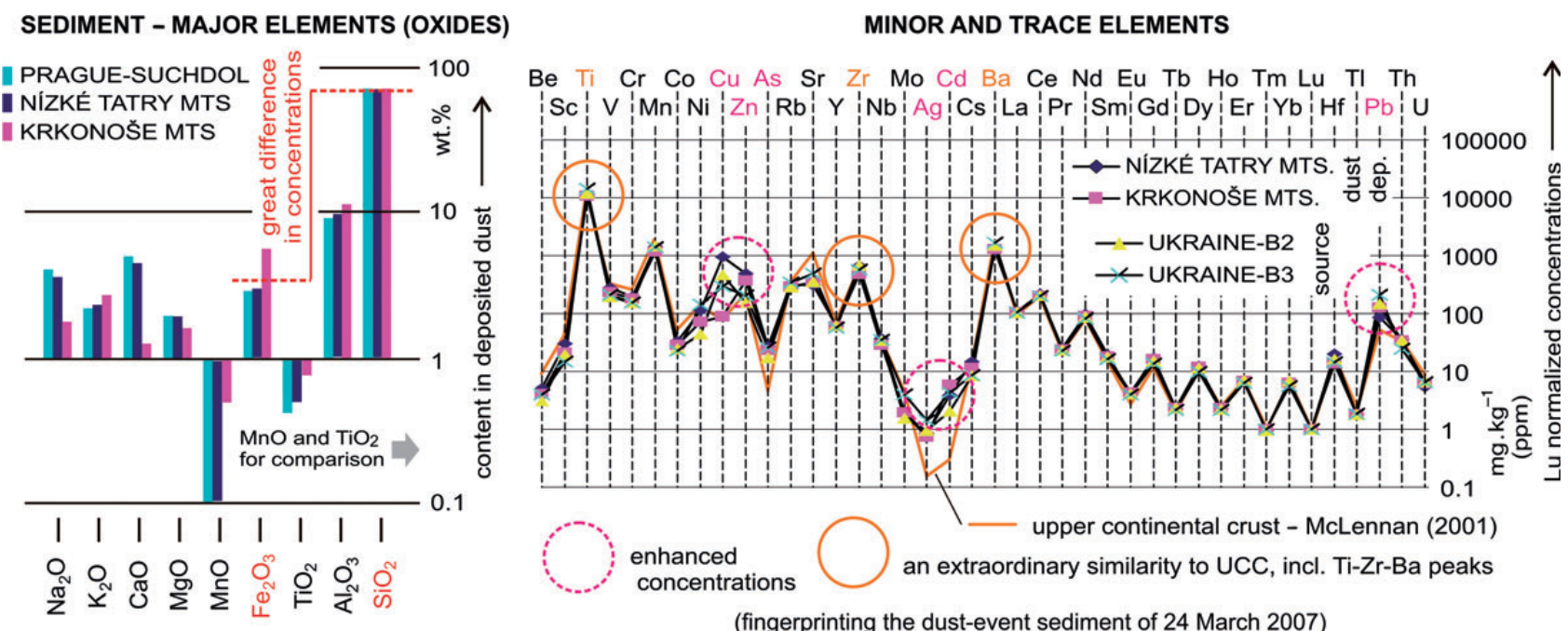

Figure 14. Summarized data and illustration in relation to element composition of the sediment (for details see text). [L. Strnad, J. Hladil]

very complex, coarse fractions $(45-750 \mu \mathrm{m}$; i.e., including also the largest, sand-sized grains). In spite of their scattering, their mass is not negligible. The contents of $\mathrm{SiO}_{2}$ are moderately increased, up to 80 wt. $\%$, while the $\mathrm{Na}_{2} \mathrm{O}, \mathrm{CaO}$ and $\mathrm{MgO}$ contents are somewhat lower than those for finer particles. This finding is in agreement with commonly expected mineralogical observations that many of these large grains consist predominantly of quartz. The overall chemical compositions of the silt to sand sediment are remarkably uniform (Tab. 3 and Fig. 14). The $\mathrm{TiO}_{2}$ contents are almost identical (about 0.5 wt. \%), which suggests that a significant part of the titanium is carried by mineral inclusions in quartz (and feldspars). The relative amounts of $\mathrm{Ti}$ in both the source and delivered materials correspond to those of upper continental crust compositions (and partly also to medium "loess", see McLennan 2001), and there is practically no reason to consider them as anomalous for eolian silts of this type.

The Hf/Sc ratio is typically $\sim 0.65, \mathrm{Zr} / \mathrm{Hf} \sim 32, \mathrm{Th} / \mathrm{U}$ $\sim 6.6$ and $\mathrm{Zn} / \mathrm{Sc} \sim 50$ (see diagrams and tables for details). These values are elevated for sediments in general but, on the other hand, may resemble some of the characteristics of loess. $\mathrm{Zn} / \mathrm{Sc}$ is markedly elevated. The $\mathrm{La} / \mathrm{Th}$ $(\sim 2.89)$ to $\mathrm{Hf} / \mathrm{Sc}(\sim 0.65)$ ratios are indicative of source rocks in the active continental margin field (for details see, e.g., Floyd et al. 1991). The distribution of REE (PAAS- and Lu-normalized) is very close to that calculated for the most common mixed eolian materials (Nozaki 2001, Hladil et al. 2006). This similarity with ACM rock-suite compositions or any old and recycled geological materials cannot be underestimated in this context (Hladil et al. 2006), as this distribution undoubtedly shows remarkably low imprints of remineralization processes on the one side and intensive aqueous weathering (and washing) on the other (Fig. 15). Cerium is not significantly depleted, and europium is practically without anomaly or perhaps shows a very slight tendency to form a positive anomaly.

A subsequent field revision of the indicated source (around the Sea of Azov and mainly along the lower part of the Dnieper River) was accompanied by sampling of typical surface soil layers with visible eolian components (fluvial/eolian origin). Two pilot samples taken E of Kherson were analysed in detail. Minor and trace element distributions, if normalized to Lu values for each sample (as a correction for various "dilution by quartz") are almost identical in both the pilot samples, matching the distributions of the same elements in the Nízké Tatry and Krkonoše samples of the dust-event sediment. Different industrially-induced anomalies of spot characteristics were found in additional Ukrainian samples, and these were consequently excluded from further study (Rakovo in the Mykolaiv District). It is remarkable that such spot anomalies contributed only slightly to the composition of the storm dust, which largely preserved its lithogenic, natural characteristics. The anomalies certainly might have had an additional effect on the chemical composition of the dust in the uplift area, but this would have been covered by the extensive sampling grid, not only by the pilot (most representative) samples. Relatively small but still visible differences were found in samples of the dust event sediment from densely populated industrial centres such as Prague. In addition, other differences between the dust sediment from the Nízké Tatry and Krkonoše Mts and two possible Ukrainian source materials were found: $\mathrm{Hf} / \mathrm{Sc}$ and $\mathrm{Zr} / \mathrm{Hf}$ ratios of the latter samples were somewhat higher, whereas the $\mathrm{Th} / \mathrm{U}$ ratios were somewhat lower. This fact is tentatively explained by selective emission of particles, their long-distance atmospheric transport (1400 to $2000 \mathrm{~km}$ ) and final depositional processes. 
Table 3. Chemical element composition of the dust-event sediment (Prague-Suchdol - PRG; Nízké Tatry Mts - TAT; Krkonoše Mts - KRK) and two surface-soil samples from the source area (SE Ukraine - UKR B2 and B3). Mean values obtained by EDX Jeol (partly also ICP-OES, on the coarse fraction) refer to major element compositions recalculated to oxides and then to a $98 \mathrm{wt} \%$ subtotal. Concentrations of minor and trace elements in the decomposed samples (including REE) were measured with ICP-MS; units mg/kg (ppm). Compare Figs 14 and 15 . [L. Strnad, A. Langrová, V. Böhmová, Z. Korbelová, J. Rohovec, J. Hladil]

\begin{tabular}{lcccccc}
\hline \multicolumn{5}{c}{ fraction $0-45 \mu \mathrm{m}$} & \multicolumn{3}{c}{ fraction $45-750 \mu \mathrm{m}$} \\
\hline instrum. & EDX & EDX & EDX & EDX & EDX & ICP-OES \\
\hline locality & PRG & TAT & KRK & mean & PRG+TAT & PRG+TAT \\
\hline oxides & & \multicolumn{5}{c}{ wt.\% } \\
\hline $\mathrm{Na}_{2} \mathrm{O}$ & 4.1 & 3.7 & 1.8 & 3.2 & 2 & 0.9 \\
$\mathrm{~K}_{2} \mathrm{O}$ & 2.2 & 2.3 & 2.7 & 2.4 & 1.8 & 2.5 \\
$\mathrm{CaO}$ & 5 & 4.6 & 1.2 & 3.6 & 1.1 & 0.9 \\
$\mathrm{MgO}$ & 2 & 2 & 1.6 & 1.9 & 1.5 & 1.1 \\
$\mathrm{MnO}$ & 0.1 & 0.1 & 0.5 & 0.2 & 0.2 & 0.1 \\
$\mathrm{Fe}_{2} \mathrm{O}_{3}$ & 2.9 & 3 & 5.6 & 3.8 & 2.8 & 3.5 \\
$\mathrm{TiO}_{2}$ & 0.4 & 0.6 & 0.8 & 0.6 & 0.5 & 0.6 \\
$\mathrm{Al}_{2} \mathrm{O}_{3}$ & 9.2 & 9.8 & 11.2 & 10.1 & 9.2 & 10.1 \\
$\mathrm{SiO}_{2}$ & 72.1 & 71.9 & 72.6 & 72.2 & 78.9 & 78.3 \\
\hline
\end{tabular}

\section{$\mathrm{Pb}$ isotope signatures}

The ICP-MS lead isotope measurements together with subsequent plotting of the ${ }^{206} \mathrm{~Pb} /{ }^{207} \mathrm{~Pb}$ to ${ }^{208} \mathrm{~Pb} /{ }^{206} \mathrm{~Pb}$ values was based on generally accepted findings that travelling dust plumes possess isotopically labelled signatures that are related to natural soil/regolith components and locally different histories of industrial pollution (Mukai et al. 2001, Ettler et al. 2005, Zhang et al. 2007). In particular, it must be considered that automotive pollution sources depend strictly on the utilization of ores for $\mathrm{Pb}$-additives in petrol (gasoline) and differ in Europe and the USA; a different ${ }^{206} \mathrm{~Pb} /{ }^{207} \mathrm{~Pb}$ isotopic composition is characteristic for natural $\mathrm{Pb}\left({ }^{206} \mathrm{~Pb} /{ }^{207} \mathrm{~Pb} 1.205-1.220\right.$; after Teutsch et al. 2001). The combination of measured and reference data allows a slight differentiation between regional trend lines (Fig. 16). The mean isotope ratios for the Prague and Nízké Tatry samples $\left({ }^{206} \mathrm{~Pb} /{ }^{207} \mathrm{~Pb}\right.$ to ${ }^{208} \mathrm{~Pb} /{ }^{206} \mathrm{~Pb}, 1.1688$ to 2.0921 and 1.1887 to 2.0742 , respectively) follow a trend line drawn from data for Central and eastern Europe. This trend line shows a somewhat different position compared to that based on North African and Middle Eastern data (Erel et al. 2006). The $\mathrm{Pb}$ isotopic composition of the Nízké Tatry sample $\left({ }^{206} \mathrm{~Pb} /{ }^{207} \mathrm{~Pb}\right.$ ratio $\left.=1.189\right)$ might indicate a really significant contribution of original crustal (i.e., natural $\mathrm{Pb}$ ) component, but the lower radiogenic lead content of the Prague sample shows a considerably higher anthropogenic overprint, probably influenced by $\mathrm{Pb}$ from EU petrol combustion. The plotted lead isotope values for the measured Ukrainian 'source' samples and 'delivered' event-sediment samples are closely clustered in the diagram (Fig. 16). Even with the low number of analysed samples available, it can be assumed that the indicated trends result from a com-

\begin{tabular}{|c|c|c|c|c|c|}
\hline \multirow{2}{*}{$\begin{array}{l}\text { instrum. } \\
\text { locality }\end{array}$} & \multicolumn{5}{|c|}{ ICP-MS } \\
\hline & PRG & TAT & KRK & UKR B2 & UKR B3 \\
\hline & \multicolumn{5}{|c|}{$\mathrm{mg} / \mathrm{kg}(\mathrm{ppm})$} \\
\hline $\mathrm{Be}$ & 1.63 & 1.75 & 1.26 & 0.39 & 0.14 \\
\hline $\mathrm{Sc}$ & 8.56 & 10.25 & 6.51 & 2.46 & 0.52 \\
\hline $\mathrm{Ti}$ & 3200 & 3600 & 3288 & 1492 & 500 \\
\hline V & 80 & 93 & 71 & 24 & 7 \\
\hline $\mathrm{Cr}$ & 110 & 66 & 54 & 19 & 5 \\
\hline $\mathrm{Mn}$ & 373 & 479 & 356 & 182 & 49 \\
\hline Co & 10.48 & 11.3 & 8.83 & 3.11 & 0.8 \\
\hline $\mathrm{Ni}$ & 51 & 38 & 22 & 6 & 5 \\
\hline $\mathrm{Cu}$ & 131 & 321 & 27 & 57 & 10 \\
\hline $\mathrm{Zn}$ & 810 & 164 & 110 & 19 & 7 \\
\hline As & 12.3 & 9.3 & 7.2 & 2.2 & 0.9 \\
\hline $\mathrm{Rb}$ & 117 & 107 & 89 & 35 & 12 \\
\hline $\mathrm{Sr}$ & 140 & 103 & 104 & 44 & 17 \\
\hline Y & 16.9 & 20.9 & 18.6 & 7.8 & 2 \\
\hline $\mathrm{Zr}$ & 179 & 222 & 143 & 85.4 & 19.5 \\
\hline $\mathrm{Nb}$ & 11.2 & 12.7 & 8.9 & 4.3 & 1.3 \\
\hline Mo & 1.65 & 0.67 & 0.6 & 0.2 & 0.14 \\
\hline $\mathrm{Ag}$ & 5.83 & 0.28 & 0.23 & 0.12 & 0.05 \\
\hline $\mathrm{Cd}$ & 3.42 & 1.3 & 1.79 & 0.26 & 0.15 \\
\hline Cs & 5.25 & 5.02 & 3.54 & 1.07 & 0.3 \\
\hline $\mathrm{Ba}$ & 2804 & 414 & 392 & 185 & 59 \\
\hline $\mathrm{La}$ & 32.4 & 36.4 & 32 & 12.9 & 3.7 \\
\hline $\mathrm{Ce}$ & 58.8 & 72.5 & 60.8 & 25.1 & 6.8 \\
\hline $\operatorname{Pr}$ & 6.78 & 8.59 & 7.3 & 3 & 0.8 \\
\hline $\mathrm{Nd}$ & 25.7 & 32.2 & 27.4 & 10.9 & 2.9 \\
\hline $\mathrm{Sm}$ & 4.99 & 6.6 & 5.61 & 2.24 & 0.58 \\
\hline $\mathrm{Eu}$ & 1.26 & 1.39 & 1.31 & 0.52 & 0.14 \\
\hline $\mathrm{Gd}$ & 4.59 & 5.82 & 5.04 & 1.92 & 0.49 \\
\hline $\mathrm{Tb}$ & 0.64 & 0.78 & 0.72 & 0.29 & 0.08 \\
\hline Dy & 3.41 & 4.18 & 3.72 & 1.43 & 0.34 \\
\hline Ho & 0.65 & 0.78 & 0.71 & 0.28 & 0.08 \\
\hline Er & 1.85 & 2.28 & 2.09 & 0.88 & 0.22 \\
\hline $\mathrm{Tm}$ & 0.26 & 0.32 & 0.31 & 0.12 & 0.04 \\
\hline $\mathrm{Yb}$ & 1.81 & 2.24 & 1.93 & 0.86 & 0.2 \\
\hline $\mathrm{Lu}$ & 0.27 & 0.34 & 0.31 & 0.13 & 0.04 \\
\hline $\mathrm{Hf}$ & 5.46 & 6.9 & 4.2 & 2.07 & 0.51 \\
\hline $\mathrm{Tl}$ & 1.26 & 0.61 & 0.55 & 0.23 & 0.07 \\
\hline $\mathrm{Pb}$ & 69 & 29 & 38 & 18 & 7 \\
\hline Th & 11.5 & 12.3 & 10.55 & 4.34 & 0.87 \\
\hline $\mathrm{U}$ & 1.77 & 1.86 & 1.91 & 0.84 & 0.23 \\
\hline
\end{tabular}


REE NORMALIZED TO PAAS AND Lu and compared with typical silt-mud forming processes

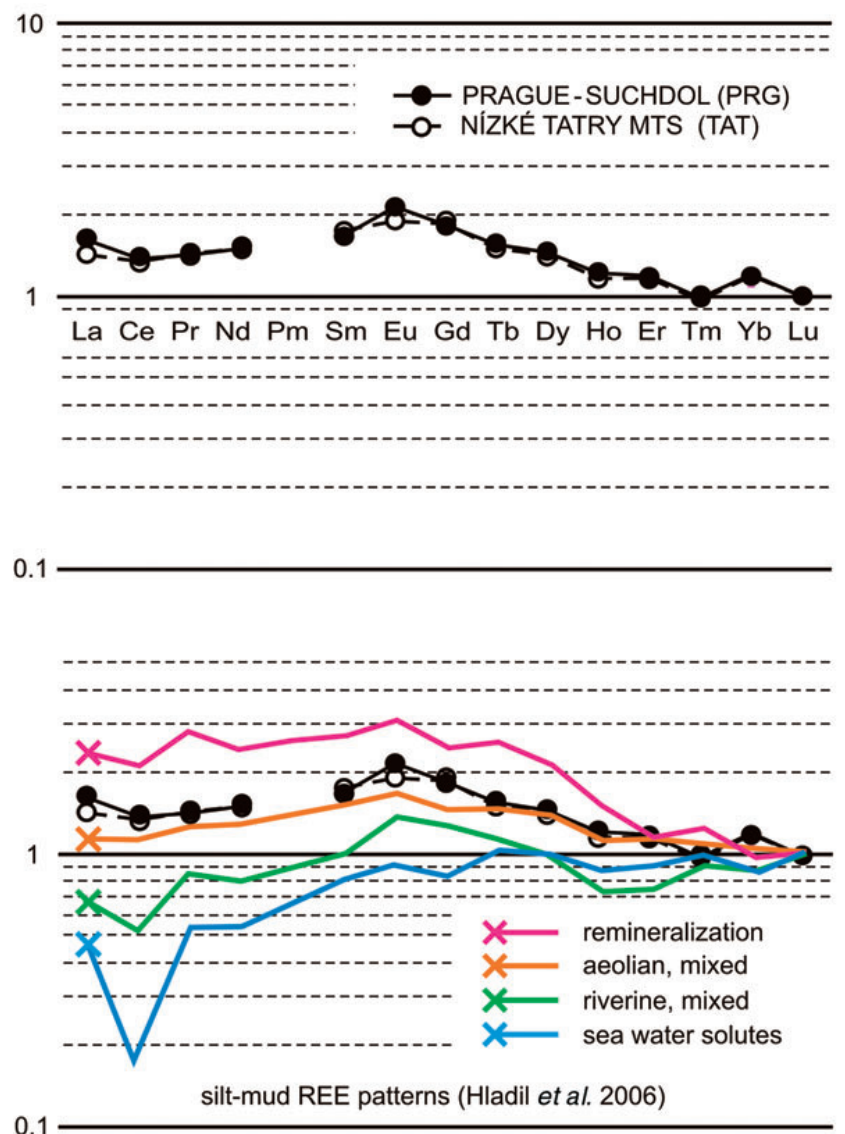

VALUES NORMALIZED TO CHONDRITE source, sediment, and comparison

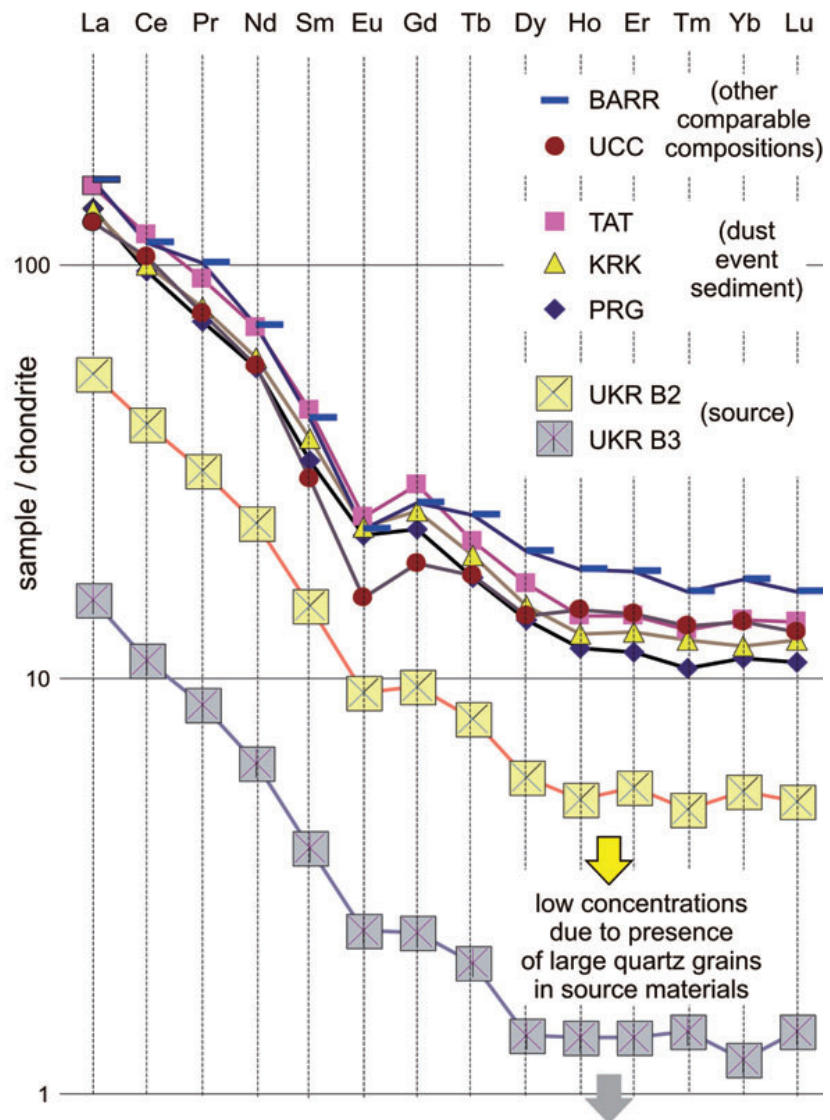

Figure 15. REE distributions in sediment (ICP-MS). Left: Distribution typical for pure lithic subtype of the dust-event sediment (Nízké Tatry Mts) and the one little modified by urban and industrial dust (Prague-Suchdol). The values normalized to PAAS (Post-Archean Australian Shale; Taylor \& McLennan 1985) and to lutetium are compared with typical diagenetical/delivery types (Nozaki 2001, Hladil et al. 2006). The REE distributions of the deposited dust are very similar to those of the most common natural eolian dust materials. Right: On the other hand, this 'eolian' type of distribution is also very similar to any averaged upper crustal materials derived from old, deeply dissected orogenic belts (granitic rocks, gneisses and metasediments) or produced by recycling of sediments. Chondrite-normalized (McDonough \& Sun 1995) distributions were used for this purpose. BARR - mean values for REE from the Middle Devonian siliciclastic deposits in the Prague Synclinorium, Barrandian area (Strnad \& Mihaljevič 2005); UCC - mean upper crust compositions (Taylor 1992); TAT, KRK and PRG - dust-event sediment, Nízké Tatry Mts, Krkonoše Mts and Prague-Suchdol; UKR B2 and B3 relatively pure eolian silt- and sand-sized material from the source area, sampled on the soil surface. [L. Strnad, J. Hladil]

bined effect of natural source and area-specific contamination along the transport path.

\section{SE Ukraine, geology of the source area}

The uplift of vigorous amounts of dust in the atmosphere was detected by radar satellite techniques SE and mainly $\mathrm{NE}$ of the Sea of Azov, i.e., in SE Ukraine, from Krasnodar (Russia) to the Melitopol, Zaporozhye-Nikopol and Krivoy Rog regions. The dust was transported to the west. The northern limit of strong dust concentrations was relatively sharp, following the line Donetsk-Dnepropetrovsk-Kirovograd. The south-eastern part of the source area was located on the Scythian Platform. The dust uplift seems to have expanded towards the $\mathrm{W}$ and NW and was most likely spreading over the Pri-Azov Massif to the Ukrainian Shield. The Donbas Foldbelt and the zone of Prypiat-Dnieper-Donetsk intracratonic rift basins were not involved because of their position relatively far in central Ukraine. The Scythian Platform was formed in the Mesozoic but the present arrangement of tectonic units is basically of Cenozoic age (Nikishin et al. 2001, Vincent et al. 2007). The broad region was controlled by the Paleogene syn-compressional and subduction-related subsidence, and the middle Miocene to Quaternary syn-collisional molasse basin formations gradually developed. Although the carbonate-dominated units reach to the shallow subsurface or to the surface in the $\mathrm{S}$ and SE, they are commonly covered by siliciclastic colluvial, proluvial and alluvial accumulations. 


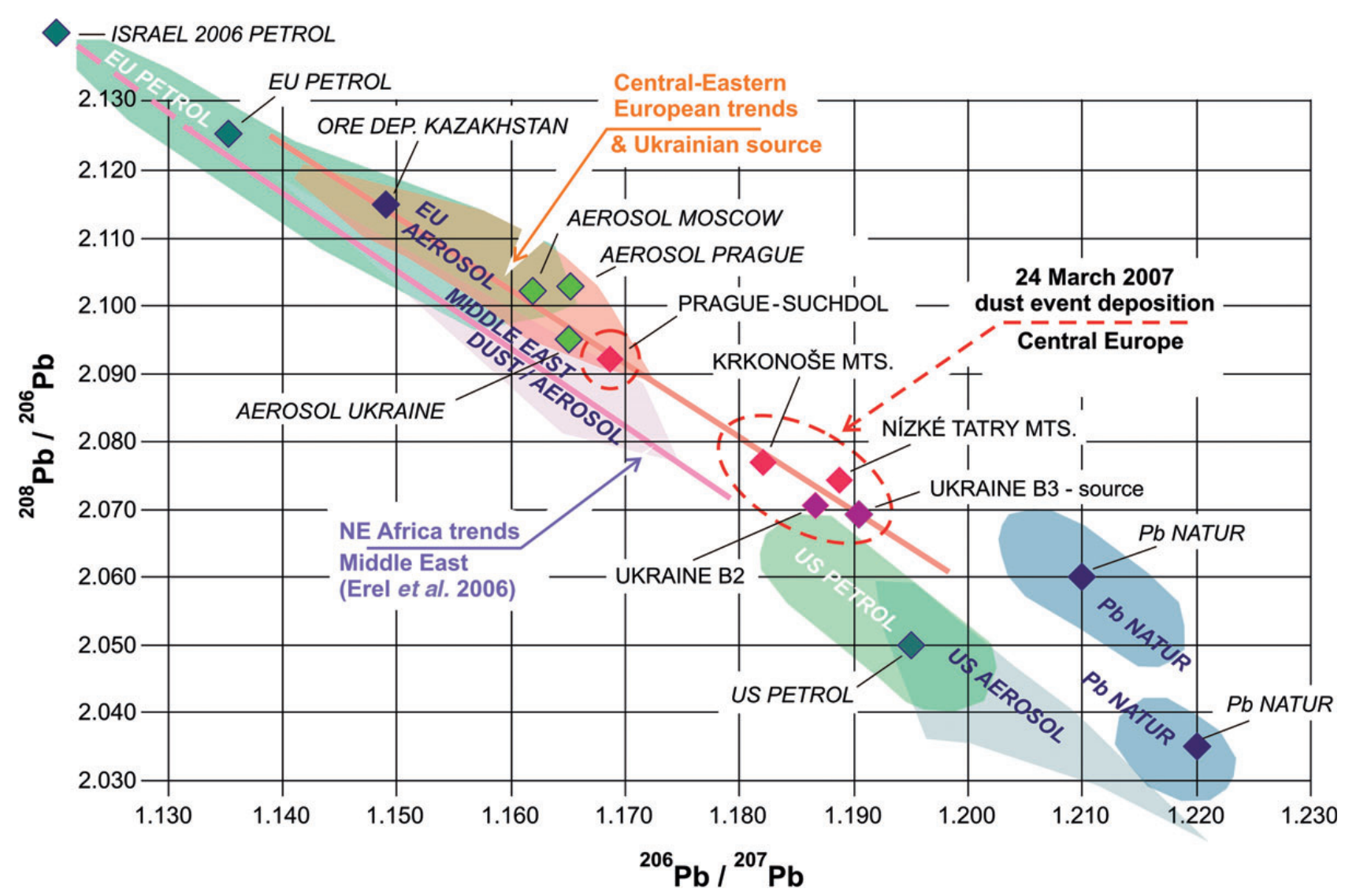

Figure 16. A plot of lead isotope ratios. Based on published data, an attempt was made to separate the North African-Middle East trendline from the Central-East European signatures. These trends may contribute to further fingerprinting of dust sediments, although this difference is small. The fields and significant points serving as background follow literature (Mukai et al. 2001, Erel et al. 2006, Ettler et al. 2004 and references cited). [L. Strnad, J. Hladil]

These allochthonous deposits contain large amounts of redistributed fluvial and eolian grains. These regions are typically covered by thick and often decarbonatized sediments. The significance of the mixing of local residues with allochthonous grain material is even stronger in the molasse basins, and can be traced equally across the Pri-Azov Massif and the south-eastern parts of the Ukrainian Shield. The Dnieper River with its tributaries brings large volumes of predominantly quartz (and feldspar) grains from the Voronezh Massif, Donbas Foldbelt and the Ukrainian Shield. The large eolian dune fields E of Kherson are good examples of the quantity and mobility of allochthonous material (Fig. 17). A slight but continuous eolian redistribution of this material is governed by south-westerly winds whereas vigorous storm redepositions act in the opposite direction (Pashkevich 1970).

Chestnut inceptisols (i.e., soils with minimal horizon development) are the common soil types in SE Ukraine, having lost bases, deep soil profiles and showing depletion in $\mathrm{Al}$ and Fe. Alluvial delivery of silicate clay and/or Al and $\mathrm{C}_{\mathrm{org}}$ is generally slight. Particularly, the moderately deflated surfaces of these chestnut soils can provide much quartz silt. The quality, availability and lifting potential of this silt, however, are variables posing challenging questions, specifically related as they are to the compositions and lifting potential of the uppermost (surface) soil layers. Concerning the quartz (and feldspar) silt grains, at least four concentration mechanisms should be considered: first, the still very active processes of fluvial and then eolian redistribution, i.e., the old crystalline materials continuously delivered by the Dnieper River and subsequently spread over the surface by the wind; secondly, enrichment by remobilized Holocene loess particles; thirdly, direct uplift of particles from the regolithic covers of Paleoproterozoic crystalline rocks, especially with respect to grain mineralogy (see above); and, fourthly, supply of the large amount of quartz from the Scythian Platform siliciclastic sediments. The soil contribution of the Scythian Platform to areas around the Sea of Azov (Fig. 17) can cause a surprising excess of boron in the dust sediment (locally $\sim 130 \mathrm{mg} / \mathrm{kg}$; ICP-OES) although the clay minerals as typical carriers of this element are rare in this sediment. This fact may be important for the tracing of the source of the Ukrainian dust. Although the anthropogenic sources such as coal combus- 

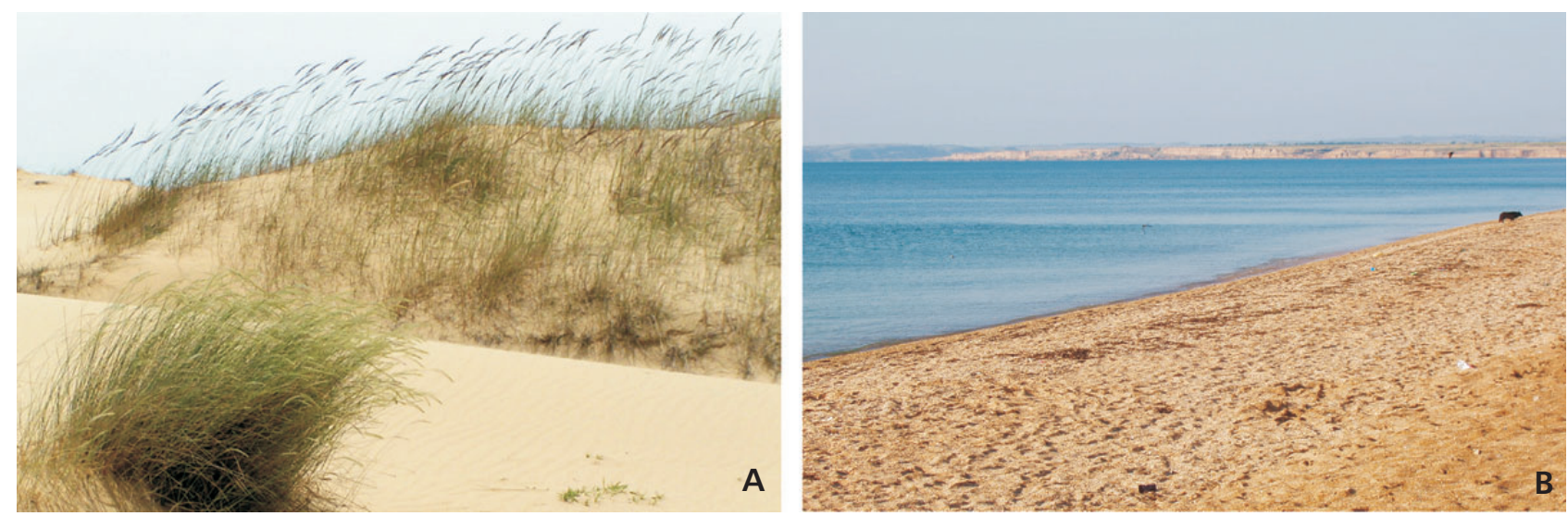

Figure 17. Field situation in SE Ukraine. Two examples around the suspected sources of eolian material. • A - uncovered, active fields of eolian sand dunes with grass and limited shrub vegetation; surroundings of Velyki Kopani village, Kherson region. The element compositions and concentrations of sampled material well correspond to those of the studied dust-event sediment. $\bullet$ B - sea of Azov, Arabatskaya Strelka. Coastal sand with shell debris and Pliocene-Pleistocene formations around. This carbonate material was poorly represented or absent in the dust of the 24-March-2007 event. [R. Melichar]

tion must also be considered, the correlations of $\mathrm{B}$ with $\mathrm{Ba}$, $\mathrm{Sb}, \mathrm{As}, \mathrm{Cd}$ are poor or negative. Nor was correlation found between $\mathrm{B}$ and $\mathrm{Hg}$ concentrations, despite elevated $\mathrm{Hg}$ content in the Donbas-Donetsk coal (Panov et al. 1999, Yudovich \& Ketris 2005). Average Hg concentrations in the analysed dust deposits from the Czech Republic are $53 \pm 8 \mathrm{ng} / \mathrm{g}$ and surprisingly even smaller in samples from the area $\mathrm{E}$ of Kherson.

\section{Palynological provenance data}

The 24-March-2007 event sediment sampled in the territory of the Czech Republic contains easily separable amounts of pollen grains together with the light soil components. The latter were represented by very fine detritus of plant tissues, fungal hyphae, conidia and spores. Scattered biomorphs like spores, sporangia and pollen grains were clearly visible even in petrological sections.

Many of the taxa encountered since the first studies (sediment from Brno-Komín) were suspicious. For example, the high numbers of pollen grains of ragweed (Ambrosia) are highly unusual for this area at this time of the year (compare also Stępalska et al. 2002 or Piotrowska \& Weryszko-Chmielewska 2006, who constrained the 1982-2004 maxima in Poland to August-September). The abundance of Ambrosia in very early spring pollen assemblages can be explained rather by transport from warmer areas richly colonized by this invasive genus. Such conditions are found in the south-easternmost parts of Ukraine. Also, the relatively high pollen values calculated for the Cupressaceae (Thuja, Juniperus, etc.) and Taxus were different from those most commonly met with in pollen materials. In addition, Aster-type pollen grains tentatively classified as Calendula/Helianthus were regularly encountered, suggesting equally a very local source in the orchards of Brno. This early speculation on a local source for the Brno site was, however, disproved by the finds of Aster-type pollen grains at the other sites. These anomalous pollen spectra characterizing the dust deposition were significantly similar over large areas and showed only several minor differences (compare the illustrations and tables).

General characteristics: Deciduous tree species (Populus, Alnus glutinosa type, Carpinus, Corylus, Salix, Ulmus, Betula alba type) prevailed in all pollen spectra of the tree and bush species (AP - arborum pollen). Elevated proportions of Alnus were found in samples from the Krkonoše Mts and of Corylus in the Nízké Tatry Mts. Lower amounts of Salix and Ulmus pollen grains were found in the Nízké Tatry samples, and Betula is suppressed in the spectra from Brno. The pollen of European coniferous tree species (Abies, Picea, Pinus sylvestris type) are present only sporadically in all samples - note the abovementioned contrast in abundance of the Taxus type and Cupressaceae. The latter types are actually dominant in the Prague and Brno samples. Surprising was the find of Larix-type pollen (larch), which are very rare even in surface soil samples taken under larch trees themselves. The other sporadically present pollen grains belong to Cornus, Fagus, Fraxinus, Hedera, Tilia, Viscum, Quercus, i.e. woody species of natural European forests. The pollen of Juglans and Oleaceae undoubtedly originate from cultivated woody species, Hippophä̈ (buckthorn) perhaps also, but typical buckhorn scrubs grow also on dunes. The area on the left bank of the Dnieper River in the Ukraine (probably along the transport path) is vegetated by undergrowth usually consisting of buckthorn, hazelnut and alder, but also spindletree, wayfaring tree, hawthorn, blackthorn or thelycrania. The pollen of Prunus type belong most likely to Prunus spinosa, as well as to cultivated taxa (Persica, Armeniaca and Amygdalus). 

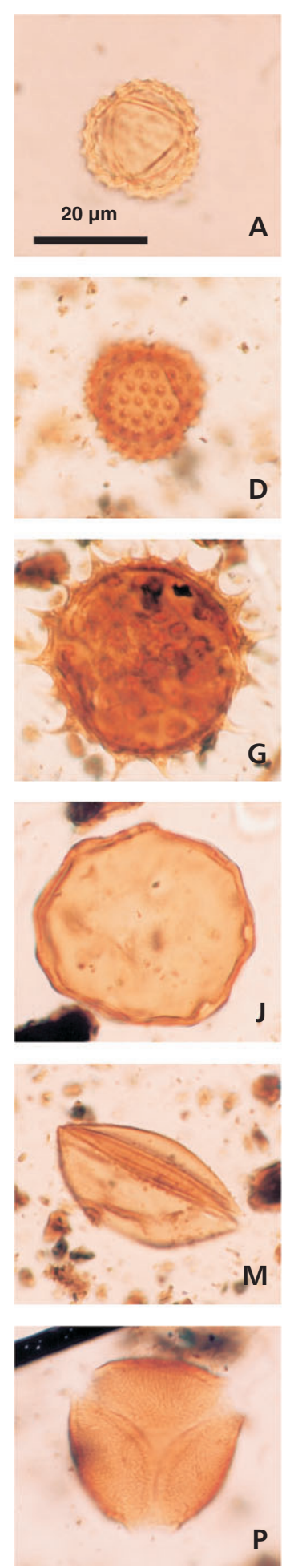
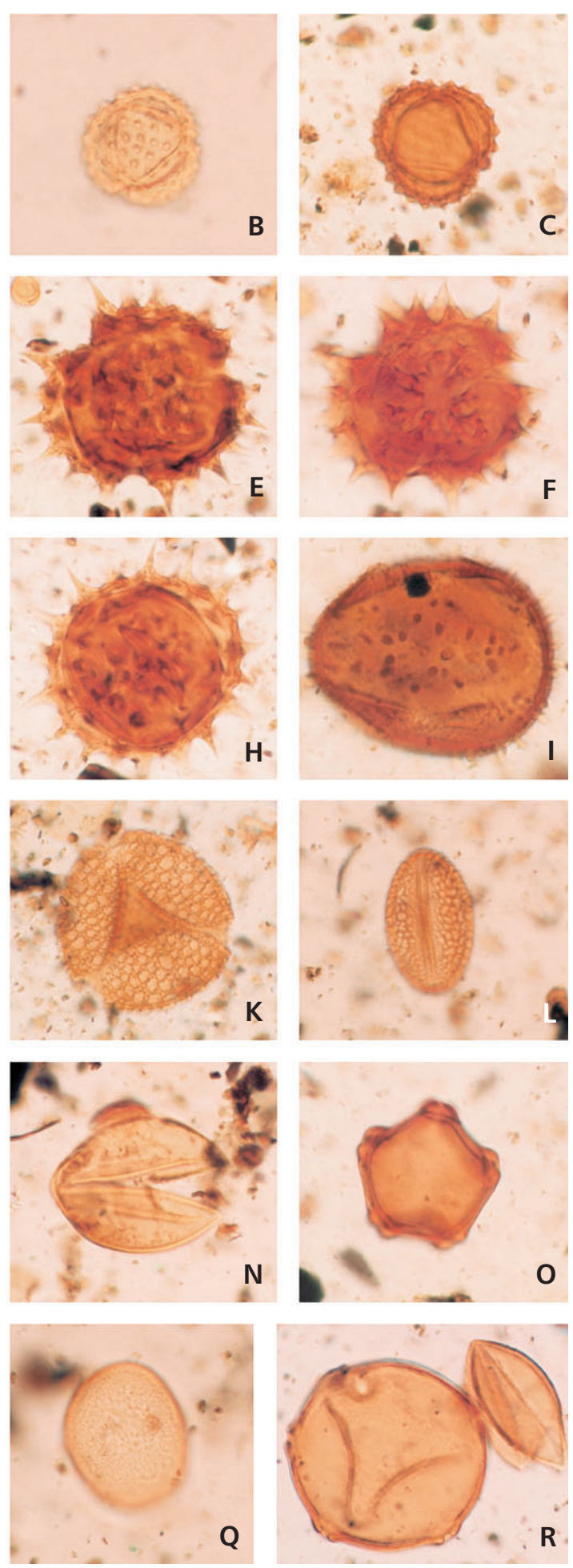
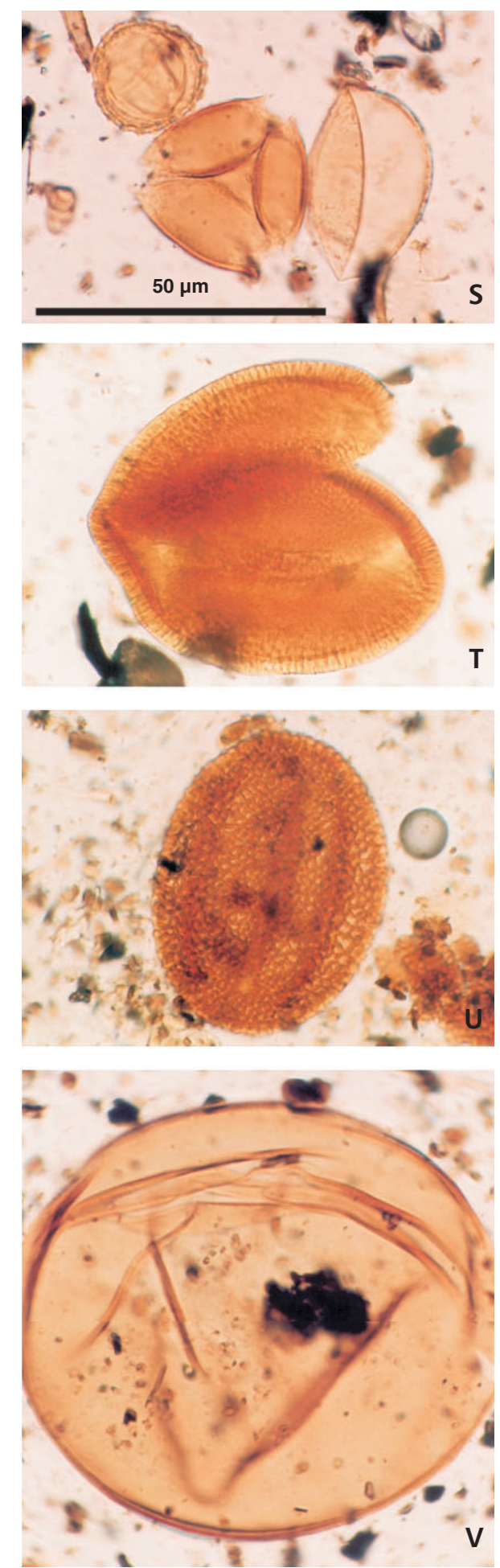

Figure 18. Examples of pollen grains extracted from the silt sediment. • A-D - Ambrosia type; A, B - different levels focused, Nízké Tatry Mts; C, D - Krkonoše Mts, focused down and up, darker colour of pollen grain. $\bullet$ E-H - Calendula/Petasites type, Krkonoše Mts; E, F - also focused down and up; G, H-two other grains illustrate low variability. $\bullet$ I - Viscum, Krkonoše Mts. $\bullet$ J - Juglans, Prague-Suchdol. $\bullet$ K - Forsythia, Brno. $\bullet$ L - Salix, Krkonoše Mts. $\bullet$ M, N - Cupressaceae; M Krkonoše Mts; N - Prague-Suchdol. $\bullet \mathrm{O}$ - Alnus glutinosa type, Krkonoše Mts. $\bullet$ P - Prunus type, Prague-Suchdol. $\bullet \mathrm{Q}-$ Populus, Prague-Suchdol. $\bullet$ R - Carpinus type grain and Cupressaceae, from left to right, Prague-Suchdol. $\bullet$ S - pollen grains of Ambrosia and Prunus types and Cupressaceae, from left to right, and hyphae of fungi (left edge), Prague-Suchdol. • T - Convolvulus, Prague-Suchdol. • U - Fagopyrum type, Brno. $\bullet$ V - Larix type, Krkonoše Mts. Scale bars - A-R: $20 \mu \mathrm{m}$, S-V: $50 \mu \mathrm{m}$. Common names: Calendula/Petasites - 'marigold, Asteraceae'; Prunus - 'prune, plum, etc.'; Ambrosia - 'ragweeds'; Cupressaceae - 'conifers like junipers, cypress, etc.'; Salix - 'willow tree'; Juglans - 'walnut'; Viscum - 'mistletoe'; Convolvulus - 'bindweed'; Larix - 'larch'; Alnus - 'common alder'; Populus - 'poplar, aspen, etc.'; Forsythia - 'forsythia'; Fagopyrum - 'buckwheat'; Carpinus - 'hornbeam'. [V. Jankovská] 
Table 4. Palynological spectra from the decomposed dust-event sediment sampled at four principal sites: Nízké Tatry Mts in Slovak Republic - TAT; Krkonoše Mts - KRK; suburbs of Brno - BRN; suburbs of Prague - PRG. Compare Fig. 18 for morphological details and preservation of selected taxa and specimens. [V. Jankovská]

\begin{tabular}{|c|c|c|c|c|}
\hline Taxon /locality & TAT & KRK & $\mathrm{BRN}$ & PRG \\
\hline \multicolumn{5}{|l|}{ AP (Trees and shrubs) } \\
\hline Abies & 1 & 1 & 0 & 0 \\
\hline Alnus glutinosa $\mathrm{t}$. & 60 & 104 & 62 & 80 \\
\hline Betula alba $\mathrm{t}$. & 23 & 48 & 8 & 23 \\
\hline Carpinus & 12 & 22 & 20 & 37 \\
\hline Cornus & 0 & 0 & 0 & 1 \\
\hline Corylus & 186 & 35 & 50 & 32 \\
\hline Fagus & 1 & 1 & 5 & 1 \\
\hline Fraxinus & 1 & 1 & 0 & 0 \\
\hline Hedera & 0 & 1 & 0 & 0 \\
\hline Ніррорһаё & 0 & 0 & 0 & 1 \\
\hline Juglans & 0 & 1 & 0 & 2 \\
\hline Juniperus & 2 & 6 & 2 & 0 \\
\hline Larix $\mathrm{t}$ & 0 & 5 & 4 & 8 \\
\hline Oleaceae & 6 & 1 & 4 & 5 \\
\hline Pinus sylvestris t. & 14 & 37 & 7 & 20 \\
\hline Picea & 6 & 4 & 3 & 1 \\
\hline Prunus t. & 0 & 1 & 1 & 16 \\
\hline Populus t. & 95 & 22 & 90 & 102 \\
\hline Rhamnus t. & 1 & 0 & 0 & 0 \\
\hline Salix & 3 & 47 & 47 & 18 \\
\hline Cupressaceae t. & 22 & 77 & 75 & 415 \\
\hline Taxus t. & 55 & 31 & 124 & 155 \\
\hline Tilia & 1 & 0 & 0 & 1 \\
\hline Ulmus & 9 & 18 & 34 & 26 \\
\hline Quercus & 4 & 1 & 3 & 1 \\
\hline Viscum & 0 & 1 & 0 & 1 \\
\hline$\Sigma \mathrm{AP}$ & 502 & 465 & 539 & 946 \\
\hline \multicolumn{5}{|l|}{ Others } \\
\hline Polypodiaceae & 1 & 0 & 0 & 0 \\
\hline Sphagnum & 0 & 0 & 0 & 1 \\
\hline Fungi & 12 & 25 & 5 & 0 \\
\hline Thecaphora (Fungi) & 0 & 0 & 0 & 1 \\
\hline
\end{tabular}

\begin{tabular}{|c|c|c|c|c|}
\hline Taxon /locality & TAT & KRK & BRN & PRG \\
\hline \multicolumn{5}{|l|}{ NAP (Herbs) } \\
\hline Anemone t. & 1 & 0 & 0 & 0 \\
\hline Ambrosia & 72 & 78 & 51 & 13 \\
\hline Artemisia & 7 & 5 & 2 & 0 \\
\hline Asteraceae Liguliflorae & 0 & 3 & 1 & 0 \\
\hline Asteraceae Tubuliflorae & 0 & 1 & 6 & 5 \\
\hline Brassicaceae & 87 & 38 & 51 & 60 \\
\hline Cannabis t. & 0 & 0 & 2 & 0 \\
\hline Calendula / Tussilago t. & 4 & 20 & 6 & 4 \\
\hline Cerealia t. & 2 & 0 & 0 & 0 \\
\hline Triticum t. (Cerealia) & 0 & 3 & 1 & 1 \\
\hline Convolvulus & 0 & 1 & 0 & 1 \\
\hline Ericaceae & 2 & 1 & 0 & 0 \\
\hline Euphrasia t. & 0 & 1 & 0 & 0 \\
\hline Fagopyrum t. & 0 & 0 & 1 & 0 \\
\hline Filipendula & 0 & 0 & 0 & 1 \\
\hline Chenopodiaceae & 22 & 23 & 13 & 2 \\
\hline Lamiaceae & 0 & 0 & 1 & 0 \\
\hline Liliaceae & 0 & 3 & 1 & 0 \\
\hline Plantago major-media & 0 & 0 & 1 & 0 \\
\hline Plantago lanceolata & 0 & 1 & 2 & 0 \\
\hline Poaceae & 2 & 14 & 8 & 1 \\
\hline Polygonum aviculare & 0 & 1 & 0 & 0 \\
\hline Ranunculaceae & 0 & 0 & 1 & 0 \\
\hline Rosaceae & 0 & 0 & 1 & 6 \\
\hline Rubiaceae & 0 & 3 & 0 & 0 \\
\hline Rumex acetosa $\mathrm{t}$. & 0 & 1 & 1 & 0 \\
\hline Rumex acetosella $\mathrm{t}$. & 1 & 0 & 0 & 0 \\
\hline Scrophulariaceae & 0 & 3 & 0 & 0 \\
\hline Sparganium t. & 0 & 1 & 0 & 0 \\
\hline Urtica & 0 & 0 & 2 & 0 \\
\hline Varia (indet.) & 6 & 16 & 17 & 5 \\
\hline$\Sigma \mathrm{NAP}$ & 206 & 217 & 169 & 99 \\
\hline
\end{tabular}

As noted above, the most conspicuous component of all these pollen spectra in the group of herbs (NAP - non arborum pollen) is Ambrosia (ragweed). Elevated pollen values were also found for Brassicaceae and partly also Chenopodiaceae. An important mark was the presence of pollen grains from the range of Asteraceae-Tubuliflorae; these were originally assigned to those of the Calendula/Helianthus type (both primarily and from the technical reasons of the routine determination). Some pollen grains appeared in part to be related to Tussilago. Such grains are therefore collectively referred to as Calendula/Tussilago type but genera like Petasites, Cosmos and Galinsoga can

also be present in some cases. The pollen spectra of 'herbs' were apparently more variable than the other partial spectra. However, many of them were rather sporadically than consistently represented in the assemblages. This is true also of the pollen of cereals and Fagopyrum. Relatively low pollen values marked the Poaceae (including also maize, Zea). In addition, natural Poaceae together with the above-mentioned Asteraceae are quite common and relatively diversified vegetation components in the Kherson area, SE Ukraine (compare Fig. 18 and Tab. 4).

All samples contained a considerable amount of pollen grains of woody species and herbs. With respect to the fact 
that the compositions were similar in all four samples (Nízké Tatry, Krkonoše, Brno-Komín and Prague-Suchdol), the obtained data can be considered as markers of this dust deposition event.

\section{Discussion}

There seems to exist an apparent difference between the estimates of total plume load made according to about $1 \mathrm{Tg}$ of real sediment across Central Europe (i.e., up to $3 \mathrm{Tg}$ of the total dust load?) and the data from this load based on $\mathrm{PM}_{10}$-related total mass estimates $(60 \mathrm{Gg}$ only - Birmili et al. op. cit.). This does not mean that we have definitely overestimated the volume of deposited sediment because these estimates were calculated according to sample-based and photo-imaging data about the thickness of the sedimentary cover as low and as realistic as possible. In addition, although the main sediment was relatively coarse (mostly of silt, and in several percent, also of sand size), the involved particles smaller than $10 \mu \mathrm{m}$ still amount to 10-15 wt.\% (100-150 Gg). Considering this amount and also the $\mathrm{PM}_{10}$ material, which most likely was not deposited in the main deposition area but remained in the atmosphere (and was deposited in more distant places later), the total mass estimates for this plume and $\mathrm{PM}_{10}$ should be increased several times. This can be caused by two things. Firstly, the $\mathrm{PM}_{10}$ size fraction in meteorology is based on the so-called aerodynamic diameter, which is defined as the size of a spherical particle with density $1 \mathrm{~g} / \mathrm{cm}^{3}$ that has the same aerodynamic properties as the given particle. For example, if we suppose a spherical particle of the density of $2 \mathrm{~g} / \mathrm{cm}^{3}$ and the aerodynamic diameter $10 \mu \mathrm{m}$, we can calculate its real diameter as $d_{p}=d_{a e}\left(\rho_{a e} / \rho_{p}\right)^{0.5}$, which is about $7 \mu \mathrm{m}$. This means that geological data coming from optical measurement of real particle sizes include also particles whose aerodynamic diameters are larger than the meteorologically defined $\mathrm{PM}_{10}$ because these particles have mostly larger density than $1 \mathrm{~g} / \mathrm{cm}^{3}$. This alone can explain this difference, at least in part. Another possible explanation of this difference relates to the dust content in clouds or the multiple-layered arrangement in some parts of the plume. For the giant mass of material of grain sizes exceeding $10 \mu \mathrm{m}$, which was evidently deposited in Central Europe, the explanation could be even more surprising - the satellite detection methods and aerosol/dust sampling apparatuses are not actually designed to detect these types of material.

Beside this unusually large amount of delivered material and its polydisperse-multimodal characteristics, the multiple pattern formation is also a conspicuous feature of this event sediment, especially if viewed from above. As described above, the thin layer of sediment exhibited irregular to rhombically-distorted square fields (windows) where the sediment was thinner than in the slightly swollen barriers between them. These structures were often complex due to superimposition of two to five different grades and types of patterns. The details of the evolution of these pattern-forming instabilities in the sediment are still not fully elucidated and are worthy of more intensive study. The fenestral structures of smallest dimensions seem to be caused primarily by the effects of shear in the just-packed silty sediment. The evidence for this assumption has been based both on direct observation of the natural sedimentation process and experiment; each artificial thin layer of this silt, if subjected to shear, has a tendency to be rearranged/self-organized into fenestral-and-barrier structures. This reasoning seems to be generally supported by variations of particle-size modality and thin and fuzzy lens structures in vertical sections. Using this model, however, we can mostly realize the small one-size structures with a maximum number of two or three fractal modifications in the same material and layer. In the millimetre to centimetre size, these structures were often modified by slightly or strongly involved oblique raindrop cratering (Hladil \& Beroušek 1993, Erpul et al. 2005), which was transformed into a system of sub-rectangular windows due to the synsedimentary redeposition of splashed sediment and sub-planar runoff of water. Such a structure is closest to that of typical terraced (dam) ponds, which can be observed on a variety of even very gently inclined surfaces over which the polydisperse particulate material is slowly transported in a low-energy sheet flow regime, usually in a diluted suspended load/bedload combination.

The discussion dealing with aspects of palynology must primarily be focused on relationships between vegetation conditions and pollen assemblages. The pollen of most woody species are taxa flowering in both Central and south-eastern Europe at approximately the same time as the dust event occurred. Most of the pollen belongs to Corylus, Populus and Alnus; these woody species flower very early and produce large amounts of pollen grains. Carpinus, Ulmus and Salix also provided important contributions to the pollen assemblages. Sporadically occurring Viscum is also an early-spring flowering element. The presence of Oleaceae pollen is connected with the early flowering of introduced decorative plants, as exemplified by Forsythia. Contrary to this, the low pollen values of woody conifers (Pinus, Picea and Abies) can even be explained by their delayed period of flowering. Logical also is the proven pollen occurrence of early flowering Larix (larch). Pollen of the same type as Larix is also possessed by Pseudotsuga taxifolia; this species is planted in central European forests, parks and gardens. Its occurrence, however, is limited to small patches and has little practical significance. Further introduced woody species commonly planted in Europe belong to the family Cupressaceae (Thuja, Biota, 
Thujopsis, Chamaecyparis and Juniperus), which flower early in the spring and produce large amounts of pollen. This also holds true for Taxus whose pollen grains were found in large amounts. Juglans and Hippophaë also now belong to species introduced to the Czech Republic but these woody species are planted throughout the whole of Europe.

Furthermore, the presence of specific markers is worthy of extended discussion. The very high pollen values of Ambrosia (ragweed) point to an origin outside the Czech and Slovak territories (Jehlík et al. 1998) and with respect to all evaluated situations, the territory of Ukraine can be supposed as the origin. Southern Ukraine (and neighbouring Russia) is a typical and prominent source of an Ambrosia-pollen rain, which has been observed, for example, in the Baltic states (Saar et al. 2000). Hungary is also a source of ragweed pollen (Rybníček et al. 2000). Of course, the Ukrainian 'herb' spectra can explain in general the origin of many other delivered pollen grains. Some typical taxa from SE Ukraine, and N and E of Crimea (Mosyakin \& Fedoronchuk 1999), are absent in the analyzed pollen assemblages. Naturally, pollen assemblages cannot provide an absolute 'copy' of the vegetation cover in the source area of the lithogenic dust. Mixing of pollen and mineral dust sources continues even during the different stages of the dust storm and the evolution of the respective plumes; the dust components are collected from different sources on the way - much likely in the steppe zone of the Ukraine close to the Czech Republic. Also the content and spectra of pollen assemblages in the surface soil layers seem to be highly variable depending on the source and mode of dust uplift (Bezusko et al. 2004). This also concerns the representatives of the family Cupressaceae and the genus Taxus. Interestingly, many summer pollen (e.g., Ambrosia) remained in a good state of preservation. In addition, the mild winter $2006 / 2007$, leaving the steppe practically without snow, allowed an extreme prolongation of vegetation growth and flowering, supplying large amounts of relatively fresh pollen grains (I.G. Bezusko \& A.G. Bezusko, pers. comm. 2007).

Extreme dust storm events of the observed magnitude are called 'black storms' in the Ukraine. An estimate of the recurrence of the biggest black-storm events is about $50 \pm$ 10 years (Pashkevich 1970). For example, the snow-covered Kiev area was enveloped by thick dust sediment on 16 February 1969; material for this deposition was collected around Donetsk, Zaporozhye, Kherson and Dnepropetrovsk; a south-easterly wind prevailed. According to Pashkevich (op. cit.), the wind of 30-40 m/s velocities can effectively deliver considerable amounts of pollen and spores over a distance of $400-600 \mathrm{~km}$ or even more. Compared to Pashkevich's black-storm samples, our four possessed a higher number of plant taxa with a higher total count of pollen grains. The cause of the rich pollen spectrum in the dust from 24 March 2007 is possibly the distinct start of the vegetation season, when many plant taxa in eastern and Central Europe were already flowering. On 16 February 1969, vegetative quiescence persisted, and the storm transported only pollen grains from the vegetation period of 1968.

Pollen spectra that were sourced in Ukraine and along the trajectory of this most recent plume (and rapidly sedimented together with polydisperse dust material in Central Europe) offer a good informative value and practically exclude an African origin of this fallen material. An African provenance is contradicted not only by the pollen spectra but mainly by the relative richness of pollen in the sediment, which would be much less after long-distance transport from North Africa or the Middle East. In general, the cumulative results from all analysed samples point rather to the East-European origin for this dust.

\section{Conclusions}

An anomalous depositional event of Ukrainian atmospheric dust in the Czech Republic and other Central European areas on 24 March 2007 was studied with special emphasis on the sedimentological characteristics of its eolian sediment. The mode of deposition was a combination of a typical eolian and that mediated by dirty rain or drizzle. The main stage of sediment deposition was considerably short (50\% of material settled during $15 \mathrm{~min}$ and $80 \%$ during $1 \mathrm{~h}$ ) and corresponded to a rapidly increased concentration of $\mathrm{PM}_{10}$ particles in the atmosphere above ground.

The study revealed that the deposited sediment is characterized by polydisperse and multimodal particle-size distributions and consists predominantly of angular to subrounded quartz particles of silt size. Only a few percent of coarser and finer material are contained. Submicrometric particles are scarce, but rare sand grains (up to $0.5 \mathrm{~mm}$ large) are regularly present. This sediment was arranged fenestrally on the substrates and frequently showed reticulate and patchy pattern formations of various sizes. The mean amounts of deposited sediment can be estimated at $2.3 \mathrm{~g} / \mathrm{m}^{2}$, although local maxima were even ten times higher. The multimodal particle-size distributions in the deposited silt originated, most likely, for two reasons: the combination of eolian and dirty-rainfall sedimentation modes and particle-size redistribution (selective packing) during the formation of reticulate pattern fabrics in the sediment.

Among the major element characteristics, the $\mathrm{Na}_{2} \mathrm{O} / \mathrm{K}_{2} \mathrm{O}, \mathrm{CaO} / \mathrm{MgO}$ and $\mathrm{MgO} / \mathrm{Fe}_{2} \mathrm{O}_{3}$ ratios are very close to those obtained for the upper continental crust (McLennan 2001), with small differences at the second 
decimal place. Manganese contents are also of the same order as expected for common UCC or natural dust sources but with visible reconcentration at the surface of grains. On the other hand, $\mathrm{TiO}_{2}$ contents of about $0.5 \mathrm{wt} . \%$ were predominantly carried by mineral inclusions in quartz (not by clay or pedogenic Ti minerals).

In minor and trace elements, the $\mathrm{Hf} / \mathrm{Sc}, \mathrm{Zr} / \mathrm{Hf}, \mathrm{Th} / \mathrm{U}$ ratios are only slightly higher than those of the most common $\mathrm{UCC}$ or sedimentary materials, but the $\mathrm{Zn} / \mathrm{Sc}$ ratio is markedly elevated. The $\mathrm{La} / \mathrm{Th}$ to $\mathrm{Hf} / \mathrm{Sc}$ values together with smooth and PAAS-close REE distributions are indicative of averaged material after long-range eolian transport in combination with the most common characteristics of mineral particulates inherited from rocks of former active continental margin settings. In general, this means that the material was not altered by any strong chemical alteration processes.

The $\mathrm{Pb}$ isotope signatures correspond to a considerably lithogenic characteristic; only the Prague sample shows a certain overprint probably influenced by EU-type petrol combustion. The combination of measured and reference data allows a slight differentiation between regional trend lines.

Results of the simultaneous study of Ukrainian surface samples suggest that the material delivered by eolian transport underwent a selective uplift of particles from chestnut inceptisols around the Sea of Azov and soils downstream around the River Dnieper. This corresponds well with siltand sand-sized materials recycled by alluvial/eolian processes from the Early Proterozoic crystalline rocks between the Pri-Azov Massif and the Ukrainian Shield. A typical example of this material is the eolian dune field $\mathrm{E}$ of Kherson.

The results of the palynological analyses of the deposited silt-sized sediment excluded an African or Middle-East provenance. In contrast, they are in good agreement with the Ukrainian source. During wind transport, the material became mixed also with other pollen grains in the atmosphere above Eastern and Central Europe. The assemblages also contain pollen from 2006, which did not undergo bacterial decomposition on the soil surface at the place where the storm originated (Ambrosia or Cerealia). The pollen spectra in samples from several distant sites are quite uniform, and provide a fingerprint of this particular depositional event. The employed set of methods can therefore be applied to the tracking of other dust deposits in the future as well as in the past.

\section{Acknowledgements}

Sedimentological study of modern dust deposits was supported by the Grant Agency AS CR, in two projects which relate to mechanics of particulates (IAAX00130702-Stromatactis) and varia- tion of background sedimentation (IAA300130702-Sclerochronology). Coordination was provided by the integrated project (AV0Z30130516-Earth System). L. Strnad acknowledges grant aid provided by the Ministry of Education of the Czech Republic (MSM0021620855-Material Flow Mechanisms). V. Jankovská appreciates data provided by L.G. Bezusko \& A.G. Bezusko, Kiev. The first author thanks J. Kondziolka, Karviná, for network management around the Instant Astronomical News (Czech Astronomical Society, more than 300 reports) and for consultation on many practical aspects of this study. Many other local and distant collaborators or correspondents kindly contributed to the project with special thanks due to D. Chladová, Boží Dar, P. Čejchan, Mlčechvosty (Borová u Poličky), V. \& J. Šír, Rokytnice nad Jizerou, M. Kolárik, Semily (Liptovský Ján), R. Maňák, Ždánice, M. Popek, Nýdek, and J. Zsadány, Púchov. GIS was kindly provided by P. Špaček, Brno. Gratefully appreciated are technical comments from K. Žák, Beroun, V. Ždímal, Prague, W. Birmili, Leipzig, S. Wurzler, Recklinghausen, and S. Turner, Brisbane, and particular thanks are due to the reviewers, G. Kocurek, Austin, Z. Dong, Lanzhou, and G. Wiggs, Oxford, whose comments and suggestions greatly improved the structure and quality of the manuscript.

\section{References}

Andersen, K.K., Bigler, M., Clausen, H.B., DAHL-JENSEN, D., Johnsen, S.J., RASMussen, S.O., SEIERSTAD, I., STEFFENSEN, J.P., SVENSSON, A., VINTHER, B.M., DAVIES, S.M., Muscheler, R., PARRENIN, F. \& RÖTHLISBERGER, R. 2007. A 60000 year Greenland stratigraphic ice core chronology. Climate of the Past Discussions 3, 1235-1260.

ASAHI NET 2007. Munsell color chart. Digitally certified and powered. http://www.asahi-net.or.jp/ xn6t-ogr/colors/mun sellchartframe.html (in Japanese).

Bezusko, L.G., Bezusko, A.G. \& Mosyakin, S.L. 2004. Contemporary state of the palynological research of soil surface layers in the steppe zone of Ukraine. $17 \mathrm{pp}$. Kholodny Institute of Botany, National Academy of Sciences of Ukraine, Kiev (in Ukrainian).

Birmili, W., Schepanski, K., ANSMANN, A., SPINDLER, G., Tegen, I., WeHner, B., NOWAK, A., ReIMER, E., MATtis, I., MÜller, K., BrÜggemann, E., Gnauk, T., Herrmann, H., Wiedensohler, A., Althausen, D., Schladitz, A., TUCH, T. \& LÖSCHAU, G. 2008. A case of extreme particulate matter concentrations over Central Europe caused by dust emitted over the southern Ukraine. Atmospheric Chemistry and Physics 8, 997-1016.

BIRYUKOV, S. 1995. The time dependence of dust adhesion on the glass surface. Journal of Aerosol Science 26(6), 1024-1024. DOI 10.1016/0021-8502(95)99409-M

Bout-Roumazeilles, V., Combourieu Nebout, N., Peyron, O., Cortio, E., Landais, A. \& Masson-Delmotte, V. 2007. Connection between South Mediterranean climate and North African atmospheric circulation during the last 50,000 yr BP North Atlantic cold events. Quaternary Science Reviews 26, 3197-3215. DOI 10.1016/j.quascirev.1007.07.015 
Bruckmann, P., Niemann, K., Wurzler, S., Engel, I., HoOgerbrugGe, R., GARUS, G. \& OlsCHEWSKI, A. 2008 in press. High $\mathrm{PM}_{10}$ levels covering large parts of Europe caused by long range transport. Gefahrstoffe - Reinhaltung der Luft (Air Quality Control, Springer VDI Verlag).

CECIL, C.B. 2004. Eolian dust and the origin of sedimentary chert. 15 pp. U.S. Geological Survey Open-File Report 2004-1098, Reston, Va.

CHIN, M., DIEHL, T., GINOUX, P. \& MALM, W. 2007. Intercontinental transport of pollution and dust aerosols: implications for regional air quality. Atmospheric Chemistry and Physics 7, 5501-5517.

Cho, G.C., Dodds, J. \& Santamarina, J.C. 2006. Particle shape effects on packing density, stiffness, and strength: natural and crushed sands. Journal of Geotechnical and Geoenvironmental Engineering 132(5), 591-602. DOI 10.1016/(ASCE) 1090-0241(2006)132:5(591)

COLOR CHARTS 2007. An online database of manufacturers standard colors. Powered by CBN Systems technology. Digitally certified and powered. http://www.colorcharts.org

EREL, Y., DAYAN, U., RABI, R., RUdich, Y. \& SteIn, M. 2006. Trans boundary transport of pollutants by atmospheric mineral dust. Environmental Science \& Technology 40, 2996-3005. DOI 10.1021/es0515021

ERPUL, G., GABRIELS, D. \& NORTON, L.D. 2005. Sand detachment by wind-driven raindrops. Earth Surface Processes and Landforms 30, 241-250. DOI 10.1002/esp.1178

ETtler, V., MihaljeviČ, M. \& KomÁReK, M. 2004. ICP-MS measurements of lead isotopic ratios in soils heavily contaminated by lead smelting: tracing the degree of pollution. Analytical and Bioanalytical Chemistry 378, 311-317. DOI 10.1007/s00216-003-2229-y

EtTler, V., VANĚK, A., MihaljeVič, M. \& BeZdičKa, P. 2005. Contrasting lead speciation in forest and tilled soils heavily polluted by lead metallurgy. Chemosphere 58(10), 1449-1459. DOI 10.1016/j.chemosphere.2004.09.084

FAY, B., GLAAB, H., JACOBSEN, I. \& SCHRODIN, R. 1994. Radioactive dispersion modeling and emergency response system at the German Weather Service. In GRYNNING, S.-V. \& MILLAN, M.M. (eds) Air Pollution Modeling and Its Application X (Plenum Press, New York), 395-403.

Floyd, P.A., Shail, R., LEVERIDGE, B.E. \& FranKe, W. 1991. Geochemistry and provenance of Rhenohercynian sandstones: implications for tectonic environment discrimination. In MORTON, A.C., TODD, S.P. \& HAUGHTON, P.D.W. (eds) Developments in Sedimentary Provenance Studies. Geological Society of London Special Publications 57, 173-188.

GAO, Y., AnDERSON, J.R. \& HUA, X. 2007. Dust characteristics over the North Pacific observed through shipboard measurements during the ACE-Asia experiment. Atmospheric Environment 41(36), 7907-7922.

DOI 10.1016/j.atmosenv.2007.06.060

Goudie, A.S. \& MidDlETON, N.J. 2001. Saharan dust storms: nature and consequences. Earth-Science Reviews 56(1-4), 179-204. DOI 10.1016/S0012-8252(01)00067-8

Grousset, F., GinouX, P., Bory, A. \& Biscaye, P. Case study of a Chinese dust plume reaching the French Alps. Geophysical Research Letters 30(6). DOI 10.1029/20002GLO16833

HLADIL, J. \& BEROUŠEK, P. 1993. Oblique raindrop impacts. Věstník Českého geologického ústavu (Bulletin of Geosciences) 68(3), 23-32.

HLADIL, J., GERŠL, M., STRNAD, L., FRÁNA, J., LANGROVÁ, A. \& SPIŠIAK, J. 2006. Stratigraphic variation of complex impurities in platform limestones and possible significance of atmospheric dust: a study with emphasis on gamma-ray spectrometry and magnetic susceptibility outcrop logging (Eifelian-Frasnian, Moravia, Czech Republic). International Journal of Earth Sciences 95(4), 703-723. DOI 10.1007/s00531-005-0052-8

HLADIL, J., KoptíKOVÁ, L., RŮŽIČKA, M. \& KUlAVIAK, L. 2007. Experimental effects of surfactants on the production of stromatactis-shaped cavities in artificial carbonate sediments. Bulletin of Geosciences 82(1), 37-50. DO1 10.3140/bull.geosci.2007.01.37

JEHLÍK, V., HEJNÝ, S., KROPÁČ, Z., LHOTSKÁ, M., KOPECKÝ, K., Slavík, B. \& Svobodová, Z. 1998. Alien expansive weeds of the Czech and Slovak Republics. 506 pp. Publ. House Academia, Prague (in Czech).

JICKELLS, T. 1995. Atmospheric inputs of metals and nutrients to the oceans: their magnitude and effects. Marine Chemistry 48(3-4), 199-214. DOI 10.1016/0304-4203(95)92784-P

JICKELLS, T.D. 1999. The inputs of dust derived elements to the Sargasso Sea; a synthesis. Marine Chemistry 68(1), 5-14. DOI 10.1016/S0304-4203(99)00061-4

KERKMAN, J., LutZ, H.J., KÖNIG, M., PRIETO, J., PYLKKo, P., RoESLI, H.P., ROSENFELD, D., SCHMETZ, J., ZWATZ-MEISE, V., Schipper, J., Georgie, C. \& SANTURETte, P. 2005. MSG interpretation guide. http://oiswww.eumetsat.org/ WEBOPS/msg_interpretation/index.html.

Koltay, E., Borbély-Kiss, I., KertésZ, Z., Kiss, A.Z. \& SZABÓ, G. 2006. Assignment of Saharan dust sources to episodes in Hungarian atmosphere by PIXE and TOMS observations. Journal of Radioanalytical and Nuclear Chemistry 267(2), 449-459. DOI 10.1007/s10967-006-0073-1

KONDZIOLKA, M. \& MAŇÁK, R. 2007. CR under the dust layer. Instant Astronomical News IAN 691, http://www.ian.cz/ detart_fr.php?id=2253.

KuKLA, G.J. 1970. Correlations between loesses and deep-sea sediments. Geologiska Foreningen i Stockholm Forhandlingar 92, 148-180.

KUKLA, G.J. 1977. Pleistocene land-sea correlations I. Earth Science Review 13, 307-374. DOI $10.1016 / 0012-8252(77) 90125-8$

KRUMBEIN, W.C. 1941. Measurement and geological significance of shape and roundness of sedimentary particles. Journal of Sedimentary Petrology 11(2), 64-72.

LENSKY, I.M. \& ROSENFELD, D. 2006. CAPSAT - clouds, aerosols, and precipitation satellite tool. Geophysical Research Abstracts 8, 05088.

LENSKY, I.M. \& ROSENFELD, D. 2008 in press. Clouds-aerosol-precipitation satellite analysis tool (CAPSAT). Atmospheric Chemistry and Physics.

LIM, J. \& MATSUMOTO, E. 2006. Bimodal grain-size distribution 
of aeolian quartz in a maar of Cheju Island, Korea, during the last 6500 years: Its flux variation and controlling factor. Geophysical Research Letters 33, L21816.

DOI $10.1029 / 2006$ GL027432

LITTMANN, T. \& STEINRÜCKE, J. 1989. Atmospheric boundary conditions of recent Saharan dust influx into Central Europe. GeoJournal 18(4), 399-406. DOI 10.1007/BF00772694

MAHANEY, W.C. 2002. Atlas of sand grain surface textures and applications. 237 pp. Oxford University Press, Oxford/New York.

MCDONOUGH, W.F. \& SUN, S.S. 1995. The composition of the Earth. Chemical Geology 120, 223-253. DOI 10.1016/0009-2541(94)00140-4

MCLENNAN, S.M. 2001. Relationships between the trace element compositions of sedimentary rocks and the upper continental crust. Geochemistry Geophysics Geosystems 2(2000GC000 109), 24 pp.

MCLENNAN, S.M. \& MURRAY, R.W. 1999. Geochemistry of sediments, 282-292. In MARSHALL, C.P. \& FAIRBRIDGE, R.W. (eds) Encyclopedia of Geochemistry. Kluwer Academic Publishers, Dordrecht.

MCLENNAN, S.M. \& TAYLOR, S.R. 1999. Earth's continental crust, 145-150. In MARSHALL, C.P. \& FAIRBRIDGE, R.W. (eds) Encyclopedia of Geochemistry. Kluwer Academic Publishers, Dordrecht.

MihaljeVič, M., Zuna, M., Ettler, V., ŠEbeK, O., Strnad, L. \& GoliÁš, V. 2006. Lead fluxes, isotopic and concentration profiles in a peat deposit near a lead smelter (Př́bram, Czech Republic). Science of the Total Environment 372, 334-344. DOI 10.1016/j.scitotenv.2006.09.019

MIMS, F.M. 2003. Solar aureoles caused by dust, smoke, and haze. Applied Optics 42, 492-496.

DOI 10.1364/AO.42.000492

MosyaKin, S.L. \& FEDORONCHUK, M.M. 1999. Vascular plants of Ukraine. A nomenclatural checklist. 345 pp. M.G. Kholodny Institute of Botany, National Academy of Sciences of Ukraine, Kiev (in Ukrainian).

MuKaI, H., MACHIDA, T., TANAKA, A., VERA, Y.P. \& UEMATSU, M. 2001. Lead isotope ratios in the urban air of eastern and central Russia. Atmospheric Environment 35, 2783-2793. DOI 10.1016/S1352-2310(00)00341-1

MUNSELL COLOR 2000. Munsell soil color chart. 22 pp. Baltimore.

Nikishin, A.M., Ziegler, P.A., PANOV, D.I., NAZARevich, B.P., BRUNET, M.-F., STEPHENSON, R.A., BOLOTOV, S.N., KorotaEV, M.V. \& TIKHOMIROV, P.L. 2001. Mesozoic and Cainozoic evolution of the Scythian Platform-Black Sea-Caucasus domain, 295-346. In ZIEGLER, P.A., CAVAZZA, W., Robertson, A.H.F. \& Crasquin-Soleau, S. (eds) PeriTethys Memoir 6: Peri-Tethyan rift/wrench basins and passive margins. Mémoires du Muséum national d'histoire naturelle Paris 186.

NOZAKI, Y. 2001. Rare earth elements and their isotopes, 2354-2366. In STEELE, J.S., TUREKIAN, K.K. \& THORPE, S.A. (eds) Encyclopedia of Ocean sciences. Academic Press, London.

PANOV, B.S., DudiK, A.M., SHEVChEnKo, O.A. \& MATLAK,
E.S. 1999. On pollution of the biosphere in industrial areas: the example of the Donets coal basin. International Journal of Coal Geology 40(2-3), 199-210.

DOI 10.1016/S0166-5162(98)00069-X

PAPAyAnnis, A., AMIRIDIS, V., BÖSENBERG, J., ChAIKOVSKi, A., De Tomasi, F., Freudenthaler, V., Grigorov, I., Mattis, I., MiteV, V., MunOZ, C., PAPPAlardo, G., NiCKOVIC, S., PISANI, G., PUCHALSKI, S., RIZI, V., TRICKL, T. \& VAUGHAN, G. 2005. First systematic observations of Saharan dust over Europe (2000-2003): Statistical analysis and results. Geophysical Research Abstracts 7(04016), 5 pp.

PASHKEVICH, G.O. 1970. Pollen-analytical research of the dust brought by "black storm" (in Russian). Ukrainskii Botanicheskii Zhurnal 27(4), 530-531.

PiotrowsKA, K. \& WerysZKo-ChMiELEWSKA, E. 2006. Ambrosia pollen in the air of Lublin, Poland. Aerobiologia 22(2), 149-156. DOI 10.1007/s10453-006-9020-4

Prins, M.A., VRIEND, M., Nugteren, G., VANDEnBERGhe, J., LU, H., ZHENG, H. \& WELTJE, G.J. 2007. Late Quaternary aeolian dust input variability on the Chinese Loess Plateau: inferences from unmixing of loess grain-size records. Quaternary Science Reviews 26, 230-242.

DOI 10.1016/j.quascirev.2006.07.002

Prospero, J.M., GinOuX, P., TORRes, O., Nicholson, S. \& GILL, T. 2002. Environmental characterization of global sources of atmospheric soil dust identified with the NIMBUS7 total ozone mapping spectrometer (TOMS) absorbing aerosol product. Reviews of Geophysics 40(1), 1002, $31 \mathrm{pp}$.

QIN, X., CAI, B. \& LIU, T. 2005. Loess record of the aerodynamic environment in the east Asia monsoon area since 60,000 years before present. Journal of Geophysical Research 110, B01204. DOI 10.1029/2004JB003131

REID, E.A., ReID, J.S., MeIER, M.M., DunlaP, M.R., ClifF, S.S., BRoumas, A., Perry, K. \& MARING, H. 2003. Characterization of African dust transported to Puerto Rico by individual particle and size segregated bulk analysis. Journal of Geophysical Research 108 (D19, PRD-7), 1-22.

REHEIS, M.C., GOODMACHER, J.C., HARDEN, J.W., MCFADDEN, L.D., ROCKWELL, T.K., SHROBA, R.R., SOWERS, J.M. \& TAYLOR, E.M. 1995. Quaternary soils and dust deposition in southern Nevada and California. Geological Society of America Bulletin 107(9), 1003-1022.

DOI 10.1130/0016-7606(1995)107<1003:QSADDI>2.3.CO;2

ROESLI, H.-P., KERKMANN, J. \& ROSENFELD, D. 2006. Harmonising SEVIRI RGB composites for operational forecasting. The 2006 EUMETSAT Meteorological Satellite Conference, Session 5, Training, http://www.eumetsat.int/Home/Main/Publications/index.htm, P.48, s5, 1-8.

RYBNíČEK, O., NOVOTNÁ, B., RYBNíČKOVÁ, E. \& RYBNÍČEK, K. 2000. Ragweed in the Czech Republic. Aerobiologia 16(2), 287-290. DOI 10.1023/A:1007611715820

SAAR, M., GudZhinskas, Z., Plompuu, T., LinnO, E., MinKIENÉ, Z. \& MOTIEKAITYTÉ, V. 2000. Ragweed plants and airborne pollen in the Baltic states. Aerobiologia 16(1), 101-106. DOI 10.1023/A:1007670229308

SAZHIN, A.N. \& VASILIEV, U.I. 1999. Dynamics of atmo- 
sphere and wind energy during dust storms. Proceedings of the International Symposium to 50th Anniversary of the United States Department of Agriculture "Wind Erosion", http://www.weru.ksu.edu/symposium/ proceedings/sazhin.pdf, A35, 1-6.

SMAlley, I.J., Kumar, R., O'HARA DHAND, K., JeFFERSON, I.F. \& EVANS, R.D. 2005. The formation of silt material for terrestrial sediments: particularly loess and dust. Sedimentary Geology 179, 321-328.

DOI 10.1016/j.sedgeo.2005.06.011

SMECK, N.E., BighaM, J.M., GUerTAL, W.F. \& HALl, G.F. 2002. Spatial distribution of lepidocrocite in a soil hydrosequence. Clay Minerals 37(4), 687-697.

DOI 10.1180/009855023740070

SODEMANN, H., PALMER, A.S., SCHWIERZ, C., SCHWIKOWSKI, M. \& WERNLI, H. 2006. The transport history of two Saharan dust events archived in an Alpine ice core. Atmospheric Chemistry and Physics 6, 667-688.

Soreghan, G.S. \& Soreghan, M.J. 2002. Atmospheric dust and algal dominance in the Late Paleozoic: A hypothesis. Journal of Sedimentary Research 72(4), 457-461. DOI $10.1306 / 011102720457$

STĘPALKA, D., SzCZEPANEK, K. \& MYSZKOWSKA, D. 2002. Variation in Ambrosia pollen concentration in Southern and Central Poland in 1982-1999. Aerobiologia 18(1), 13-22. DOI 10.1023/A:1014926216282

STRNAD, L. \& MiHALJEVIČ, M. 2005. Sedimentary provenance of Mid-Devonian clastic sediments in the Teplá-Barrandian Unit (Bohemian Massif): $\mathrm{U}-\mathrm{Pb}$ and $\mathrm{Pb}-\mathrm{Pb}$ geochronology of detrital zircons by laser ablation ICP-MS. Mineralogy and Petrology 84(1-2), 47-68. DOI 10.1007/s00710-004-0057-1

StRnad, L., MiHALJEVIČ, M. \& ŠEBEK, O. 2005. Laser ablation and solution ICP-MS determination of REE in USGS BIR-1G, BHVO-2G and BCR-2G glass reference materials. Geostandards and Geoanalytical Research 29(3), 303-314. DOI 10.1111/j.1751-908X.2005.tb00902.

Sun, D., Bloemendal, J., REA, D.K., AN, Z., VANDENBERGHe, J., LU, H., SU, R. \& LIU, T. 2004. Bimodal grain-size distribution of Chinese loess, and its palaeoclimatic implications. Catena 55(3), 325-340. DO1 10.1016/S0341-8162(03)00109-7

Sun, D., Bloemendal, J., ReA, D.K., VANDENBERGHE, J., JIANG, F., AN, Z. \& SU, R. 2002. Grain-size distribution function of polymodal sediments in hydraulic and aeolian environ- ments, and numerical partitioning of the sedimentary components. Sedimentary Geology 152(3), 263-277. DOI $10.1016 / \mathrm{S} 0037-0738(02) 00082-9$

TANNER, W.F. 1958. The zig-zag nature of type $\mathrm{i}$ and type iv curves. Journal of Sedimentary Petrology 28, 372- 375.

TAYLOR, S.R. 1992. Solar system evolution: A new perspective. 307 pp. Cambridge University Press.

TAYLOR, S.R. \& MCLENNAN, S.M. 1985. The continental crust: Its composition and evolution. $312 \mathrm{pp}$. Blackwell.

Teutsch, N., EREL, Y., HALICZ, L. \& BAnIN, A. 2001. Distribution of natural and anthropogenic lead in Mediterranean soils. Geochimica et Cosmochimica Acta 65, 2853-2864.

DOI 10.1016/S0016-7037(01)00607-X

VinCENT, S.J., MORTON, A.C., CARTER, A., GiBBS, S. \& BARABADZE, T.G. 2007. Oligocene uplift of the Western Greater Caucasus: an effect of initial Arabia-Eurasia collision. Terra Nova 19, 160-166. DOI 10.1111/j.1365-3121.2007.00731.x

VOLLMER, M. 2005. Effects of absorbing particles on coronas and glories. Applied Optics 44, 5658-5666.

DOI 10.1364/AO.44.005658

YAMAGUCHI, K.E., JOHNSON, C.M., BEARD, B.L. \& OHMOTO, H. 2005. Biogeochemical cycling of iron in the Archean-Paleoproterozoic Earth: Constraints from iron isotope variations in sedimentary rocks from the Kaapvaal and Pilbara Cratons. Chemical Geology 218, 135-169.

DOI 10.1016/j.chemgeo.2005.01.020

YIZHAQ, H. 2005. A mathematical model for aeolian megaripples on Mars. Physica A: Statistical Mechanics and its Applications 357(1), 57-63. DOI 10.1016/j.physa.2005.05.070

YoshinaGA, S. 1998. Accumulation rate of tropospheric dust in and around the Japan Islands during the last Quaternary. Quaternary Research (Japan) 37, 205-210 (in Japanese with English abstract).

Yudovich, Y.E. \& KeTRIS, M.P. 2005. Mercury in coal, a review, part 1, geochemistry. International Journal of Coal Geology 62(3), 107-134. DOI 10.1016/j.coal.2004.11.002

ZENDER, C.S., Miller, R.L. \& TEgEN, I. 2004. Quantifying mineral dust mass budgets: Terminology, constraints, and current estimates. Eos 85(48), 509-512.

DOI 10.1029/2004EO480002

ZHANG, G.L., YANG, F.G., ZHAO, W.J., ZHAO, Y.G., YANG, J.L. \& GONG, Z.T. 2007. Historical change of soil $\mathrm{Pb}$ content and $\mathrm{Pb}$ isotope signatures of the cultural layers in urban Nanjing. Catena 69(1), 51-56. DOI 10.1016/j.catena.2006.04.013

\section{Appendix - Technical notes and comments on methods and approaches}

The authors started this study spontaneously at the moment this event occurred, using existing network connections as fast as possible. Thus, the study has many ad-hoc features. Individual observations as well as sampling operations were finished during several hours and days. The substrates covered by $4-15 \mathrm{~cm}$ of fresh snow in mountain areas during 22 and 23 March 2007 (or randomly cleaned just during these days, in lowlands) made the sediment sampling procedure more controllable than usual. The best conditions were found at five selected localities; in the Nízké Tatry Mts, Krkonoše Mts, Prague-Suchdol, Brno-Komín and E Bohemian Polička area. Sediment samples from these sites were analyzed in more detail ( $c f$. Tab. 1 and Fig. 8 for location details). Two pilot localities from the area of Kherson, SE Ukraine, are also listed in Table 1 . The extraordinary character of this event and qualified attention of volunteer astronomers extended considerably the standard possibilities of geological and meteorologi- 
cal monitoring. This geological and multi-disciplinary approach to analyzing the massive and rapidly deposited dust-event sediments seems to open new perspectives in the research on dust plumes.

Certain co-authors have had particular responsibility for research fields and related paragraphs or chapters in this paper: M. Šálek, J. Schwarz \& J. Smolík (meteorology); L. Strnad \& J. Rohovec (geochemistry); A. Langrová \& V. Böhmová (electron microprobe analysis and scanning electron microscopy); V. Jankovská (palynology); and R. Melichar (geology of Ukraine).

From a technical viewpoint, the satellite radiometric measurements and work with colour image composites requires further explanation. Data from the Meteosat 8 geostationary satellite (MSG-1) were produced by the SEVIRI imaging radiometer. Electromagnetic radiation of the Earth surface was measured from a position over the Equator and the Gulf of Guinea every 15 minutes in 12 spectral bands, including the High Resolution Visible (HRV) band with a resolution of $2 \times 3 \mathrm{~km}$ at the 50 degree latitude. The other 11 channels are in visible, near-infrared and infrared bands ( 0.6 to $14.4 \mu \mathrm{m})$ with a resolution of $4 \times 6 \mathrm{~km}$ at the same latitude. SEVIRI data were particularly used in the form of red-green-blue (RGB) composites of pictures taken in particular channels to visualize the dust concentration in the atmosphere and the evolution of the dust-laden flow. 'Dust', one of the RGB combinations, is described in Lensky \& Rosenfeld (2006, 2008, $c f$. also Kerkman et al. 2005). The main purpose of the product was detection of dust and sand storms, usually observed over Africa and the Middle East. However, it was later found that this product also provided very good information of cloud microphysics and, unlike similar products utilizing solar (visible) channels, it can be used through a whole 24 hour period. 'Dust' is one of the MSG products most frequently utilized operationally by meteorological forecasters. A later modification is used at the Czech Hydrometeorological Institute (CHMI) for conditions over Central Europe and is presently referred to as 24-hour microphysics ( $c f$. also Roesli et al. 2006). The recommended values for the algorithms used here are given in Table 5.

Computation of dust particle trajectory in the atmosphere: The model used was developed in Meteo France for operational computation of three-dimensional prognostic air particle trajectories, which can serve as part of the emergency warning system for accidental release of pollutants. Formal (citable) publication does not exist, but similar principles were developed for DWD Trajek (Fay et al. 1994). The adapted 'Meteo-France' Trajek model presently operates at Czech Hydrometerological Institute with data inputs coming from the ECMWF (European Centre for Medium-Range Forecasting); it is able to make trajectory forecast for 5 days in advance. The wind forecast is based on a deterministic model (model T799 in 2007) and the particular air parcel follows the time-dependent wind vectors in the time step of 5 minutes up to the predefined time deadline (5 days). Mathematically, the trajectory is defined as

$$
\frac{\mathrm{d} x}{\mathrm{~d} t}=v_{x}(x, y, z, t), \quad \frac{\mathrm{d} y}{\mathrm{~d} t}=v_{y}(x, y, z, t), \quad \frac{\mathrm{d} z}{\mathrm{~d} t}=\mathrm{v}_{z}(x, y, z, t),
$$

where $x, y$ and $z$ denote perpendicular axes in space, $t$ is time, $v_{x}(x, y, z, t), v_{y}(x, y, z, t)$ and $v_{z}(x, y, z, t)$ refer to the wind velocity in corresponding directions, which is generally variable in the space and time. The symbols represent the ratio of the infinitesimal change of the components of the trajectory to the infinitesimal time increment, or, in other words, the time derivatives. The trajectory is obtained by integration of these equations, which is done numerically by replacement of the infinitesimal increments by finite elements (small enough to avoid large errors) that are then computed by a numerical model of the atmosphere. Note that if one uses only the stationary state of the atmosphere (i.e., neither development nor shift of eddies), the trajectory becomes a streamline.

Sampling and handling of the sediment monitoring data: Although the sampling was possible at several tens of different places, only five most reliable sites were selected for extensive collecting of material for subsequent analyses. Two of these sites were in mountain areas (Nízké Tatry and Krkonoše Mts) at altitudes above $1000 \mathrm{~m}$ a.s.l. There was a fresh (clear white) cover of snow that precipitated during the previous two days, and the dust (mostly silt and sand) deposited on an almost absolutely sterile substrate. Here, the sediment was carefully collected together with the uppermost, about $8 \mathrm{~cm}$-thick layer of snow and kept in large plastic bottles as used for water sampling. Three sites were also selected in the lowland and mid-altitude areas (PragueSuchdol, Brno-Komín and Borová u Poličky - Tab. 1 and Fig. 8). Luckily, appropriate large, smooth and subhorizontal surfaces were thoroughly cleaned just before the deposition event at these sites; a table-tennis table, balcony tiles and a large, flat roof, and the hood of a car, respectively. The surfaces were washed/brushed under moderate channelized flow of clean water, and the sediment was also collected in plastic bottles. In laboratories, the particulate material settled in distilled water, the overlying water was then decanted off (to a layer equal to that of the sediment), and this amount was gently dried at temperatures no higher than $50^{\circ} \mathrm{C}$. Dry sediment was gently submitted to ultrasonic vibration, and then irregularly shaken to obtain a sub-homogeneous distribution of grains. For grain size analyses, six one-layer scatters of sediment particles from each sample were prepared and studied by scanning electron microscopy, where the objects were traced in a square grid $(\mathrm{N}=6 \times 225=1350)$. Equivalent diameters of the particles were calculated using image analysis. Special emphasis was given to $5 \mu \mathrm{m}$ particle-size categories below the $45 \mu \mathrm{m}$ mid-coarse-silt level. Relatively rare (but not uncommon, $\leq 10 \mathrm{wt} . \%$ ) bulky grains of sub-millimetre size were identified separately, using larger grid cells. These are an integral part of this event sediment, as they occurred consistently, in sufficient amounts and on clean and well watched substrates (with practically no contamination between deposition and sampling). The main tool for comparison of the sediment thickness at other localities, both within these larger sites and in the IAN (Instant Astronomical News) and other networks, was the image-analysis comparison of sediment colour and structure with the reference samples of measured density and thickness. The numerous rapid point analyses helped to calibrate this process.

One sampling circumstance must be mentioned in relation to chemical analyses of the sediment. The samples collected with snow (and those washed from clean surfaces) were kept in distilled water for tens of hours. Therefore, the analysed particulate material was certainly depleted from possible water-soluble colloid complexes or easily soluble inorganic ions. The study actually concentrated on solid-particle sediment because the dirty-rain sedimentation mode (with infiltration and/or washing effects) may 
Table 5. The recommended algorithms of the RGB combinations of the SEVIRI radiometer for the products Dust and 24h-microphysics. [M. Śálek]

\begin{tabular}{lcrrrrrr}
\hline & & \multicolumn{3}{c}{ PRODUCT DUST } & \multicolumn{2}{c}{ PRODUCT 24H MF } \\
\hline BEAM & CHANNEL & \multicolumn{2}{c}{ RANGE } & GC & RANGE & GC \\
RED & IR12.0 - IR10.8 & -4 & +2 & 1.0 & -4 & +2 & 1.0 \\
GREEN & IR10.8 - IR8.7 & 0 & +15 & 2.5 & 0 & +6 & 1.2 \\
BLUE & IR10.8 & +261 & +289 & 1.0 & +248 & +303 & 1.0 \\
\hline
\end{tabular}

$\mathrm{GC}$ - gamma correction

lead to great chaos in these easily soluble components. At this point, we refer to aerosol monitoring systems (herein, and largely in Birmili et al. op. cit.). The trace element concentrations in naturally deposited silty sediment were determined by several methods with special emphasis on the ICP-MS techniques, under the following conditions. The total digestion of sediment $(\mathrm{HF}+$ $\left.\mathrm{HClO}_{4}\right): 0.1 \mathrm{~g}$ of each sample was digested in $10 \mathrm{~mL} \mathrm{HF} 49 \%$ (v/v) and $1 \mathrm{~mL} \mathrm{70 \%} \mathrm{(v/v)} \mathrm{HClO}_{4}$ in PTFE vessels (Savillex) on a hot plate $\left(150{ }^{\circ} \mathrm{C}\right)$. The sample was evaporated to $0.5 \mathrm{~mL}$ of the digest, dissolved in $2 \%(\mathrm{v} / \mathrm{v}) \mathrm{HNO}_{3}$ and transferred to $100 \mathrm{~mL}$ volumetric flask. All samples (and procedural blanks) were further diluted five-fold by $2 \%(\mathrm{v} / \mathrm{v}) \mathrm{HNO}_{3}$. Chemicals reagent grade (Merck); acids double distilled, deionized water (Millipore); solutions in HDPE bottles (Nalgene) - for other relevant details see Strnad et al. (2005). The decomposition was followed by conventional solution nebulisation. Standard configuration of quadrupole-based ICP-MS PQ3 (VG Elemental) was used, equipped with a water-cooled $\left(\sim 4{ }^{\circ} \mathrm{C}\right)$ spray chamber with Meinhard-type nebuliser. Data were acquired in the peak jumping mode with 3 points measured per mass peak and instrument sensitivity at $2.5 \times 10^{4} \mathrm{cps}$ per $1 \mathrm{ng} \cdot \mathrm{mL}^{-1115} \mathrm{In}$. The total acquisition time was $3 \times 40$ seconds. The measured isotopes were selected with respect to their most abundant species, free from isobaric overlap and minimum oxide interferences. The calibration curves were prepared with multi-element calibration standard ARISTAR (BDH Laboratory Supplies). Data were processed on-line using VG PlasmaLab software and applying corrections for instrumental drift. The count rates for the measured elements were corrected on the basis of interpolation of the ${ }^{74} \mathrm{Ge},{ }^{115} \mathrm{In}$ and ${ }^{187} \mathrm{Re}$ correction factors. The analytical precision, calculated as one relative standard deviation
RSD, ranged from 0.5 to $8 \%$. The accuracy was controlled using the G-2 and BCR-2 (USGS) reference materials. The quadrupole ICP-MS configuration for the $\mathrm{Pb}$ isotopic composition was the same (for the detailed analytical conditions and data acquisition parameters see Ettler et al. 2004, Mihaljevič et al. 2006). Correction for mass bias was performed using NIST SRM 981 (a common lead isotopic standard) after every analysed sample. The standard errors for measurements of ${ }^{206} \mathrm{~Pb} /{ }^{207} \mathrm{~Pb}$ and ${ }^{208} \mathrm{~Pb} /{ }^{206} \mathrm{~Pb}$ were below $\sim 0.5 \%$ (relative). The accuracy of the measurements was controlled by repeated analyses of the AGV-2 reference material (USGS; ${ }^{206} \mathrm{~Pb} /{ }^{207} \mathrm{~Pb}=1.2085 \pm 0.0006,{ }^{208} \mathrm{~Pb} /{ }^{206} \mathrm{~Pb}=$ $2.0415 \pm 0.0013)$. Besides the ICP-MS and EDX techniques, major element concentrations were determined by optical emission spectroscopy (ICP-OES) to widen the range of analysed elements and give other insights or ways of verification of the data. The ICP-OES data were used to show possible variations in major element oxides in the category of large grains (Tab. 3, left part), with special emphasis on determination of non-metals, light elements, and specifically boron. On the other hand, the determination of $\mathrm{Hg}$ by means of cold vapour atomic absorption spectrometry (CV-AAS) was preferred (on the specialized, advanced mercury analyzer - AMA 254, ALTEC). Thermodesorption analysis distinguishing $\mathrm{Hg}^{2+}$ weakly bound to clay minerals from $\mathrm{Hg}$ bound to organic matter or sulphides was not realized due to the very low (trace to accessory) amounts of these carriers in the analysed silt and sand sediment.

The palynological samples from the deposited dust were prepared using standard procedures of deflocculation and digestion. Flotation, mechanical and density/size separation procedures were not employed for several reasons, but particularly because of the abrasive potential of angular silt grains. Hydrochloric acid of low concentration was used to remove possible calcite, and 24-h digestion of silicate minerals in hydrofluoric acid was used for the reduction of amounts of dominant quartz. After pretreatment in potassium hydroxide, the material was treated with acetic acid, acetic anhydride and sulphuric acid (acetolysis) to reduce the amounts of 'cellulistic' materials and provide better visibility of palynomorphs. After the last washing procedure, the prepared samples were deposited in glycerol. Pollen grains were determined, counted and photographed using the $32 \times 24 \mathrm{~mm}$ pollen slides in an Olympus BX61 microscope at magnifications $\times 400-1000$. 